Monitoring Procedure for Field Test \& Demo Systems with Compression Heat Pumps Driven by Photovoltaic Solar Energy 


\section{Monitoring Procedure} for Field Test \& Demo Systems with Compression Heat

\section{Pumps Driven by}

Photovoltaic Solar

\section{Energy}

Franscisco Aguilar Valero ${ }^{1}$, Daniel Neyer ${ }^{2}$ and Pedro Vicente Quiles ${ }^{1}$ June 2018

Task 53 / Report C1-1, http://dx.dol.org/10.18777/ieashc-task53-2019-0008

${ }^{1}$ Universidad Miguel Hernández de Elche

Avenida de la Universidad, Edificio Innova, 03203 Elche, Spain

Phone:+34 966658561

e-mail: pedro.vicente@umh.es

${ }^{2}$ University of Innsbruck

Technikerstrasse 13, A-6020 Innsbruck

Phone: +43512507 63651

E-mail: daniel.neyer@uibk.ac.at 


\section{Contents}

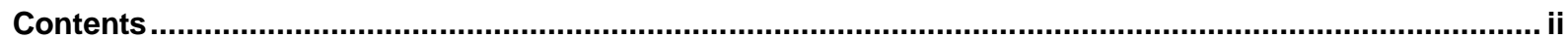

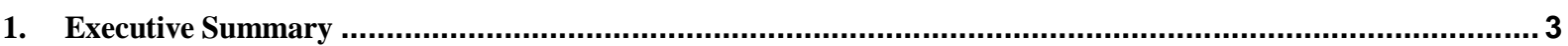

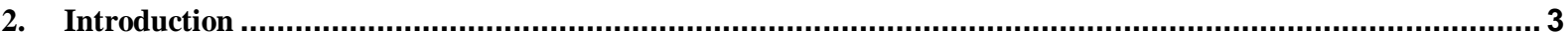

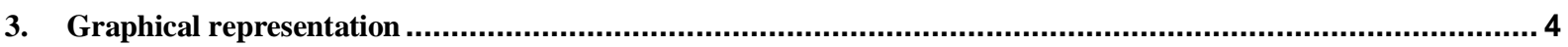

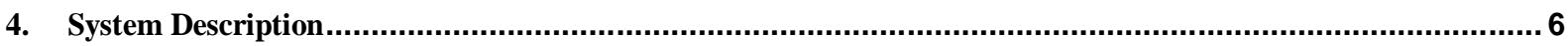

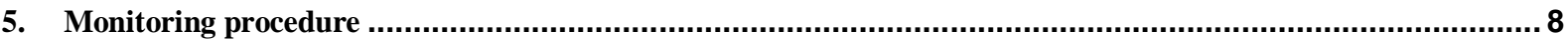

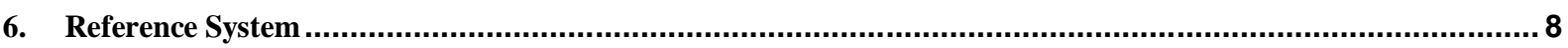

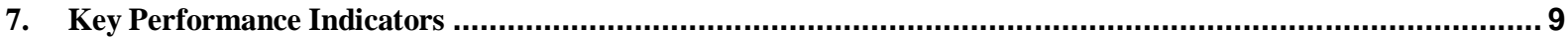

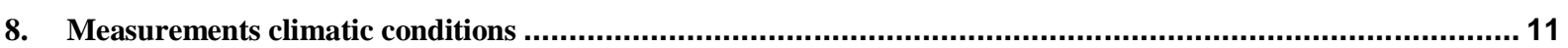

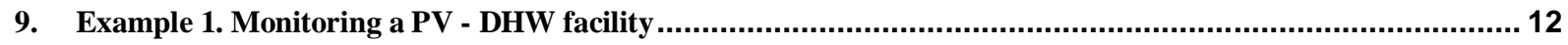

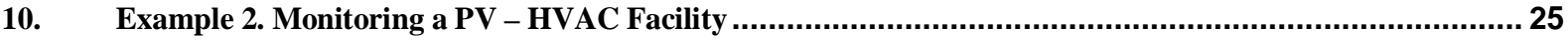

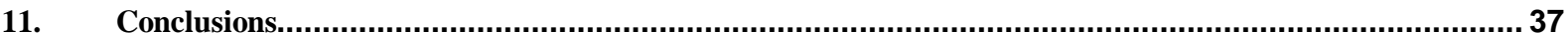

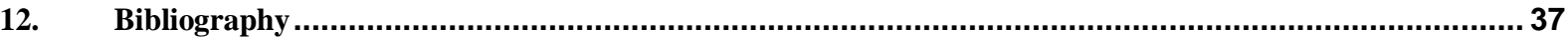

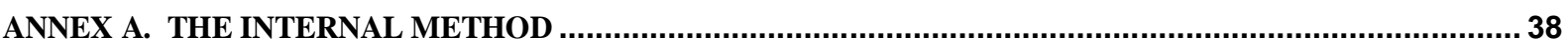

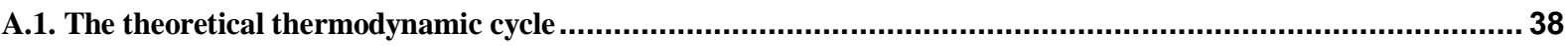

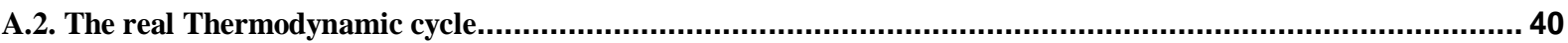

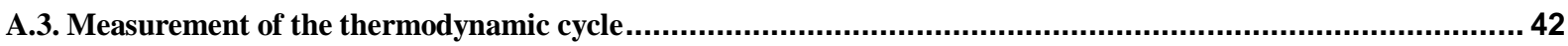

A.4. Other measurement methods for the refrigerant mass flow ................................................................. 44

ANNEX B. MEASURING AND INSTRUMENTATION ...................................................................... 45

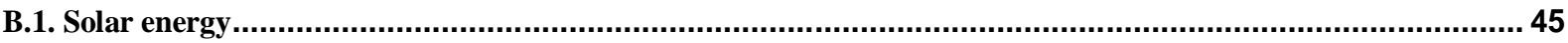

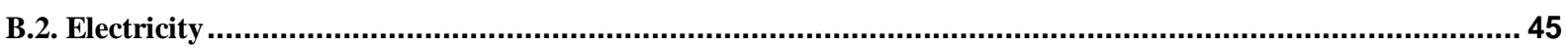

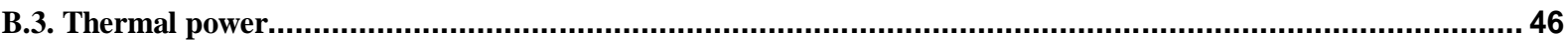

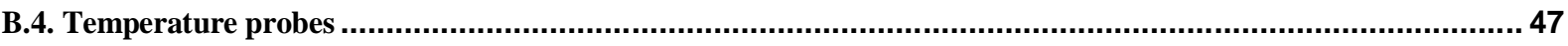

ANNEX C. MEASUREMENT UNCERTAINTIES ............................................................................ 48

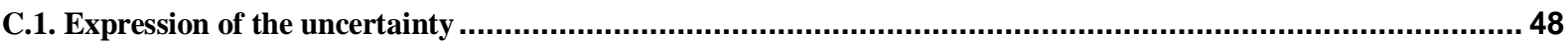

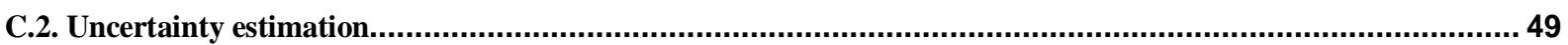

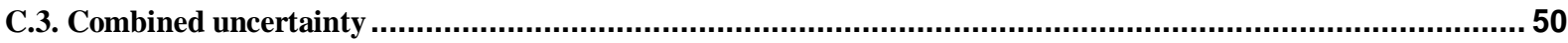

C.4. Example 1. Uncertainty of the measured thermal power produced by a boiler.............................................51

C.5. Example 2. Uncertainty of the measured power produced by a PV panel .................................................52 


\section{Executive Summary}

Monitoring of field test systems and demonstration projects for new generation solar cooling \& heating systems is fundamental to analyze their performances, to identify, their possibilities and to verify the quality of the proposed solutions. This work is done in Subtask C, called "Testing and demonstration projects", using the results of Subtasks A and B.

In this framework, the principal goal of work package " $\mathrm{C} 1$ " is to prepare the testing and the monitoring methodology to measure the performances of field tests or demo projects.

This document is the deliverable D-C1.1 "Monitoring procedure for field test \& demo systems", which is focused on installations with compression heat pumps driven by photovoltaic solar energy. The past and ongoing results from IEA SHC Task 38, 44 and 48 has been considered in order to propose how to properly monitor these new generation solar cooling and heating systems. This final deliverable of a monitoring procedure includes:

- A generic scheme of PV driven compression heat pumps

- Electrical and thermal flows to be measured

- Definition of Performance Ratio Indicators (KPI)

- 2 Examples where the proposed methodology has been applied

- Measurement methods for air to air heat pumps

- Instrumentation

- Uncertainty analysis applied to field test \& demo systems of PV-compression heat pumps

\section{Introduction}

Monitoring of installed solar assisted cooling and heating systems represents a fundamental tool in order not only to optimize the monitored system itself, but as well to draw conclusions for a suited selection of design and control for future installations.

This is especially true for a technology in an early stage of market penetration, as it is the case for heat pumps where the compressor can take part of the electricity from PV panels.

Figure 1 shows a general scheme of a compression heat pump driven by photovoltaics.

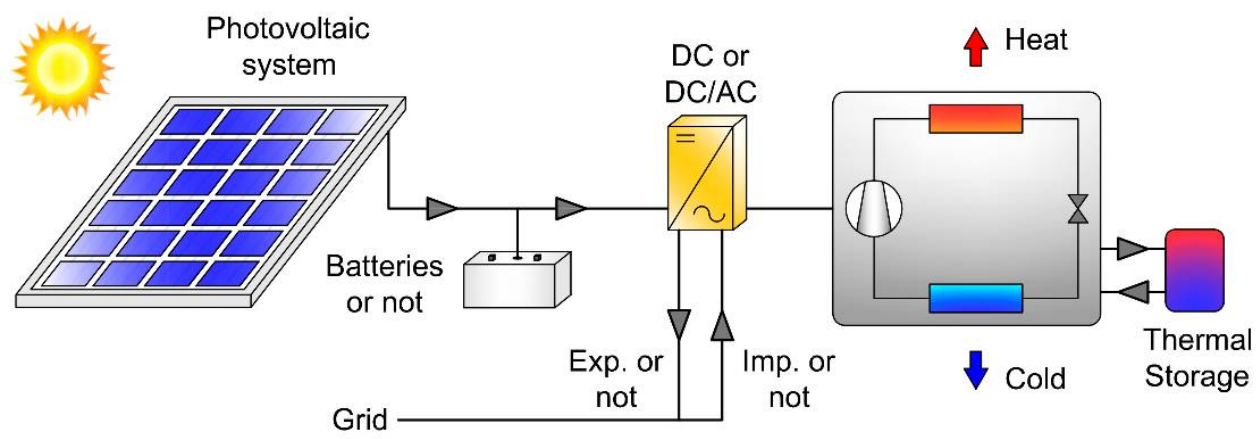

Figure 1 Compression heat pump driven by PV panels

To the date, most of the designed systems are small scale $(<20 \mathrm{~kW}$ cooling or heating capacity), and therefore the systems may work or not with refrigerant. 
The monitoring procedure is carried out in 3 scales:

Data collection: Systems change continuously their behavior and it is necessary to take data in small time steps (1 to 5 minutes).

- Daily data. In 24 hours maybe between 288 and 1440 data of every measure variable. It is necessary to determine a daily behavior of every data.

- Seasonal data. It is not possible neither necessary to measure 365 days of a year. Anyway, if a representative study is needed, it will be necessary to measure at least during 10 days every month: 120 days.

The monitoring procedures have been proposed to be used on facilities that are working in real conditions, or in laboratory conditions that simulate real conditions. Solar heating and cooling systems should be measured at different climatic conditions of temperature and solar radiation.

Objectives:

1. To determine the primary energy savings that is possible to get with these systems: annual solar contribution, electricity produced by the PV panels that is consumed by the unit.

2. To identify the best practices hence of best design solutions in relationship with the climate conditions, the building features and use, occupation conditions and so on.

3. To calibrate numerical models that may be employed to achieve objectives 1 and 2 with minimum cost.

The procedure defines the recommended monitoring equipment required to evaluate the energy performance of the existing systems. So it is not restricted to the IEA activities and the mentioned systems but can support the development of further monitoring campaigns.

\section{Graphical representation}

It is difficult (probably impossible) to represent all the systems that can be developed to be employed with photovoltaics, because in fact, all systems could be driven with the electricity produced by PV panels.

The methodology presented in this document has been proposed with these restrictions:

- The compressor should be hermetic.

- The method is for use on field applications.

- The unit capacity is lower to $12 \mathrm{~kW}$.

- In air to air heat pumps, the thermal flow will be estimated analyzing the refrigerant cycle.

Figure 2 shows a diagram for the representation of a monitored system. This scheme enables to represent different systems by deleting those parts which do not exist in the system under investigation. 


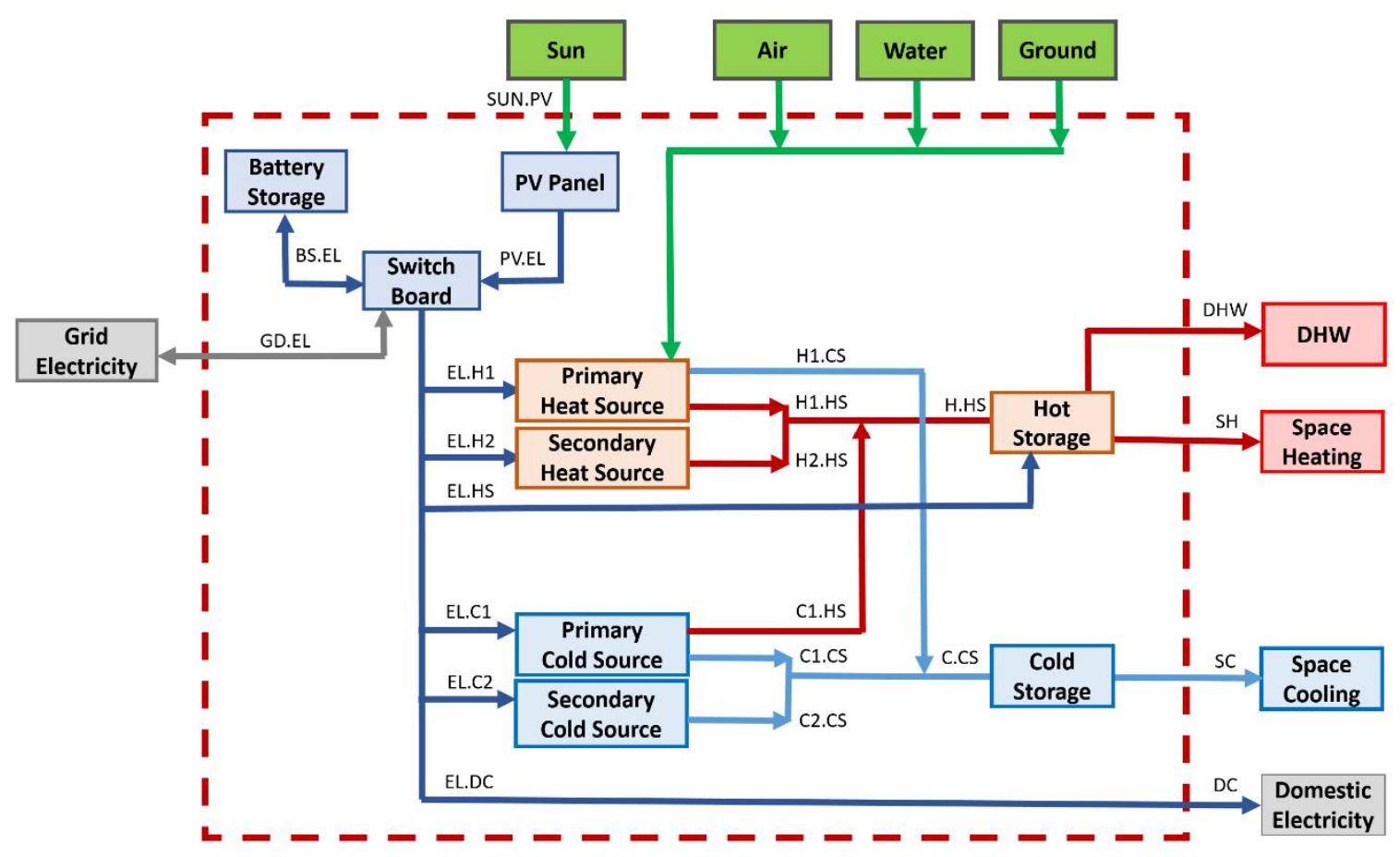

Figure 2 Energy flows for a PV driven solar heating, cooling and DHW production system

The proposed scheme includes the elements listed and described in Table 1. The electrical and thermal flows involved in a photovoltaic assisted SHC system (Figure 2) are listed and described in Table 2. 
Table 1 List and description of the elements involved in a photovoltaic SHC system (Figure 2)

\begin{tabular}{|l|c|l|}
\hline Heating, Cooling and DHW & \multicolumn{2}{l|}{} \\
\hline ELEMENTS & Nomenc & Description \\
\hline PV Panel & PV & Photovoltaic electricity produce by PV panels \\
\hline Switch board & EL & Element or point where photovoltaic - grid - batteries electricity is mixed \\
\hline Battery storage & BS & Electrical storage \\
\hline Primary heat source & H1 & Heat pump driven totally of partially by photovoltaic energy \\
\hline Primary cold source & C1 & Reversible heat pump that may work on heating or cooling mode \\
\hline Secondary heat source & H2 & A secondary system that provides heat if the primary heat source is not able to do it \\
\hline Secondary cold source & C2 & A secondary system that provides cold if the primary heat source is not able to do it \\
\hline Hot storage & HS & Hot storage tank. It will represent the point where all hot productions are mixed \\
\hline Cold storage & HS & Cold storage tank. It will represent the point where all cold productions are mixed \\
\hline DEMANDS & Nomenc & Description \\
\hline Domestic hot water & DHW & Domestic hot water demand of the system \\
\hline Space heating & SH & Space heating demand of the system \\
\hline Space cooling & SC & Space cooling demand of the system \\
\hline Domestic electricity & DE & Domestic electricity conected to he system (usually it will not be considered) \\
\hline SOURCES & Nomenc & Description \\
\hline Grid electricity & GD & Crid electricity (can provide or extracr energy to the system) \\
\hline Sun & SUN & Sun energy \\
\hline Air & AIR & Air energy to condense or evaporate the heat pump refrigerant \\
\hline Water & WAT & Water energy to condense or evaporate the heat pump refrigerant \\
\hline Ground & GRN & Ground energy to condense or evaporate the heat pump refrigerant \\
\hline
\end{tabular}

\section{System Description}

General data on the system have to be entered. The following minimum date are proposed:

- Name

- Final use

- Location

- Mean solar energy radiation in the horizontal at the location $\left(\mathrm{kWh} / \mathrm{m}^{2}\right)$

- Mean temperature at the location

- Nominal characteristics of the heat pump (Eurovent)

- Peak power of the PV panels

- A scheme of the full system

- A description of the control strategy of the system 
Table 2 List of electrical and thermal flows involved in a photovoltaic assisted SHC system (Figure 2)

\begin{tabular}{|c|c|c|c|c|}
\hline \multicolumn{5}{|l|}{ Heating, Cooling and DHW } \\
\hline Energy Data & Nomenc. & ENERGY & FROM & TO \\
\hline Sun to Photovoltaic Panels & SU.PV & SUN & SU & PV \\
\hline Maximum photovoltaic production & PV.Max & ELECTRICITY & \multicolumn{2}{|c|}{ MAX. POTENTIAL } \\
\hline Photovoltaic to Switch Board & PV.EL & ELECTRICITY & PV & EL \\
\hline Grid to Switch Board & GD.EL & ELECTRICITY & GD & EL \\
\hline Battery to Switch board & BS.EL & ELECTRICITY & BS & EL \\
\hline Switch board and bateries looses & EL.LO & LOOS & BS & LOOS \\
\hline Total Switch Board Electricity to System & EL.System & ELECTRICITY & EL & System \\
\hline Switch Board Electricity to Primary Heat Source & EL.H1 & ELECTRICITY & EL & $\mathrm{H} 1$ \\
\hline Switch Board Electricity to Secondary Heat Source & EL.H2 & ELECTRICITY & EL & $\mathrm{H} 2$ \\
\hline Switch Board Electricity to Heat Storage & EL.HS & ELECT/HEAT & EL & HS \\
\hline Switch Board Electricity to Primary Cold Source & EL.C1 & ELECTRICITY & EL & $\mathrm{C} 1$ \\
\hline Switch Board Electricity to Secondary Cold Source & EL.C2 & ELECTRICITY & EL & $\mathrm{C} 2$ \\
\hline Switch Board Electricity to Domestic Electricity & EL.DE & ELECTRICITY & EL & DE \\
\hline Total Switch Board Electricity to System & EL.System & ELECTRICITY & $\mathrm{EL}$ & System \\
\hline Primary Heat Source to Heat Storage and Distribution & H1.HS & HEAT & $\mathrm{H} 1$ & HS \\
\hline Secondary Heat Source to Heat Storage and Distribution & H2.HS & HEAT & H2 & HS \\
\hline Primary Cold Source to Heat Storage and Distribution & C1.HS & COLD & $\mathrm{C} 1$ & HS \\
\hline Swith board Electricity on Heat Storage & EL.HS & HEAT & $E L$ & HS \\
\hline Thermal Energy on Heat Storage and Distribution & HHS & HEAT & \multicolumn{2}{|c|}{ HS HEAT INEET } \\
\hline Primary Cold Source to Cold Storage and Distribution & C1.CS & COLD & $\mathrm{C} 1$ & CS \\
\hline Secondary Cold Source to Cold Storage and Distribution & C2.CS & COLD & C2 & CS \\
\hline Primary Heat Source to Cold Storage and Distribution & $\mathrm{H} 1 . \mathrm{CS}$ & HEAT & $\mathrm{H} 1$ & CS \\
\hline Thermal Energy on Cold Storage and Distribution & C.CS & COLD & \multicolumn{2}{|c|}{ CS COLD NLET } \\
\hline Total Space Cooling from System & QSC.System & COLD & CS & SC \\
\hline Total Space Heating from System & QSH.System & HEAT & HS & SH \\
\hline Total DHW from System & QDHW.System & HEAT & HS & DHW \\
\hline al Thermal Eneg) & $n$ & $\mathrm{D}+\mathrm{H}$ & $\mathrm{CS}+\mathrm{HT}$ & Sys \\
\hline
\end{tabular}




\section{Monitoring procedure}

The monitoring procedure consists of an excel file where monitored data are collected and elaborated on daily, monthly or yearly basis.

The monitoring procedure can be carried out on two levels:

1. First level: Daily Data. Calculation of COP, Primary Energy Ratio, Solar Contribution, Production Factor, etc. of a day. Data taken every 1 to 5 minutes will be processed in order to obtain a daily data of every parameter: convert $\mathrm{kW}$ data on $\mathrm{kWh}$ per day.

2. Second level: Monthly, Seasonal data. The mean data of every day processed will be joined to get monthly and seasonal data of COP, Primary Energy Ratio, Solar Contribution, Production Factor, etc.

The methodology of the method described in this document gives procedures to measure or determinate some thermal flux on field application tests:

- If the thermal flux is given by cooling or heating a water or water/glycol circuit, then it will be directly measured with an energy flow meter.

- If the thermal flux is directly given by the heat pump refrigerant to the air or to a tank, then it will calculated indirectly by the heat pump refrigerant. The "Internal Method" is described in Annex A.

- Tank loses may as well be estimated by doing specific tests focused on their determination.

The procedure presented in this document will follow as possible the procedure developed for Solar Heat Driven Chiller (SHDC) by IEA SHC Task 38 "Monitoring Procedure for Solar Cooling Systems" and by IEA SHC Task 48 "Deliverable M-C4.3 - Final report Measurement and Verification Procedures". These documents are available on the Task Web page-

\section{Reference System}

Most key figures defined in the procedure for the evaluation of the performance of the monitored system require data on energy used for heating, cooling and DHW to be converted into primary energy (Total Primary Energy or non-Renewable Primary Energy).

The calculation of the energy use needs the definition of efficiency figures of the applied heating, cooling and DHW systems. In practice such efficiencies have to be defined for the heat and cold backup systems and depend of course on the technology used. The following range of figures are usual:

Gas boiler seasonal efficiency (it can be Natural Gas or Propane):

$$
\eta_{\text {BOILER,Ref }}=0.90-0.92 \frac{\mathrm{kWh}_{\mathrm{TH}}}{\mathrm{kWh}_{\mathrm{GAS}}} \quad \text { Eq. } 1
$$

Moreover, it can be assumed that the reference boiler has some electrical consumption:

$$
\mathrm{EC}_{\mathrm{BOILER}, \mathrm{Ref}}=0.02-0.03 \frac{\mathrm{kWh}_{\mathrm{EL}}}{\mathrm{kWh}_{\mathrm{TH}}} \quad E q .2
$$

Seasonal Performance Factor of vapor compression unit in cooling mode:

$$
\mathrm{SPF}_{\mathrm{REF}, \text { COOLING }}=2.40-2.60 \frac{\mathrm{kWh}_{\mathrm{TH}}}{\mathrm{kWh}_{\mathrm{EL}}} \quad \text { Eq.3 }
$$


On the other hand it is necessary to fix the primary energy factors for the main energy carriers used in the installations, i.e. electricity and fossil fuels like oil and natural gas. The electricity conversion factor depends on the country. The following "primary energy factors (PEF)" defined according to the EN 15603 can be used:

$$
\begin{aligned}
\mathrm{PEF}_{\mathrm{EL}}=2.0-3.0 \frac{\mathrm{kWh}_{\mathrm{PE}}}{\mathrm{kWh}_{\mathrm{EL}}} & E q .4 \\
\mathrm{PEF}_{\mathrm{GAS}}=1.0-1.2 \frac{\mathrm{kWh}_{\mathrm{PE}}}{\mathrm{kWh}_{\mathrm{GAS}}} & E q .5
\end{aligned}
$$

Table 3 shows proposed values for the Reference System. If the Country Regulation specifies other values, then it would be recommended to use those ones.

\section{Table 3 Reference system needed to evaluate a photovoltaic SHC system}

\begin{tabular}{|l|l|l|}
\hline $\begin{array}{l}\text { REFERENCE SYSTEM. INPUT DATA } \\
\text { Efficiencies and Conversion factors }\end{array}$ & \multicolumn{1}{|c|}{ Nomenc. } & \multicolumn{1}{|c|}{ Usual Values } \\
\hline Efficiency of Reference System for Heating, boiler & EFFBOILER,Ref & $92 \%$ for a Natural Gas Boiler \\
Electrical Consumption of the Reference boiler & ECBOILER,Ref & $2 \%$ electricity consumption for a NG Boiler \\
Efficiency of Reference System for Cooling, Chiller & EFFCOOLING,Ref & 2,50 for a reference chiller \\
Primary energy factor for Electricity & PEFEL & 2,50 Primary Energy \\
Primary energy factor for Gas & PEFGAS & 1,11 Primary Energy \\
\hline
\end{tabular}

Reference Gas and Electricity consumption from the heating, cooling and DHW demand.

$$
\begin{gathered}
\mathrm{GAS}_{\mathrm{SH} . D H W R e f}=\frac{\mathrm{Q}_{\mathrm{SH}}+\mathrm{Q}_{\mathrm{DHW}}}{\eta_{\text {BOILER,Ref }}}(\mathrm{kWh}) \quad E q .6 \\
\mathrm{E}_{\mathrm{SH} . D H W . R e f}=\left(\mathrm{Q}_{\mathrm{SH}}+\mathrm{Q}_{\mathrm{DHW}}\right) \cdot \mathrm{EC}_{\mathrm{BOILER,Ref}}(\mathrm{kWh}) \\
\mathrm{E}_{\mathrm{SC} . \mathrm{Ref}}=\frac{\mathrm{Q}_{\mathrm{SC}}}{\mathrm{EFF}_{\text {COOLING,Ref }}}(\mathrm{kWh}) \quad E q .7
\end{gathered}
$$

The Non-Renewable Primary Energy Consumed by the Reference System is given by:

$$
\mathrm{PnRE}_{\mathrm{Ref}}=\mathrm{GAS}_{\mathrm{SH} . \mathrm{DHW} \cdot \mathrm{Ref}} \cdot \mathrm{PEF}_{\mathrm{GAS}}+\mathrm{E}_{\mathrm{SH} . \mathrm{DHW} \cdot \mathrm{Ref}} \cdot \mathrm{PEF}_{\mathrm{EL}}+\mathrm{E}_{\mathrm{SC} . \mathrm{Ref}} \cdot \mathrm{PEF}_{\mathrm{EL}} \quad \text { Eq.9 }
$$

\section{Key Performance Indicators}

General data on the system have to be entered: name, location and final use of the installation together with sizes, technologies and units of the major SHC components (i.e. PV panels, compression unit, tanks, back-up systems).

The first level of information is taken from the monitored data taken every $1-5$ minutes. Data will be taken every minute if the unit works in a variable regime due to, for example, defrost cycles or because it's an ON/OFF unit working at low loads. If the system works stable, then the monitoring time can be 5 minutes.

The conversion from power data in $\mathrm{kW}$ to energy data in $\mathrm{kWh}$ can be done by summing every data multiplied by the time step in hours ( 1 minute $=\Delta \mathrm{t}=1 / 60 ; 5$ minutes $=\Delta \mathrm{t}=1 / 20)$. For electrical and thermal flows, taken 1 data every two minutes and for 1 day calculations:

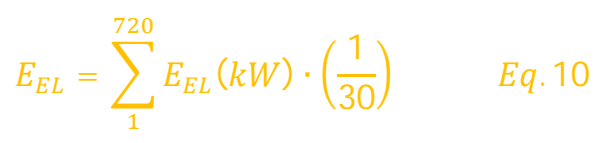




\section{$Q_{S C}=\sum_{1}^{720} Q_{S C}(k W) \cdot\left(\frac{1}{30}\right)$}

The Non-Renewable Primary Energy Consumed by the System, if only PV and grid electricity is employed, is given by:

$$
\mathrm{PnRE}_{\mathrm{Sys}}=\mathrm{E}_{\mathrm{GD} . \mathrm{EL}} \cdot \mathrm{PEF}_{\mathrm{EL}} \quad E q .12
$$

Five KPI's are employed to evaluate the performance of the SHC system. Every parameter can be calculated from Space Cooling (SC), Space Heating (SH), Domestic Hot Water (DHW) or to the system if the unit produces more than one service.

\section{Seasonal Performance Ratio}

The SPF (Seasonal Performance Ratio) is the ratio of useful heat and/or cold in relation to the electricity consumption needed. For example:

$$
\begin{aligned}
& \text { Primary Heating Source: } \mathrm{SPF}_{\mathrm{H} 1}=\frac{\mathrm{Q}_{\mathrm{H} 1 . \mathrm{HS}}}{\mathrm{E}_{\mathrm{EL} . \mathrm{H} 1}} \quad E q .13 \\
& \text { Primary Cooling Source: } \mathrm{SPF}_{\mathrm{C} 1}=\frac{\mathrm{Q}_{\mathrm{C} 1 . \mathrm{CS}}}{\mathrm{E}_{\mathrm{EL} . \mathrm{C} 1}} \quad E q .14
\end{aligned}
$$

\section{Primary Energy Ratio, PERnRE}

The Primary Energy Ratio PERnRE, indicates the relation between the PnRE employed by the analyzed system and the PnRE employed by the Reference for the same energy demand.

$$
\mathrm{PER}_{\mathrm{nRE}}=\frac{\mathrm{PnRE}_{\mathrm{Ref}}}{\mathrm{PnRE}_{\mathrm{Sys}}} \quad \text { Eq.15 }
$$

\section{Fraction Savings, FSAVnRE}

The Fraction Savings of non-Renewable Primary Energy, FSAVnRE indicates the \% of non-Renewable Primary Energy consumption.

$$
\operatorname{FSAV}_{\mathrm{nRE}}(\%)=\frac{\mathrm{PnRE}_{\mathrm{Ref}}-\mathrm{PnRE}_{\mathrm{Sys}}}{\mathrm{PnRE}_{\mathrm{Ref}}} \quad \text { Eq.16 }
$$

\section{Equivalent Seasonal Performance Factor, SPFEQU}

The Equivalent Seasonal Performance Factor SPFEQU, indicates the grid electricity needed for producing the energy demand. This parameter can be considered like a mean COP or EER, but in real working conditions.

$$
\mathrm{SPF}_{\mathrm{EQU}}=\frac{\mathrm{Q}_{\mathrm{Sys}}}{\mathrm{E}_{\mathrm{PV} . \mathrm{EL}}} \quad \text { Eq.17 }
$$

\section{Solar contribution, $\mathrm{SC}(\%)$}

$\%$ of total electricity that has been provided by the PV panels

$$
\mathrm{SC}(\%)=\frac{\mathrm{E}_{\mathrm{PV} . \mathrm{EL}}}{\mathrm{E}_{\mathrm{GD} . E \mathrm{LL}}+\mathrm{E}_{\mathrm{PV} . \mathrm{EL}}} \quad E q .18
$$

Or \% of total heat and cold that has been provided by the PV panels

$$
\%_{\mathrm{PV}}=\frac{\mathrm{Q}_{\mathrm{PV}}}{\mathrm{Q}_{\mathrm{UNITS}}}=\frac{\mathrm{E}_{\mathrm{PV} . \mathrm{C} 1} \cdot \mathrm{SPF}_{\mathrm{C} 1}+\mathrm{E}_{\mathrm{PV} . \mathrm{H} 1} \cdot \mathrm{SPF}_{\mathrm{H} 1}+\mathrm{E}_{\mathrm{PV} . \mathrm{HS}}}{\mathrm{Q}_{\mathrm{C} 1 . \mathrm{CS}}+\mathrm{Q}_{\mathrm{C} 2 . \mathrm{CS}}+\mathrm{Q}_{\mathrm{H} 1 . \mathrm{HS}}+\mathrm{Q}_{\mathrm{H} 2 . \mathrm{HS}}+\mathrm{Q}_{\mathrm{EL} . \mathrm{HS}}} \quad E q .19
$$




\section{Production factor, PF}

Thermal heat that has been provided by the facility by the maximum that can be provided by the same electricity.

$$
\mathrm{PF}=\frac{\mathrm{Q}_{\text {Sys }}}{2.5 \cdot\left(\mathrm{E}_{\mathrm{GD} . \mathrm{EL}}+\mathrm{E}_{\mathrm{PV} . \mathrm{Max}}\right)} \quad \text { Eq.20 }
$$

This production factor takes into account is the electricity is well employed in the SHC system. In this parameter it does not matter if the electricity comes from the grid of from photovoltaic panels.

An alternative definition can be done, by using the SPF of $\mathrm{H} 1$ and $\mathrm{H} 2$ :

$$
\mathrm{PF}=\frac{\mathrm{E}_{\mathrm{PV} . \mathrm{C} 1} \cdot \mathrm{SPF}_{\mathrm{C} 1}+\mathrm{E}_{\mathrm{PV} . \mathrm{H} 1} \cdot \mathrm{SPF}_{\mathrm{H} 1}+\mathrm{E}_{\mathrm{PV} . \mathrm{HS}}}{\mathrm{E}_{\mathrm{PV} . M a x . \mathrm{C}} \cdot \mathrm{SPF}_{\mathrm{C} 1}+\mathrm{E}_{\mathrm{PV} \text {.Max.H }} \cdot \mathrm{SPF}_{\mathrm{H} 1}} \quad E q .21
$$

Where $E_{P V . M a x . C}$, is the maximun PV energy when the system is working on cooling mode and $E_{P V . M a x . H}$ is the maximun PV energy when the system is working on heating mode.

\section{Measurements climatic conditions}

It is necessary to give information about the conditions at every measured day. Many Key Performance Indicators calculated in the last section depends on the climatic conditions or in the working conditions of the system. The proposed climatic conditions to be determined are:

- $\mathrm{T}_{\mathrm{M}, 24 \mathrm{~h}}$ Mean outlet temperature in 24 hours.

- $\mathrm{T}_{\mathrm{M}, \mathrm{HPon}}$ Mean outlet temperature when the heat pump is $\mathrm{ON}$

- $\mathrm{E}_{\mathrm{SOL}} / \mathrm{A}_{\mathrm{PV}}$ Solar energy radiation $\mathrm{kWh} / \mathrm{m}^{2}$ day.

Theses parameters may also be useful:

- $\mathrm{RH}_{\mathrm{M}, 24 \mathrm{~h}}$ Mean relative humidity in 24 hours

- $\mathrm{RH}_{\mathrm{M}, \mathrm{HP} \text { on }}$ Mean relative humidity when the heat pump is $\mathrm{ON}$

- $\mathrm{V}_{\mathrm{W}}, \mathrm{D}_{\mathrm{w}}$ Mean wind velocity and direction in 24 hours

It is considered that $\mathrm{T}_{\mathrm{M}, 24 \mathrm{~h}}, \mathrm{~T}_{\mathrm{M}, \mathrm{HPon}}$ and $\mathrm{E}_{\mathrm{SOL}} / \mathrm{A}_{\mathrm{PV}}$ are the minimum variables that must be given.

Another reference conditions should be as well measured.

In HVAC air to air heat pumps:

- $\mathrm{T}_{\mathrm{LOCAL}}, \mathrm{RH}_{\mathrm{LOCAL}}$ Mean temperature and mean relative humidity in the space that is being cooled or heated

In air to air heat pumps for domestic hot water applications:

- $\mathrm{T}_{\mathrm{M}, \mathrm{IN}}$, Mean water temperature in the inlet

- $\mathrm{T}_{\mathrm{M}, \mathrm{OUT}}$, Mean water temperature in the outlet (DHW preparation temperature). 


\section{Example 1. Monitoring a PV - DHW facility}

Figure 3 shows an example of monitoring facility of a domestic hot water system produced by a heat pump driven by photovoltaic energy. The characteristics of the system are:

- There are no batteries

- There is not an external support (joule effect or boiler)

- When the heat pump if OFF the PV electricity is derived to the electrical heater located in the tank

- There is not electricity exported to the grid.

The scheme of the installation is shown in Figure 3.

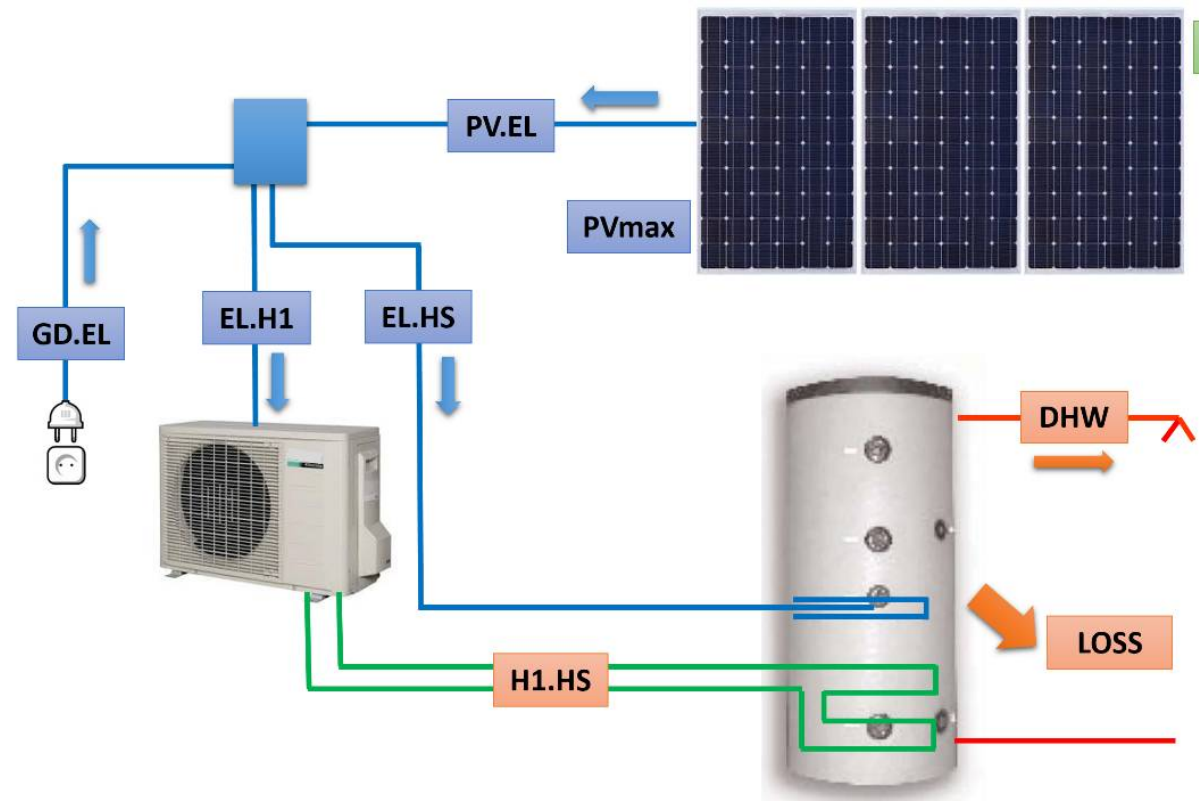

Figure 3 PV driven solar heating system of a DHW production installation. The unit is tested simulating field conditions in the laboratory of Miguel Hernandez University of Elche, Spain

The monitoring procedure can be applied to simplified systems. Figure 4 shows an installation with these simplifications to the general drawn showed in Figure 2.

Table 4 shows the list of measurements taken every 2 minutes. 


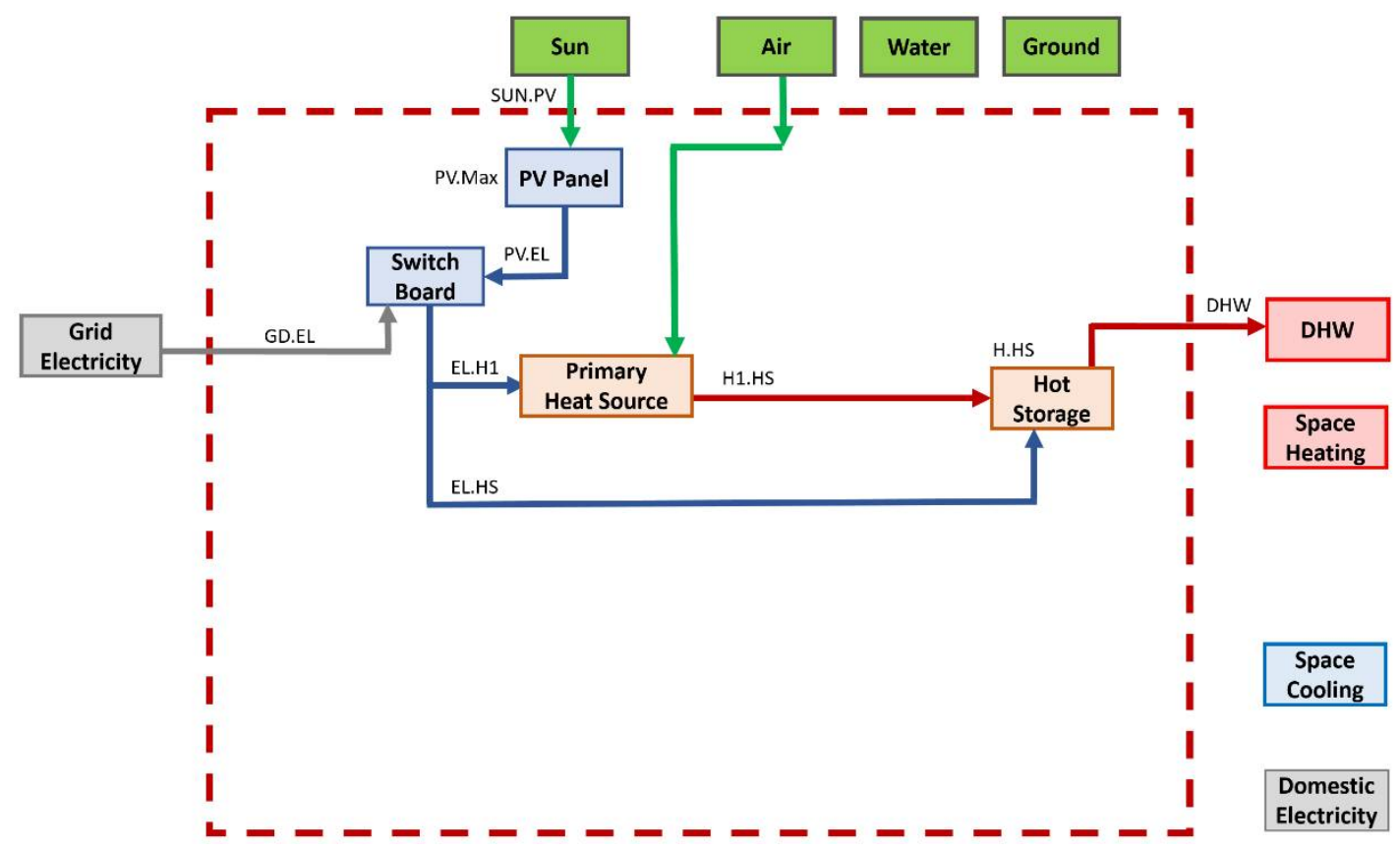

Figure 4 Energy flows for a PV driven DHW production system. Simplified model according to the general scheme

Table 4 Parameters recorded in the trial every 2 minutes.

\begin{tabular}{|l|l|l|}
\hline Description & Symbology & Units \\
\hline Compressor inlet temp. & $\mathrm{T}_{1}$ & ${ }^{\circ} \mathrm{C}$ \\
\hline Compressor discharge temp. & $\mathrm{T}_{2}$ & ${ }^{\circ} \mathrm{C}$ \\
\hline Condenser outlet temp. & $\mathrm{T}_{3}$ & ${ }^{\circ} \mathrm{C}$ \\
\hline Evaporator inlet temp. & $\mathrm{T}_{4}$ & ${ }^{\circ} \mathrm{C}$ \\
\hline Evaporating pressure & $\mathrm{p}_{\mathrm{E}}$ & $\mathrm{bar}$ \\
\hline Condensing pressure & $\mathrm{p}_{\mathrm{C}}$ & $\mathrm{bar}$ \\
\hline DWH inlet temperature & $\mathrm{T}_{\mathrm{W}, \mathrm{IN}}$ & ${ }^{\circ} \mathrm{C}$ \\
\hline DWH outlet temperature & $\mathrm{T}_{\mathrm{W}, \mathrm{OUT}}$ & ${ }^{\circ} \mathrm{C}$ \\
\hline Solar irradiance & $\mathrm{G}_{\mathrm{W}}$ & $\mathrm{W} / \mathrm{m}^{2}$ \\
\hline Outside temperature & $\mathrm{T}_{\mathrm{O}}$ & ${ }^{\circ} \mathrm{C}$ \\
\hline Relative Humidity & $\mathrm{HR}$ & ${ }^{\circ}$ \\
\hline Wind Speed & $\mathrm{V}_{\mathrm{w}}$ & $\mathrm{m} / \mathrm{s}$ \\
\hline Wind direction & $\mathrm{D}_{\mathrm{w}}$ & ${ }^{\circ}$ \\
\hline Electricity absorbed by the unit & $\mathrm{P}_{\mathrm{H} 1}$ & $\mathrm{~kW}$ \\
\hline Electricity taken from the grid & $\mathrm{P}_{\mathrm{GD}}$ & $\mathrm{kW}$ \\
\hline Photovoltaic panels current & $\mathrm{I}_{\mathrm{PV}}$ & $\mathrm{A}$ \\
\hline Photovoltaic panels voltage & $\mathrm{V}_{\mathrm{PV}}$ & $\mathrm{V}$ \\
\hline
\end{tabular}

\section{ELECTRICAL ENERGY FLOWS}

The electrical and thermal energy flows produced in the facility are calculated in a daily basis, from the data measured every 2 minutes ( 720 data in 24 hours). 
The electrical energy produced by the PV panels in is dc current and use to be at a voltage of 24-28 Volt. In this facility the energy is converted to ac current at 220 Volt. The converter has an efficiency of $97 \%$ (this data was given by the manufacturer and it was tested that the value is correct. The electrical energy produced by the PV panels is given by:

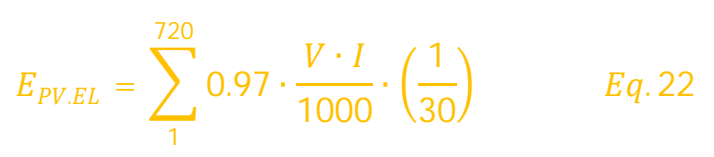

Figure 5 shows the measurements of the electricity produced by 2 PV panels during 24 hours. The electrical energy produced by the PV panels is EPV.EL $=2.077 \mathrm{kWh}$.

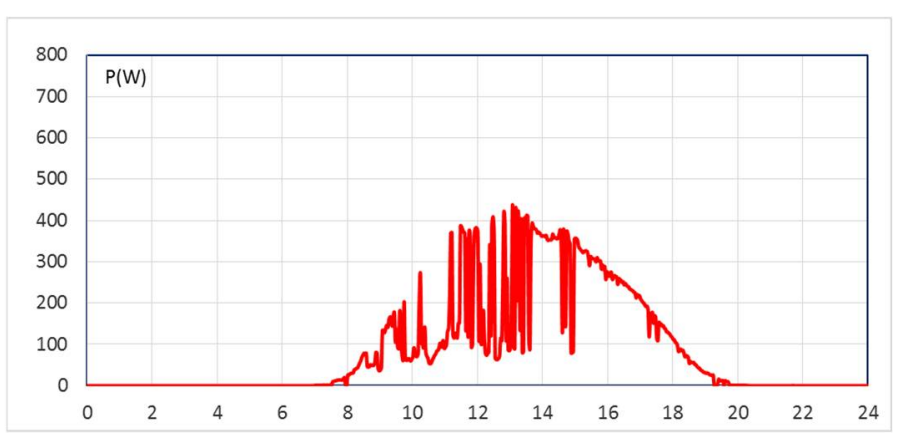

Figure 5 Field measurements of the electrical energy produced by 2 PV panels during one day (EPV.EL)

EEL.H1: Switch board to primary heat pump (electrical energy consumed by the heat pump)

The electrical energy consumed by the heat pump is measured directly with an electrical meter.

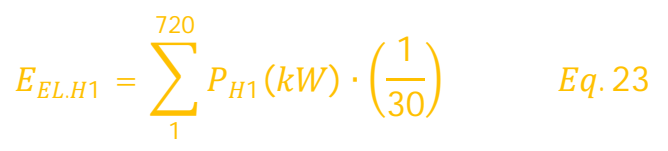

Figure 6 shows the measurements of the electricity consumed by a heat pump for DHW production during 24 hours. The total electrical energy consumed by the heat pump is EEL.H1=1.678 $\mathrm{kWh}$.

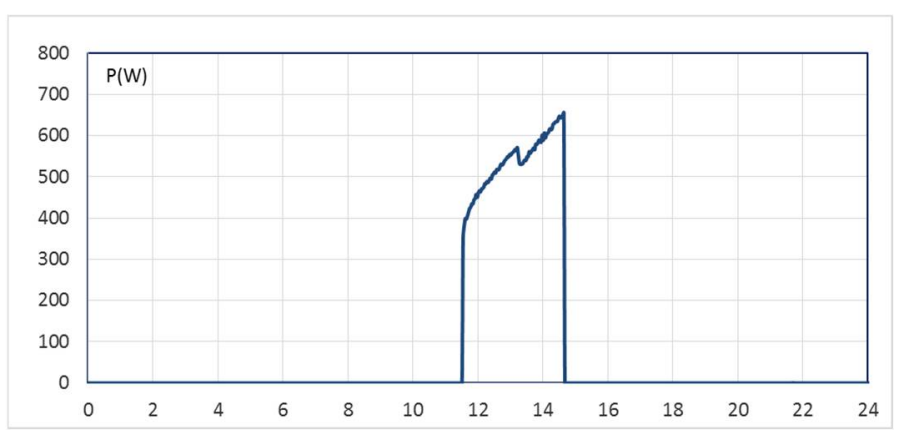

Figure 6 Field measurements of the electrical energy consumed by the DHW heat pump during one day

EGD.EL: Grid electricity to switch board (electrical energy taken from the grid)

The electrical energy taken from the grid is measured directly with an electrical meter. The electrical energy consumed from the grid is calculated by: 


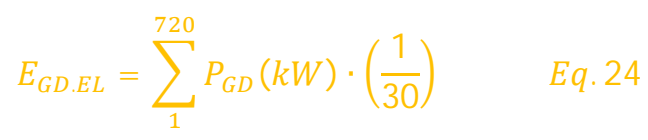

In this facility, some electricity is provided by the grid when the heat pump is ON, as shown in Figure 7. $($ EGD.EL $=0.836 \mathrm{kWh})$

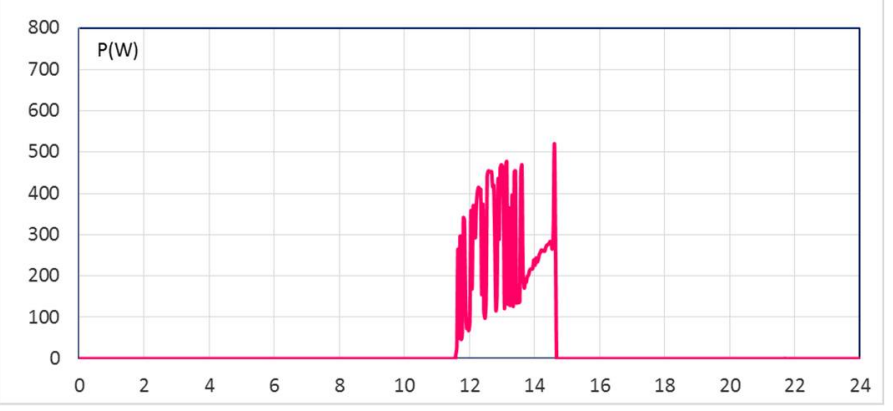

Figure 7 Field measurements of the electrical energy taken from the grid during one day

\section{EEL.HS: Switch board to hot storage (electrical energy consumed in the tank by joule effect)}

When the heat pump does not work, the electrical energy produced by the PV panels is derived to an electrical heater. Therefore:

$$
\text { When } H 1 \text { is OFF } \Rightarrow E_{E L . H S}=\sum_{1}^{720} 0.97 \cdot \frac{V \cdot I}{1000} \cdot\left(\frac{1}{30}\right) \quad \text { Eq.25 }
$$

The calculation of this parameter will depend on how the system works. Figure 8 shows the electrical energy that is consumed in the electrical heater. In this facility, only PV energy is derived to the electrical heater: EEL.HS=1.235 kWh.

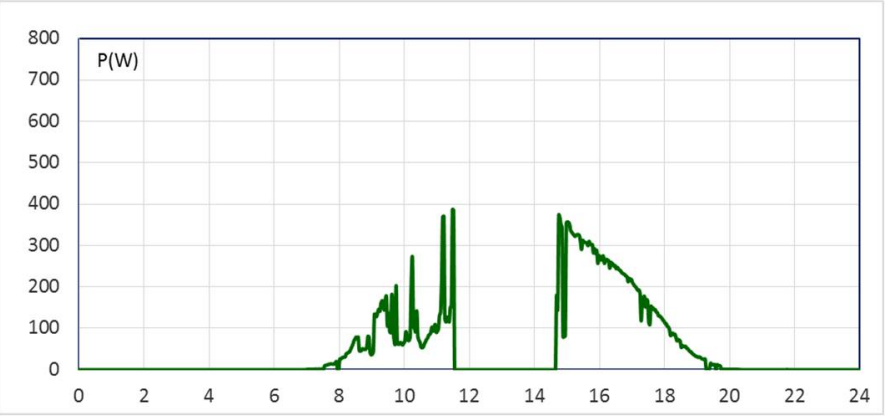

Figure 8 Field measurements of the electrical energy consumed in the electrical heater by joule effect

\section{THERMAL ENERGY FLOWS}

In this facility, there are 2 thermal flows that introduce energy in the systems:

- Primary heat source to heat storage (QH1.HS). Is the thermal energy produced by the heat pump and conducted to the heat storage.

- Switch electricity to heat storage (QEL.HS). Thermal energy produced by the electrical heater. This system is designed to derive only PV electricity to the electrical heater. 
The total thermal energy on storage and distribution is:

$$
\mathrm{Q}_{\mathrm{H} . \mathrm{HS}}=\mathrm{Q}_{\mathrm{H} 1 . \mathrm{HS}}+\mathrm{Q}_{\mathrm{EL} . \mathrm{HS}} \quad E q .26
$$

There are 2 thermal flows that consume energy:

- Domestic hot water demand (DHW). Thermal energy employed for DHW production

- Tank Losses (hot storage losses) QHS.LOs. Tank losses cannot be measured and are calculated as:

$$
\text { - } \mathrm{Q}_{\mathrm{HS} . \mathrm{LOS}}=\mathrm{Q}_{\mathrm{H} . \mathrm{HS}}-\mathrm{Q}_{\mathrm{HS} . \mathrm{DHW}} \quad E q .27
$$

Moreover it can be tested that the energy accumulated in the tank from the beginning to the end of the measurement is the same, i.e. the tank temperature at 0 hours must be the same (or select 24 hours when $\Delta \mathrm{T}_{\mathrm{HS}}=0$.

QH1.HS: Primary Energy Source to Heat Storage (thermal useful energy produced by the heat pump)

In the measurements, the thermal energy produced by the heat pump is measured employing the "Internal Method" methodology described in Annex A. The methodology needs to measure the data listed in Table 5.

Table 5 Parameters needed to calculate QH1.HS by the named: Internal Method.

\begin{tabular}{|l|l|l|}
\hline Description & Symbology & Units \\
\hline Compressor inlet temp. & $\mathrm{T}_{1}$ & ${ }^{\circ} \mathrm{C}$ \\
\hline Compressor discharge temp. & $\mathrm{T}_{2}$ & ${ }^{\circ} \mathrm{C}$ \\
\hline Condenser outlet temp. & $\mathrm{T}_{3}$ & ${ }^{\circ} \mathrm{C}$ \\
\hline Evaporator inlet temp. & $\mathrm{T}_{4}$ & ${ }^{\circ} \mathrm{C}$ \\
\hline Evaporating pressure & $\mathrm{p}_{\mathrm{E}}$ & $\mathrm{bar}$ \\
\hline Condensing pressure & $\mathrm{p}_{\mathrm{C}}$ & $\mathrm{bar}$ \\
\hline Elect. absorbed by the compressor & $\mathrm{P}_{\mathrm{COMP}}$ & $\mathrm{kW}$ \\
\hline
\end{tabular}

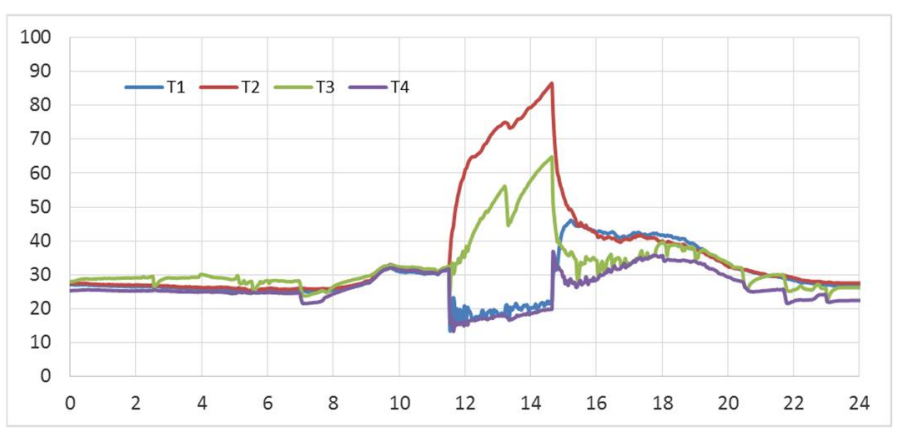

Figure 9 Field measurements of the temperatures of the 4 points of the thermo-dynamical cycle, according to Figure 26. Refrigerant: R134a 


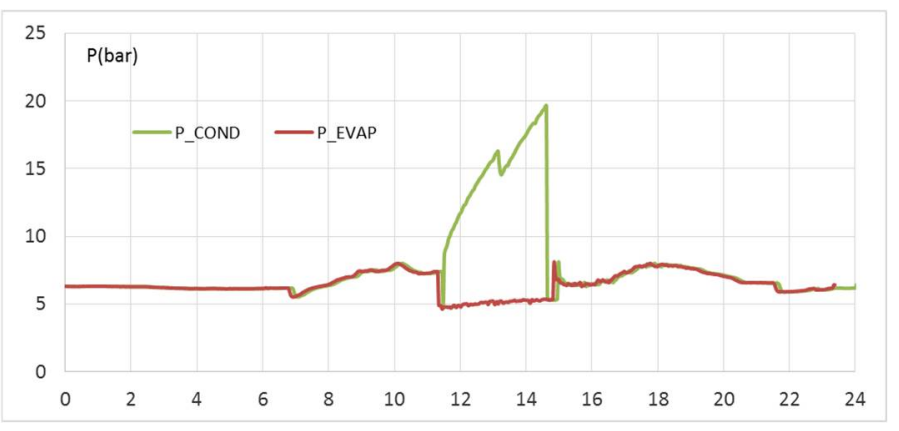

Figure 10 Field measurements of the pressures in the inlet and in the outlet of the compressor

The electrical energy consumed by the unit compressor was measured and is $50 \mathrm{~W}$ less than the electrical power consumed by the unit, so the curve is the one presented in Figure 6 but with $50 \mathrm{~W}$ lower.

Figure 11 shows the results of thermal flow every 2 minutes calculated applying the "Internal Method" methodology explained in Annex A.

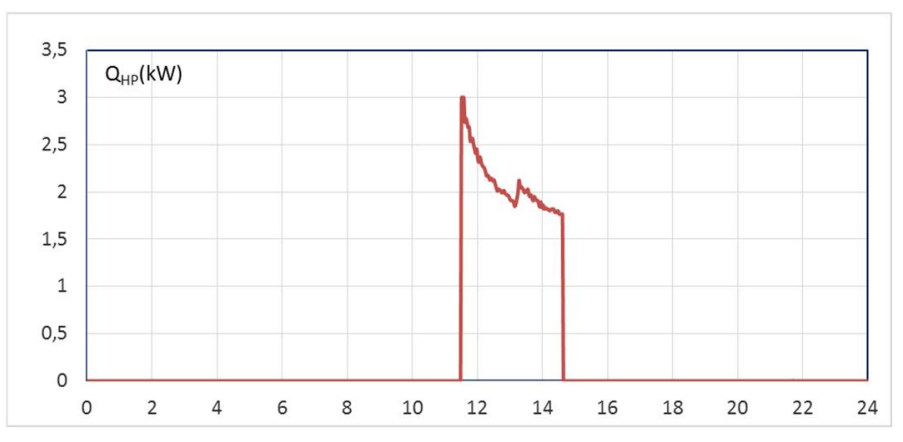

Figure 11 Thermal flow produced by the heat pump unit for DWH production

The thermal energy produced by the heat pump and sent to the hot storage tank, QH1.HS is calculated by:

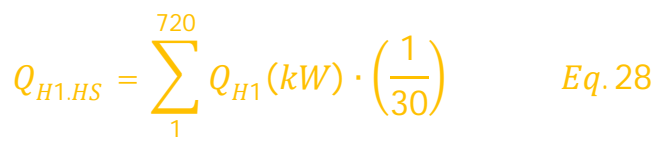

For the day that is being analyzing in this example, the thermal energy produced by the heat pump and storage in the tank is QH1.HS=6.547 kWh.

\section{QEL.HS: Thermal energy produced by the electrical heater}

This thermal energy fits with the electricity consumed by the electrical heater, QH1.HS= EH1.HS $=1.235 \mathrm{kWh}$.

\section{QH.HS: Total thermal energy on heat storage tank and distribution}

The thermal energy that the hot storage tank receives from the heat pump and from the electrical heater is:

- $\mathrm{Q}_{\mathrm{H} . \mathrm{HS}}=\mathrm{Q}_{\mathrm{H} 1 \mathrm{HS}}+\mathrm{Q}_{\mathrm{EL} . \mathrm{HS}}$

Eq. 29 
For the day that is being analyzing in this example, QH.HS $=6.547+1.235=7.782 \mathrm{kWh}$

QDWH: Thermal energy needed for DHW production

The water consumption is produced 6 times, where every time, a water consumption of about 22 liters in 5 minutes is produced. The energy consumption is showed in Figure 12.

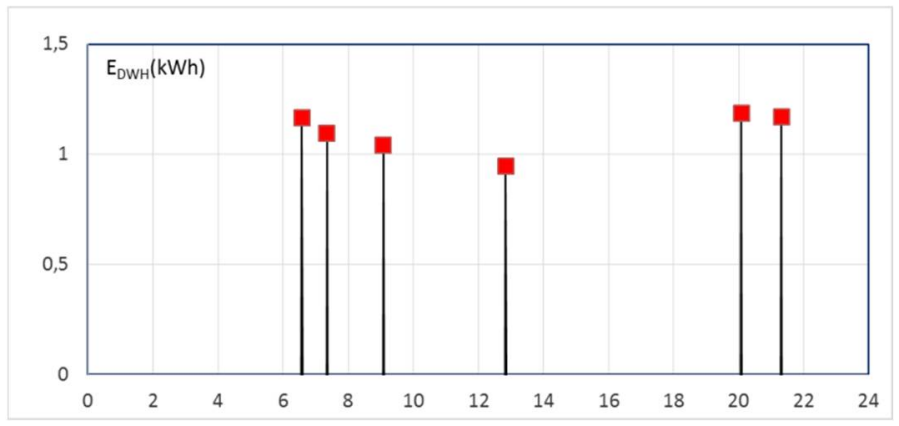

Figure 12 Energy consumed when each of the 6 water consumptions is produced

The thermal energy needed for DHW production, QDHW is calculated by:

$$
\mathrm{Q}_{\mathrm{DHW}}=\sum_{1}^{6} \mathrm{Q}_{\mathrm{DHW}}(\mathrm{kWh}) \quad \text { Eq.30 }
$$

For the analyzed day it is $\mathrm{Q}_{\mathrm{DHW}}=6.603 \mathrm{kWh}$.

\section{DETERMINATION OF MEASURING CONDITIONS}

The efficiency of NG SHC systems depend on climatic conditions measured. Here, the most important daily reference conditions are calculated.

\section{$T_{M, 24 h}:$ Mean outlet temperature in 24 hours}

Is the mean value of the 720 measurements taken in 24 hours (one every 2 minutes).

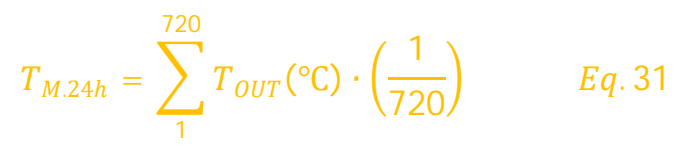

Figure 13 shows the outlet temperatures measured during the analyzed day. The mean temperature in 24 hours was: $\mathrm{T}_{\mathrm{M}, 24 \mathrm{~h}}=26.5^{\circ} \mathrm{C}$.

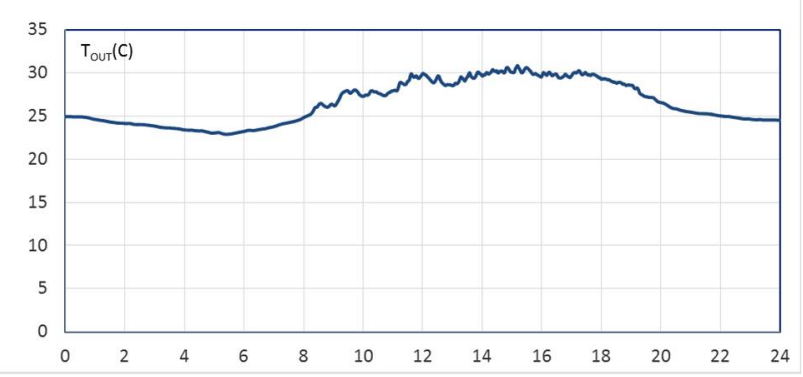


The heat pump was working during 3.13 hours. To analyze the efficiency of the heat pump, it is worthy to determine the mean outlet temperature when the heat pump is working

$$
\text { If } H P=O N \Rightarrow T_{M \cdot H P O n}=\sum_{1}^{i} T_{\text {OUT }}\left({ }^{\circ} \mathrm{C}\right) \cdot\left(\frac{1}{i}\right) \quad \text { Eq.32 }
$$

Figure 13 shows the outlet temperatures measured during the analyzed day. The mean temperature when the heat pump was working was: $\mathrm{T}_{\mathrm{M}, \mathrm{HPon}}=29.9^{\circ} \mathrm{C}$

\section{$\mathrm{E}_{\mathrm{SOL}} / \mathrm{A}_{\mathrm{PV}}$ : Solar energy radiation $\mathrm{kWh} / \mathrm{m}^{2}$ day}

Solar contribution, production factor, etc. depends on the solar radiation received by the PV panels. The measurement has been carried out in the PV panels with an inclination of $45^{\circ}$, and oriented to South.

$$
E_{S U N} / A_{P V}\left(k W h / m^{2}\right)=\sum_{1}^{720} G\left(W / m^{2}\right) \frac{1}{30 \cdot 1000} \quad E q .33
$$

Figure 14 shows the irradiation in $\mathrm{W} / \mathrm{m}^{2}$ measured during 24 hours. The solar energy radiation during the analyzed was $\mathrm{E}_{\mathrm{SUN}} / \mathrm{A}_{\mathrm{PV}}=5.85 \mathrm{kWh} / \mathrm{m}^{2}$ day

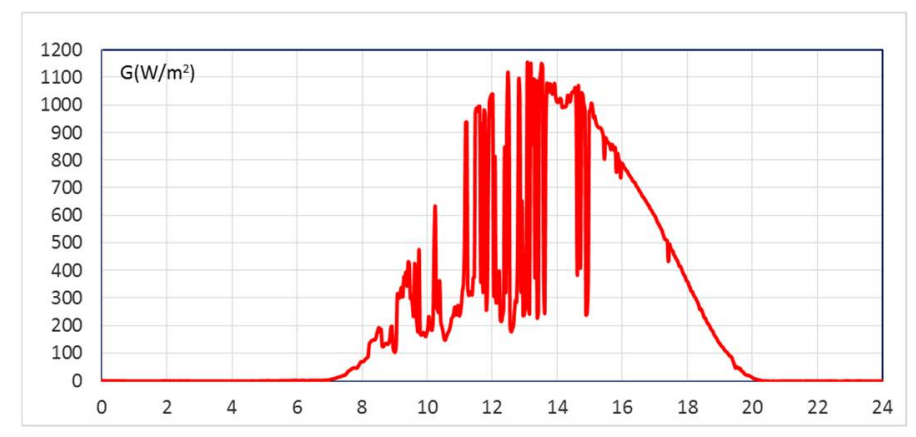

Figure 14 Solar irradiation in W/ $\mathrm{m}^{2}$ measured in 24 hours (South, inclimation $=45^{\circ}$ )

\section{DHW preparation temperatures}

In order to determine the influence of the temperatures of DHW preparation on heat pump efficiency, it is necessary to give preparation temperatures. Figure 15 shows the water temperatures in the tank inlet and outlet in the 6 DWH consumptions that were carried out.

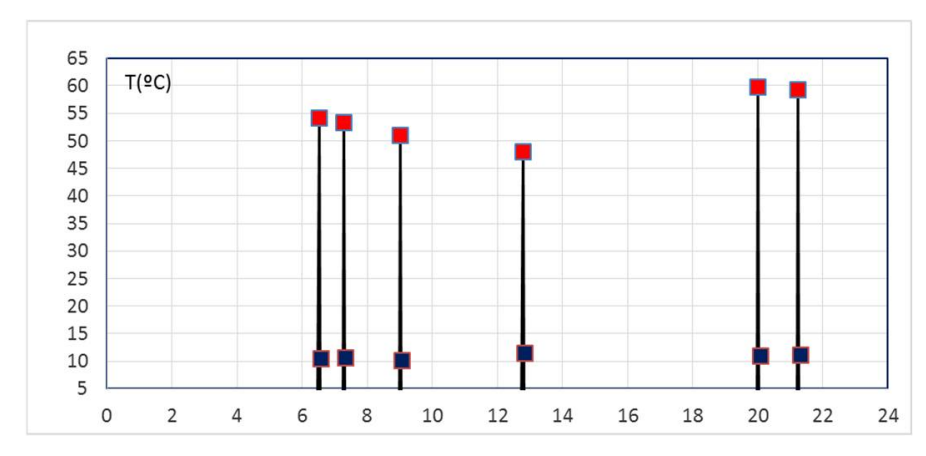


Mean water temperature in the inlet:

$$
\mathrm{T}_{\mathrm{DHW}, \mathrm{IN}}=\sum_{1}^{6} \mathrm{~T}_{\mathrm{DWH}, \mathrm{IN}} / 6=10.8{ }^{\circ} \mathrm{C} \quad E q .34
$$

Mean water temperature in the outlet (preparation temperature):

$$
\mathrm{T}_{\mathrm{DHW}, \text { OUT }}=\sum_{1}^{6} \mathrm{~T}_{\mathrm{DWH}, \mathrm{OUT}} / 6=53.8{ }^{\circ} \mathrm{C} \quad \text { Eq. } 35
$$


Figure 16 shows the results of one year of measurements. Each day was calculated following the procedure explained in the previous section.

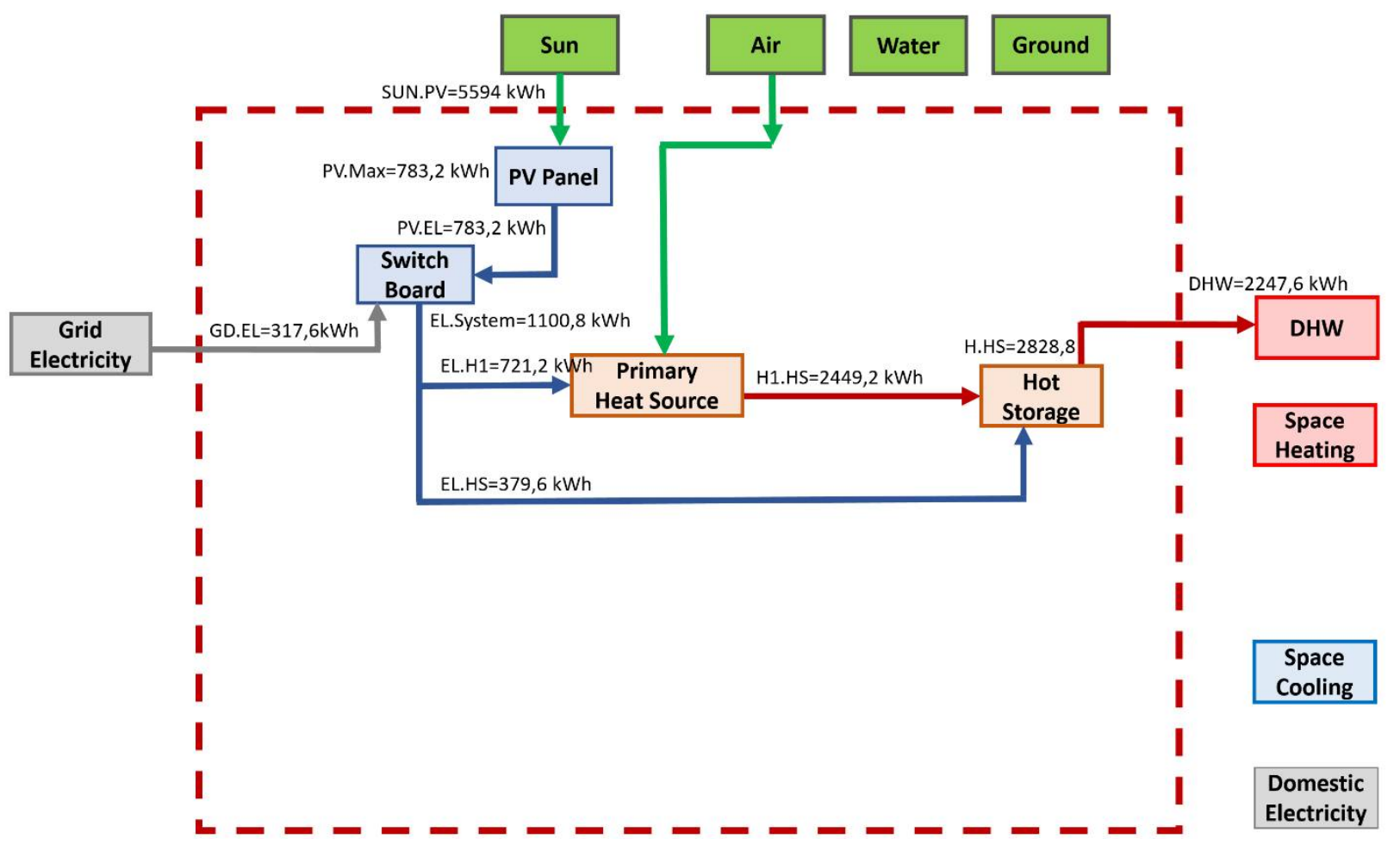

Figure 16 One year results of a PV assisted Heat Pump for Domestic Hot Water production

The input data is shown in Tables 6 and 7. 
Table 6 Annual data. PV-HP for DWH. Monthly input data

\begin{tabular}{|c|c|c|c|c|c|c|c|c|c|c|c|c|c|c|}
\hline \multicolumn{15}{|l|}{ HEATING, COOLING, DHW. SYSTEM INPUT DATA } \\
\hline Energy Data & Nomenc. & Year & Jan & Feb & Mar & Apr & May & Jun & Jul & Aug & Sep & Oct & Nov & Dec \\
\hline Sun to Photovoltaic Panels & SU.PV & 5594,0 & 447,3 & 436,0 & 460,6 & 555,0 & 484,9 & 473,6 & 529,2 & 493,8 & 458,6 & 484,9 & 345,0 & 425,1 \\
\hline Maximum photovoltaic production & PV.Max & 783,2 & 62,6 & 61,0 & 64,5 & 77,7 & 67,9 & 66,3 & 74,1 & 69,1 & 64,2 & 67,9 & 48,3 & 59,5 \\
\hline Photovoltaic to Switch Board & PV.EL & 783,2 & 62,6 & 61,0 & 64,5 & 77,7 & 67,9 & 66,3 & 74,1 & 69,1 & 64,2 & 67,9 & 48,3 & 59,5 \\
\hline Grid to Switch Board & GD.EL & 317,6 & 27,9 & 27,4 & 31,3 & 20,4 & 27,0 & 24,3 & 22,0 & 23,6 & 24,0 & 23,6 & 33,9 & 32,2 \\
\hline Battery to Switch board & BS.EL & 0,0 & 0,0 & 0,0 & 0,0 & 0,0 & 0,0 & 0,0 & 0,0 & 0,0 & 0,0 & 0,0 & 0,0 & 0,0 \\
\hline Switch board and bateries looses & EL.LOS & 0,0 & 0,0 & 0,0 & 0,0 & 0,0 & 0,0 & 0,0 & 0,0 & 0,0 & 0,0 & 0,0 & 0,0 & 0,0 \\
\hline Total Switch Board Electricity to System & EL,System & 1100,8 & 90,5 & 88,5 & 95,8 & 98,1 & 94,9 & 90,6 & 96,1 & 92,7 & 88,2 & 91,5 & 82,2 & 91,8 \\
\hline Switch Board Electricity to Primary Heat Source & EL.H1 & 721,2 & 71,3 & 67,5 & 67,6 & 61,5 & 60,8 & 53,4 & 52,4 & 50,8 & 50,1 & 55,8 & 60,6 & 69,4 \\
\hline Switch Board Electricity to Secondary Heat Source & EL.H2 & 0,0 & 0,0 & 0,0 & 0,0 & 0,0 & 0,0 & 0,0 & 0,0 & 0,0 & 0,0 & 0,0 & 0,0 & 0,0 \\
\hline Switch Board Electricity to Heat Storage & EL.HS & 379,6 & 19,2 & 21,0 & 28,2 & 36,6 & 34,1 & 37,2 & 43,7 & 41,9 & 38,1 & 35,7 & 21,6 & 22,3 \\
\hline Switch Board Electricity to Primary Cold Source & EL.C1 & 0,0 & 0,0 & 0,0 & 0,0 & 0,0 & 0,0 & 0,0 & 0,0 & 0,0 & 0,0 & 0,0 & 0,0 & 0,0 \\
\hline Switch Board Electricity to Secondary Cold Source & EL.C2 & 0,0 & 0,0 & 0,0 & 0,0 & 0,0 & 0,0 & 0,0 & 0,0 & 0,0 & 0,0 & 0,0 & 0,0 & 0,0 \\
\hline Switch Board Electricity to Domestic Electricity & EL.DE & 0,0 & 0,0 & 0,0 & 0,0 & 0,0 & 0,0 & 0,0 & 0,0 & 0,0 & 0,0 & 0,0 & 0,0 & 0,0 \\
\hline Total Switch Board Electricity to System & EL,System & 1100,8 & 90,5 & 88,5 & 95,8 & 98,1 & 94,9 & 90,6 & 96,1 & 92,7 & 88,2 & 91,5 & 82,2 & 91,8 \\
\hline Primary Heat Source to Heat Storage and Distribution & $\mathrm{H} 1 . \mathrm{HS}$ & 2449,2 & 215,1 & 193,2 & 206,2 & 225,3 & 222,3 & 194,4 & 198,1 & 199,3 & 190,2 & 198,7 & 196,2 & 210,2 \\
\hline Secondary Heat Source to Heat Storage and Distribution & $\mathrm{H} 2 . \mathrm{HS}$ & 0,0 & 0,0 & 0,0 & 0,0 & 0,0 & 0,0 & 0,0 & 0,0 & 0,0 & 0,0 & 0,0 & 0,0 & 0,0 \\
\hline Primary Cold Source to Heat Storage and Distribution & C1.HS & 0,0 & 0,0 & 0,0 & 0,0 & 0,0 & 0,0 & 0,0 & 0,0 & 0,0 & 0,0 & 0,0 & 0,0 & 0,0 \\
\hline Swith board Electricity on Heat Storage & EL.HS & 379,6 & 19,2 & 21,0 & 28,2 & 36,6 & 34,1 & 37,2 & 43,7 & 41,9 & 38,1 & 35,7 & 21,6 & 22,3 \\
\hline Thermal Energy on Heat Storage and Distribution & $\mathrm{HIS}$ & 2828,7 & 234,4 & 214,2 & 234,4 & 261,9 & 256,4 & 231,6 ? & 241,8 & 241,2 & 228,3 & 234,4 & 217,8 & 232,5 \\
\hline Primary Cold Source to Cold Storage and Distribution & C1.CS & 0,0 & 0,0 & 0,0 & 0,0 & 0,0 & 0,0 & 0,0 & 0,0 & 0,0 & 0,0 & 0,0 & 0,0 & 0,0 \\
\hline Secondary Cold Source to Cold Storage and Distribution & C2.CS & 0,0 & 0,0 & 0,0 & 0,0 & 0,0 & 0,0 & 0,0 & 0,0 & 0,0 & 0,0 & 0,0 & 0,0 & 0,0 \\
\hline Primary Heat Source to Cold Storage and Distribution & H1.CS & 0,0 & 0,0 & 0,0 & 0,0 & 0,0 & 0,0 & 0,0 & 0,0 & 0,0 & 0,0 & 0,0 & 0,0 & 0,0 \\
\hline Thermal Energy on Cold Storage and Distribution & $C, C S$ & 0,0 & 0,0 & 0,0 & 0,0 & 0,0 & 0,0 & 0,0 & 0,0 & 0,0 & 0,0 & 0,0 & 0,0 & 0,0 \\
\hline Total Space Cooling from System & SC & 0,0 & 0,0 & 0,0 & 0,0 & 0,0 & 0,0 & 0,0 & 0,0 & 0,0 & 0,0 & 0,0 & 0,0 & 0,0 \\
\hline Total Space Heating from System & $\mathrm{SH}$ & 0,0 & 0,0 & 0,0 & 0,0 & 0,0 & 0,0 & 0,0 & 0,0 & 0,0 & 0,0 & 0,0 & 0,0 & 0,0 \\
\hline Total DHW from System & DHW & 2247,6 & 172,4 & 158,8 & 172,1 & 200,7 & 197,8 & 195,92 & 207 & 206,5 & 192,6 & 195,6 & 172,2 & 175,8 \\
\hline Total Thermal Enegy from System & System & 2247,6 & 172,4 & 158,8 & 172,1 & 200,7 & 197,8 & 195,9 & 207,4 & 206,5 & 192,6 & 195,6 & 172,2 & 175,8 \\
\hline
\end{tabular}

Table 7 Definition of the Reference System input parameters

\begin{tabular}{|c|c|c|c|c|c|c|c|c|c|c|c|c|c|c|}
\hline \multicolumn{15}{|l|}{ REFERENCE SYSTEM. INPUT DATA } \\
\hline Efficiencies and Conversion factors & Nomenc. & Year & Jan & Feb & Mar & Apr & May & Jun & Jul & Aug & Sep & Oct & Nov & Dec \\
\hline Efficiency of Reference System for Heating, boiler & EFFво & 0,92 & 0,92 & 0,92 & 0,92 & 0,92 & 0,92 & 0,92 & 0,92 & 0,92 & 0,92 & 0,92 & 0,92 & 0,92 \\
\hline Electrical Consumption of the Reference boiler & ECBOILER,Ref & 0,02 & 0,02 & 0,02 & 0,02 & 0,02 & 0,02 & 0,02 & 0,02 & 0,02 & 0,02 & 0,02 & 0,02 & 0,02 \\
\hline Efficiency of Reference System for Cooling, Chiller & EFFCOOLING, Ref & 2,50 & 2,50 & 2,50 & 2,50 & 2,50 & 2,50 & 2,50 & 2,50 & 2,50 & 2,50 & 2,50 & 2,50 & 2,50 \\
\hline Primary energy factor for Electricity & PEFEL & 2,50 & 2,50 & 2,50 & 2,50 & 2,50 & 2,50 & 2,50 & 2,50 & 2,50 & 2,50 & 2,50 & 2,50 & 2,50 \\
\hline Primary energy factor for Gas & PEFGAS & 1,11 & 1,11 & 1,11 & 1,11 & 1,11 & 1,11 & 1,11 & 1,11 & 1,11 & 1,11 & 1,11 & 1,11 & 1,11 \\
\hline
\end{tabular}

\section{CALCULATION OF REFERENCE KEY PERFORMANCE INDICATORS}

One year results are calculated in order to show how the different KPI's are calculated.

The Reference Gas and Electricity consumption is calculated from the DHW demand.

$$
\begin{gathered}
\mathrm{GAS}_{\text {SH.DHW.Ref }}=\frac{\mathrm{Q}_{\text {DHW }}}{\eta_{\text {HEAT,Ref }}}=\frac{2247.6}{0.92}=2443.0 \mathrm{kWh} \\
\mathrm{E}_{\text {SH.DHW.Ref }}=\mathrm{Q}_{\text {DHW }} \cdot \mathrm{EC}_{\text {BOILER,Ref }}=2247.6 \cdot 0.02=45.0 \mathrm{kWh}
\end{gathered}
$$

The Non-Renewable Primary Energy Consumed by the Reference System is given by:

$$
\mathrm{PnRE}_{\mathrm{Ref}}=\mathrm{GAS}_{\mathrm{SH} . \mathrm{DHW} . \mathrm{Ref}} \cdot \mathrm{PEF}_{\mathrm{GAS}}+\mathrm{E}_{\mathrm{SH} . \mathrm{DHW} . \mathrm{Ref}} \cdot \mathrm{PEF}_{\mathrm{EL}}
$$




$$
\mathrm{PnRE}_{\mathrm{Ref}}=2443.0 \times 1.11+45.0 \times 2.50=2826.8 \mathrm{kWh}
$$

Monthly results are as well presented in Table 8. Depending on which PEF are used, it is possible to determine Total primary energy or Non-renewable primary ratio (as it is done in this example).

\section{Table 8 Calculation of the Reference System Indicators}

\begin{tabular}{|c|c|c|c|c|c|c|c|c|c|c|c|c|c|c|}
\hline \multicolumn{15}{|l|}{ REFERENCE SYSTEM } \\
\hline Energy Data of the Reference System & Nomenc. & Year & Jan & Feb & Mar & Apr & May & Jun & Jul & Aug & Sep & Oct & Nov & Dec \\
\hline REF. Natural Gas for Space Heating and DHW & GASSH,DHW,Ref & 2443,0 & 187,3 & 172,6 & 187,0 & 218,2 & 215,0 & 212,9 & 225,4 & 224,4 & 209,3 & 212,6 & 187,2 & 191,1 \\
\hline REF. Electricity for Space Heating and DHW & ELSH,DHW,Ref & 45,0 & 3,4 & 3,2 & 3,4 & 4,0 & 4,0 & 3,9 & 4,1 & 4,1 & 3,9 & 3,9 & 3,4 & 3,5 \\
\hline REF. Electricity for Space Cooling & ELsc,Ref & 0,0 & 0,0 & 0,0 & 0,0 & 0,0 & 0,0 & 0,0 & 0,0 & 0,0 & 0,0 & 0,0 & 0,0 & 0,0 \\
\hline TOTAL REF ELECTRICITY & ELRef & 45,0 & 3,4 & 3,2 & 3,4 & 4,0 & 4,0 & 3,9 & 4,1 & 4,1 & 39 & 3,9 & 3,4 & 3,5 \\
\hline TOTAL REF GAS & GASRef & 2443,0 & 187,3 & 172,6 & 187,0 & 218,2 & 215,0 & 2129 & 225,4 & 224,4 & 209,3 & 212,6 & 187,2 & 191,1 \\
\hline PRIM NON RENEWABLE ENERGY OF REFERENCE & PnRERef & 2826,8 & 216,8 & 199,7 & 216,4 & 252,4 & 248,8 & 246,4 & 260,8 & 259,7 & 242,2 & 246,0 & 216,6 & 221,1 \\
\hline
\end{tabular}

A first KPI indicator is the Primary Energy Ratio (PER) which indicates the final heat that can be obtained with one kWh of primary energy. Monthly results are shown in Table 9.

$$
\mathrm{PER}_{\mathrm{NRE}, \mathrm{Ref}}=\frac{\mathrm{Q}_{\mathrm{DHW}}}{\mathrm{PnRE}_{\mathrm{Ref}}}=\frac{2247.6}{2826.8}=0.795
$$

\begin{tabular}{|c|c|c|c|c|c|c|c|c|c|c|c|c|c|c|}
\hline \multicolumn{15}{|l|}{ REFERENCE SYSTEM } \\
\hline PER Kpi of the Reference System & Nomenc. & Year & Jan & Feb & Mar & Apr & May & Jun & Jul & Aug & Sep & Oct & Nov & Dec \\
\hline PER for space cooling reference system & PERnRE,Ref,SC & 0,000 & 0,000 & 0,000 & 0,000 & 0,000 & 0,000 & 0,000 & 0,000 & 0,000 & 0,000 & 0,000 & 0,000 & 0,000 \\
\hline PER for space heating reference system & PERnRE,Ret,SH & 0,000 & 0,000 & 0,000 & 0,000 & 0,000 & 0,000 & 0,000 & 0,000 & 0,000 & 0,000 & 0,000 & 0,000 & 0,000 \\
\hline PER for DHW reference system & PERNRE,Ref,DHW & 0,795 & 0,795 & 0,795 & 0,795 & 0,795 & 0,795 & 0,795 & 0,795 & 0,795 & 0,795 & 0,795 & 0,795 & 0,795 \\
\hline PER for the reference system & PERNRE, RefSYS & 0,795 & 0,795 & 0,795 & 0,795 & 0,795 & 0,795 & 0,795 & 0,795 & 0,795 & 0,795 & 0,795 & 0,795 & 0,795 \\
\hline
\end{tabular}

Table 9 Calculation of Primary Energy Ration of the Reference System

\section{CALCULATION OF SYSTEM KEY PERFORMANCE INDICATORS}

Three kPis are employed to evaluate the performance of the SHC unit. Every parameter can be calculated form Space Cooling (SC), Space Heating (SH), Domestic Hot Water (DHW) or to the system if the unit produces more than one service. In this example, DHW $=$ System.

The Non-Renewable Primary Energy Consumed by the Analyzed System is given by:

$$
\begin{gathered}
\mathrm{PnRE}_{\mathrm{Sys}}=\mathrm{E}_{\mathrm{GD} . \mathrm{EL}} \cdot \mathrm{PEF}_{\mathrm{EL}} \\
\mathrm{PnRE}_{\text {Sys }}=317.6 \times 2.50=794.0 \mathrm{kWh}
\end{gathered}
$$

Monthly results are as well presented in Table 8. Depending on which PEF are used, it is possible to determine Total primary energy or Non-renewable primary ratio (as it is done in this example).

\section{Primary Energy Ratio PERnRE}

The Primary Energy Ratio PERnRE, indicates the relation between the PnRE employed by the analyzed system and the PnRE employed by the Reference for the same energy demand.

$$
\mathrm{PER}_{\mathrm{nRE}}=\frac{\mathrm{PnRE}_{\mathrm{Ref}}}{\mathrm{PnRE}_{\mathrm{Sys}}}=\frac{2826.8}{794.0}=2.83
$$

Table 10 shows the Primary Energy Ratio of the System, month by month and the final annual result. 
Table 10 Primary Energy Ratio of the Analyzed System

\begin{tabular}{|c|c|c|c|c|c|c|c|c|c|c|c|c|c|c|}
\hline \multicolumn{15}{|l|}{ SYSTEM. RESULTS } \\
\hline PER Kpi of the System & Nomenc. & Year & Jan & Feb & Mar & Apr & May & Jun & Jul & Aug & Sep & Oct & Nov & Dec \\
\hline PER for space cooling & PERnRE,SC & 0,00 & 0,00 & 0,00 & 0,00 & 0,00 & 0,00 & 0,00 & 0,00 & 0,00 & 0,00 & 0,00 & 0,00 & 0,00 \\
\hline PER for space heating & PERnRE,SH & 0,00 & 0,00 & 0,00 & 0,00 & 0,00 & 0,00 & 0,00 & 0,00 & 0,00 & 0,00 & 0,00 & 0,00 & 0,00 \\
\hline PER for DHW & PERnRE,DHW & 2,83 & 2,47 & 2,31 & 2,20 & 3,94 & 2,93 & 3,22 & 3,77 & 3,51 & 3,21 & 3,32 & 2,03 & 2,18 \\
\hline PER for the system & PERnRE & 2,83 & 2,47 & 2,31 & 2,20 & 3,94 & 2,93 & 3,22 & 3,77 & 3,51 & 3,21 & 3,32 & 2,03 & 2,18 \\
\hline
\end{tabular}

\section{Fraction Savings FSAVnRE}

The Fraction Savings of non-Renewable Primary Energy, FSAVnRE indicates the \% of non-Renewable Primary Energy consumption.

$$
\operatorname{FSAV}_{\mathrm{nRE}}(\%)=\frac{\mathrm{PnRE}_{\mathrm{Ref}}-\mathrm{PnRE}_{\text {Sys }}}{\operatorname{PnRE}_{\mathrm{Ref}}}=\frac{2826.8-794.0}{2826.8}=71.9 \%
$$

This parameter (or 100- FSAVnRE) use to be employed to define the energy efficiency scale.

\section{Table 11 Fraction Savings of non-Renewable Primary Energy of the Analyzed System}

\begin{tabular}{|c|c|c|c|c|c|c|c|c|c|c|c|c|c|c|}
\hline \multicolumn{15}{|l|}{ SYSTEM. RESULTS } \\
\hline FRACTIONAL SAVINGS & Nomenc. & Year & Jan & Feb & Mar & Apr & May & Jun & Jul & Aug & Sep & Oct & Nov & Dec \\
\hline Fractional savings for space cooling & FSAVnRE,PER,SC & $0,0 \%$ & $0,0 \%$ & $0,0 \%$ & $0,0 \%$ & $0,0 \%$ & $0,0 \%$ & $0,0 \%$ & $0,0 \%$ & $0,0 \%$ & $0,0 \%$ & $0,0 \%$ & $0,0 \%$ & $0,0 \%$ \\
\hline Fractional savings for space heating & FSAVnRE,PER,SH & $0,0 \%$ & $0,0 \%$ & $0,0 \%$ & $0,0 \%$ & $0,0 \%$ & $0,0 \%$ & $0,0 \%$ & $0,0 \%$ & $0,0 \%$ & $0,0 \%$ & $0,0 \%$ & $0,0 \%$ & $0,0 \%$ \\
\hline Fractional savings for DHW & FSAVnRE,PER,DWH & $71,9 \%$ & $67,8 \%$ & $65,6 \%$ & $63,8 \%$ & $79,8 \%$ & $72,9 \%$ & $75,3 \%$ & $78,9 \%$ & $77,3 \%$ & $75,2 \%$ & $76,1 \%$ & $60,9 \%$ & $63,5 \%$ \\
\hline Fractional savings of the system & FSAV & $71,9 \%$ & $678 \%$ & $65,6 \%$ & $638 \%$ & $798 \%$ & $72,9 \%$ & $75,3 \%$ & $78,9 \%$ & $77,3 \%$ & $75,2 \%$ & $76,1 \%$ & $60,9 \%$ & $63,5 \%$ \\
\hline
\end{tabular}

\section{Equivalent Seasonal Performance Factor SPFEQU}

The Equivalent Seasonal Performance Factor SPFEQU, indicates the grid electricity needed for producing the energy demand. This parameter can be considered like a mean COP or EER, but in working conditions.

$$
\mathrm{SPF}_{\mathrm{EQU}}=\frac{\mathrm{Q}_{\text {Sys }}}{\mathrm{E}_{\mathrm{PV} . \mathrm{EL}}}=\frac{2247.6}{317.6}=7.08
$$

Table 12 shows the SPFEQ month by month.

\begin{tabular}{|c|c|c|c|c|c|c|c|c|c|c|c|c|c|c|}
\hline \multicolumn{15}{|l|}{ SYSTEM. RESULTS } \\
\hline SEASONAL PERFORMANCE FACTOR & Nomenc. & Year & Jan & Feb & Mar & Apr & May & Jun & Jul & Aug & Sep & Oct & Nov & Dec \\
\hline SPF Equivalent for cooling & SPFEQU,SC & 0,00 & 0,00 & 0,00 & 0,00 & 0,00 & 0,00 & 0,00 & 0,00 & 0,00 & 0,00 & 0,00 & 0,00 & 0,00 \\
\hline SPF Equivalent for space heating & SPFEQU,SH & 0,00 & 0,00 & 0,00 & 0,00 & 0,00 & 0,00 & 0,00 & 0,00 & 0,00 & 0,00 & 0,00 & 0,00 & 0,00 \\
\hline SPF Equivalent for DHW & SPFEQU,DHW & 7,08 & 6,18 & 5,79 & 5,50 & 9,84 & 7,33 & 8,06 & 9,42 & 8,76 & 8,03 & 8,30 & 5,08 & 5,45 \\
\hline SPF Equivalent for system & SPFEQU & 7,08 & 6,18 & 5,79 & 5,50 & 9,84 & 7,33 & 8,06 & 9,42 & 8,76 & 8,03 & 8,30 & 5,08 & 5,45 \\
\hline
\end{tabular}

Table 12 Equivalent Seasonal Performance Factor of the Analyzed System

\section{Solar contribution $\mathrm{SC}(\%)$}

$\%$ of total electricity that has been provided by the PV panels

$$
\mathrm{SC}(\%)=\frac{\mathrm{E}_{\mathrm{PV} . \mathrm{EL}}}{\mathrm{E}_{\mathrm{GD} . \mathrm{EL}}+\mathrm{E}_{\mathrm{PV} . \mathrm{EL}}}=\frac{783.2}{1100.8}=71.1 \%
$$

\section{Production factor $(\%)$}

Thermal heat that has been provided by the facility by the maximum that can be provided by the same electricity (from the grid or from PV). In this unit: EPV,Max = EPV,EL.

$\mathrm{PF}=\frac{\mathrm{Q}_{\mathrm{Sys}}}{2.5 \cdot\left(\mathrm{E}_{\mathrm{GD} . \mathrm{EL}_{\mathrm{L}}}+\mathrm{E}_{\mathrm{PV} . \mathrm{Max}}\right)}=\frac{2247.6}{2.5 \times 1100.8}=81.7 \%$ 


\section{Example 2. Monitoring a PV - HVAC Facility}

The monitoring procedure has been applied to a PV - HVAC system. Figure 17 shows the scheme of the installation. The characteristics of the systems are:

- The installation do not export energy to the grid

- There are no batteries

- There is not a secondary heat or cold source neither joule effect

- Three PV panels connected to the grid (very similar to those connected to the unit) are as well monitored in order to measure the maximum power that PV may produce: PVmax.

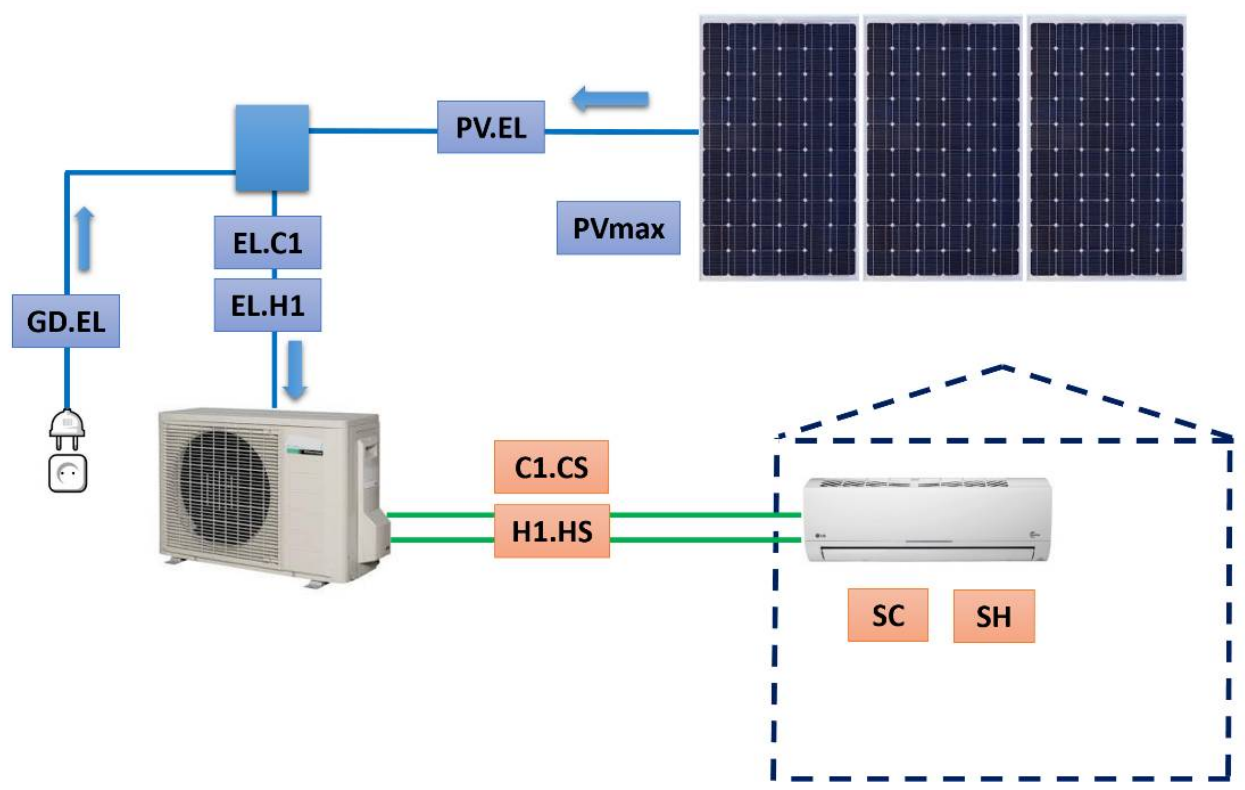

Figure 17 PV driven solar heating and cooling system of a HVAC inverter unit. The airr-conditioner was tested on field conditions in an office located in Alicante, Spain

The general drawn of the system, according to energy flows represented in Figure 2 is shown in Figure 18. Table 13 shows the data taken every 5 minutes. 


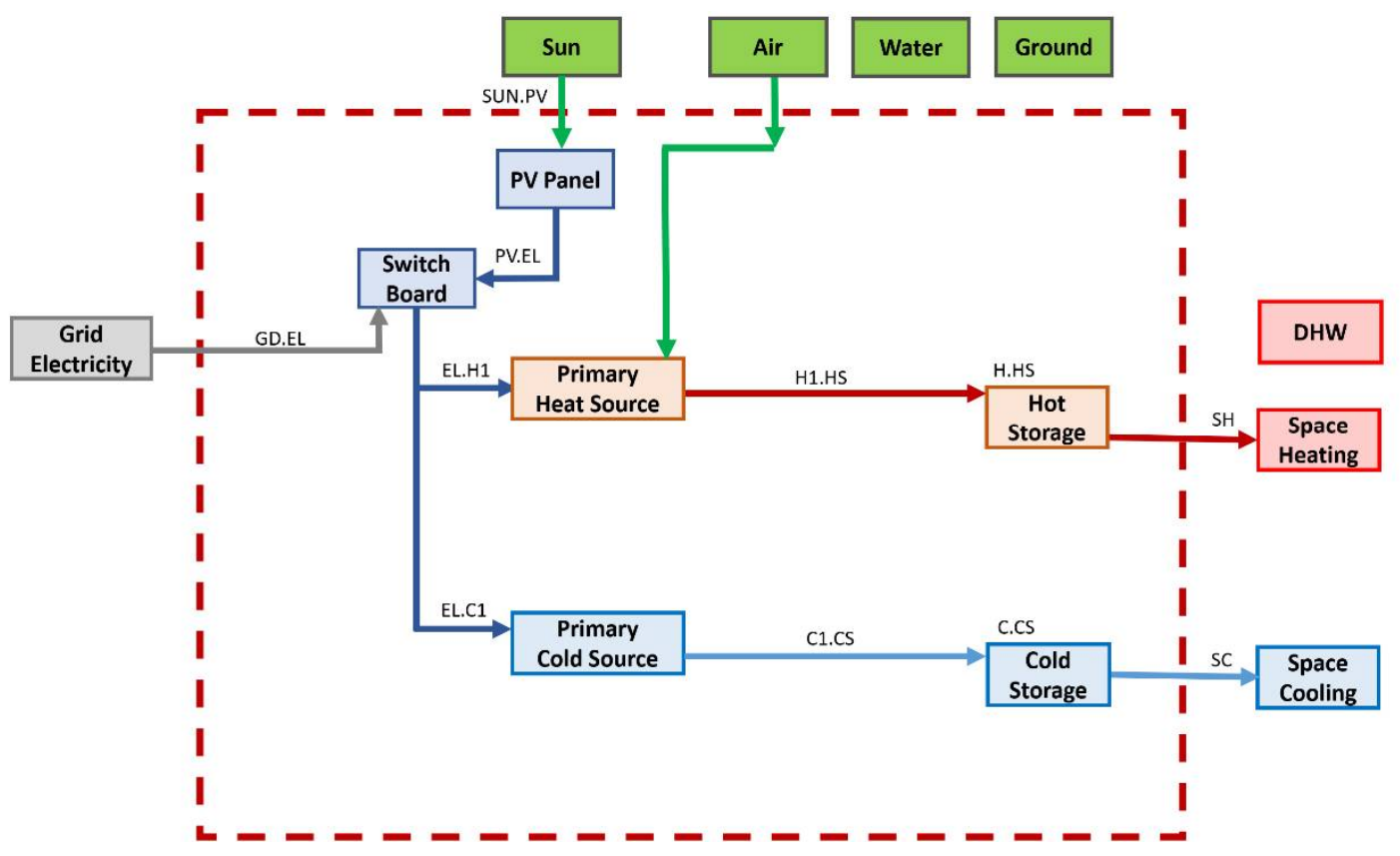

Figure 18 PV driven solar heating and cooling system of a HVAC inverter unit. Energy flows

Table 13 Parameters recorded in the trial every 5 minutes

\begin{tabular}{|l|l|l|}
\hline Description & Symbology & Units \\
\hline Compressor inlet temp. & $\mathrm{T}_{1}$ & ${ }^{\circ} \mathrm{C}$ \\
\hline Compressor discharge temp. & $\mathrm{T}_{2}$ & ${ }^{\circ} \mathrm{C}$ \\
\hline Condenser outlet temp. & $\mathrm{T}_{3}$ & ${ }^{\circ} \mathrm{C}$ \\
\hline Evaporator inlet temp. & $\mathrm{T}_{4}$ & ${ }^{\circ} \mathrm{C}$ \\
\hline Evaporating pressure & $\mathrm{p}_{\mathrm{E}}$ & $\mathrm{bar}$ \\
\hline Condensing pressure & $\mathrm{p}_{\mathrm{C}}$ & $\mathrm{bar}$ \\
\hline Solar irradiance & $\mathrm{G}$ & $\mathrm{W} / \mathrm{m}^{2}$ \\
\hline Inside temperature & $\mathrm{T}_{\mathrm{INL}}$ & ${ }^{\circ} \mathrm{C}$ \\
\hline Outside temperature & $\mathrm{T}_{\mathrm{OUT}}$ & ${ }^{\circ} \mathrm{C}$ \\
\hline Relative Humidity & $\mathrm{HR}$ & $\%$ \\
\hline Wind Speed & $\mathrm{V}$ & $\mathrm{m} / \mathrm{s}$ \\
\hline Wind direction & $\mathrm{D}$ & $\mathrm{deg}$ \\
\hline Electricity absorbed by the unit & $\mathrm{P}_{\mathrm{UNIT}}$ & $\mathrm{kW}$ \\
\hline Electricity taken from the grid & $\mathrm{P}_{\mathrm{GD}}$ & $\mathrm{kW}$ \\
\hline Unit photovoltaic panels current & $\mathrm{I}_{\mathrm{PV}, \mathrm{UNIT}}$ & $\mathrm{A}$ \\
\hline Unit photovoltaic panels voltage & $\mathrm{V}_{\mathrm{P}, \mathrm{UNIT}}$ & $\mathrm{V}$ \\
\hline Grid photovoltaic panels current & $\mathrm{I}_{\mathrm{PV}, \mathrm{GD}}$ & $\mathrm{A}$ \\
\hline Grid photovoltaic panels voltage & $\mathrm{V}_{\mathrm{PV}, \mathrm{GD}}$ & $\mathrm{V}$ \\
\hline
\end{tabular}

\section{ELECTRICAL ENERGY FLOWS}

The electrical and thermal energy flows produced in the facility are calculated in a daily basis, from the data measured every 5 minutes ( 288 data in 24 hours). 
EPV.EL: Electrical energy produced by the PV panels connected to the air-conditioner (photovoltaic energy to switch board)

The electrical energy produced by the PV panels in produced and used in the air-conditioner at a voltage of 24-28 V d.c. The electrical energy produced by the $3 \mathrm{PV}$ panels is given by:

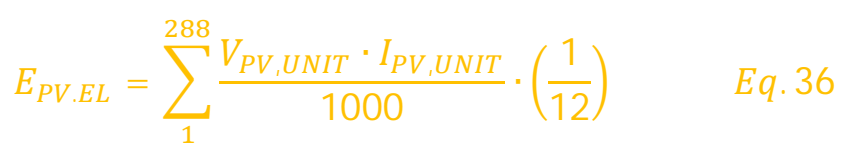

Figure 19 shows the measurements of the electricity produced by the 3 PV panels during 24 hours. The electrical energy produced by the PV panels is EPV.EL $=2.26 \mathrm{kWh}$.

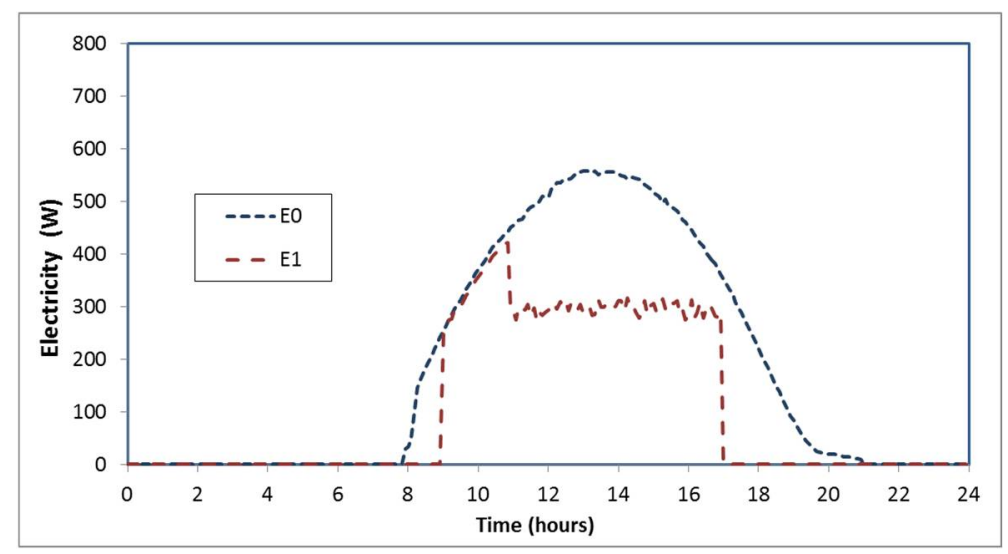

Figure 19 Field measurements of the electrical energy produced by 3 PV panels during one day

The unit works from 9 to 17:00 h, so the three PV panels connected to it, do not produce any energy out of the air-conditioning timetable. Moreover, as it is shown in Figure 5, the unit only needs about $300 \mathrm{~W}$ from 11:30 to 17:00 and the PV panels connected to the unit only produce this energy, while the panels connected to the grid generate more energy.

\section{EPVmax: Maximum electricity that may be produced by the PV panels}

The unit takes the electricity from the PV panels and from the grid simultaneously. Sometimes, the unit can be stopped and therefore the PV panels. Three PV panels connected to the grid have been measured in order to determine the maximum electricity that may be produced by the PV panels connected to the unit.

The electrical energy produced by the PV panels connected to the grid is given by:

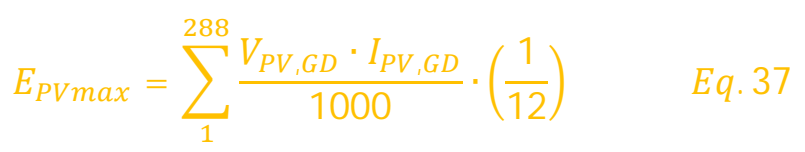


Figure 19 shows the measurements of the electricity produced by 3 PV panels connected to the grid during 24 hours. The electrical energy produced by the PV panels is EPVmax $=4.41 \mathrm{kWh}$. This valued may be calculated from the Solar Radiation measured by a pyranometer multiplied by the PV panel mean efficiency.

\section{EGD.EL: Grid energy to switch board (electrical energy taken from the grid)}

The electrical energy taken from the grid is measured directly with an electrical meter. The electrical energy consumed from the grid is calculated by:

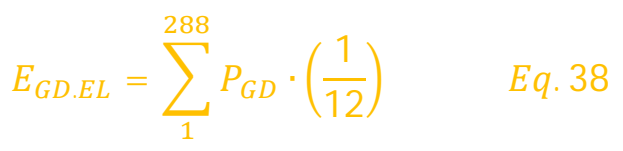

In this facility, some electricity is taken from the grid when the heat pump is ON, as shown in Figure 20. $(\mathrm{E} 5=0.60 \mathrm{kWh})$. The unit takes some electricity from the grid from 9 to 11:30. From 11:30 to 17:00, only 14W are needed for the unit control system.

\section{EEL.H1, EEL.C1: Switch board to primary cold or heat source (electrical energy consumed by the heat pump)}

The electrical energy consumed by the heat pump is calculated as the sum of the electricity taken from the PV panels and the electricity taken from the grid.

$\begin{array}{lll}\text { - If HP in Cooling mode } \Rightarrow \mathrm{E}_{\mathrm{EL} . \mathrm{C} 1}={ }_{\mathrm{E}_{\mathrm{GD} . \mathrm{EL}}}{ }^{+}{ }_{\mathrm{EPV} . \mathrm{EL}} & E q .39 \\ \text { - } \quad \text { If HP in Heating mode } \Rightarrow \mathrm{E}_{\mathrm{EL} . \mathrm{H} 1}={ }_{\mathrm{E}_{\mathrm{GD} . \mathrm{EL}}}{ }^{+}{ }_{\mathrm{EPV} . \mathrm{EL}} & \text { Eq.40 }\end{array}$

Figure 20 shows the measurements of the electrical energy flows during 24 hours working in cooling mode. For this day, the electrical energy consumed by the HVAC unit is EEL.C1=2.86 kWh and EEL.H1=0 kWh.

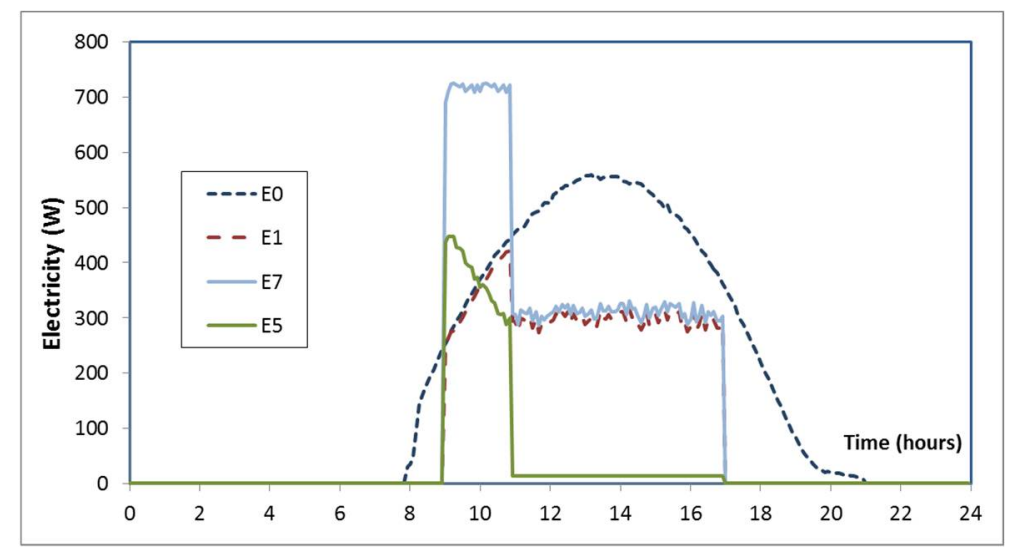

Figure 20 Field measurements of the electrical energy consumed by the PV - HVAC system during one day

\section{THERMAL ENERGY FLOWS}

In this facility, there is only one thermal flow that introduces energy in the system, which is the thermal energy produced by the heat pump: cooling mode QC1.CS, heating mode QH1.HS. 
QH1.HS, QC1.CS: Thermal energy produced by the heat pump

In the measurements, the thermal energy produced by the heat pump is measured employing the "Internal Method". The methodology needs to measure the data listed in Table 14.

Table 14 Parameters needed to calculate QH1.HS, QC1.cs by the "Internal Method"

\begin{tabular}{|l|l|l|}
\hline Description & Symbology & Units \\
\hline Compressor inlet temp. & $\mathrm{T}_{1}$ & ${ }^{\circ} \mathrm{C}$ \\
\hline Compressor discharge temp. & $\mathrm{T}_{2}$ & ${ }^{\circ} \mathrm{C}$ \\
\hline Condenser outlet temp. & $\mathrm{T}_{3}$ & ${ }^{\circ} \mathrm{C}$ \\
\hline Evaporator inlet temp. & $\mathrm{T}_{4}$ & ${ }^{\circ} \mathrm{C}$ \\
\hline Evaporating pressure & $\mathrm{P}_{\mathrm{E}}$ & $\mathrm{bar}$ \\
\hline Condensing pressure & $\mathrm{P}_{\mathrm{C}}$ & $\mathrm{bar}$ \\
\hline Elect. absorbed by the compressor & $\mathrm{P}_{\mathrm{COMP}}$ & $\mathrm{kW}$ \\
\hline
\end{tabular}

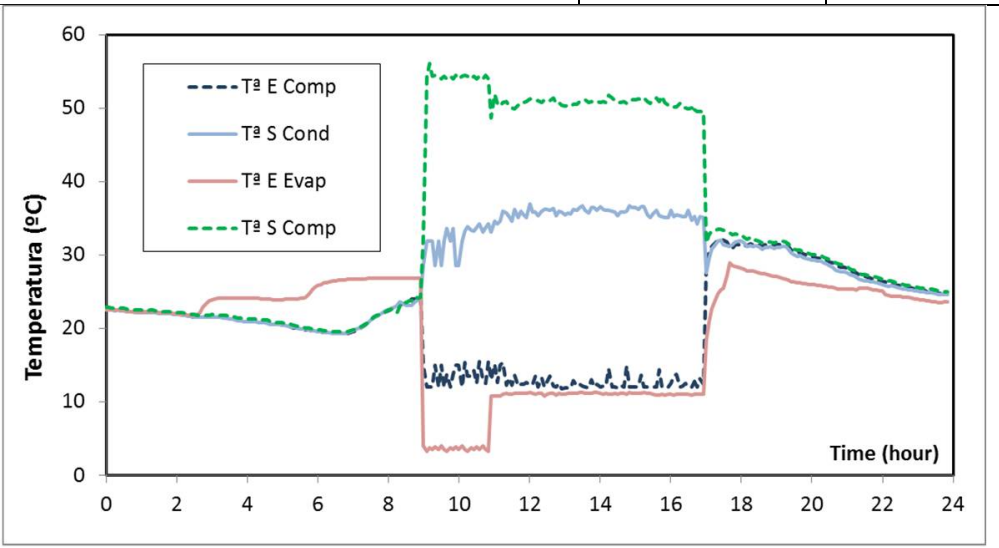

Figure 21 Field measurements of the temperatures of the 4 points of the thermo-dynamical cycle. Refrigerant: R410A

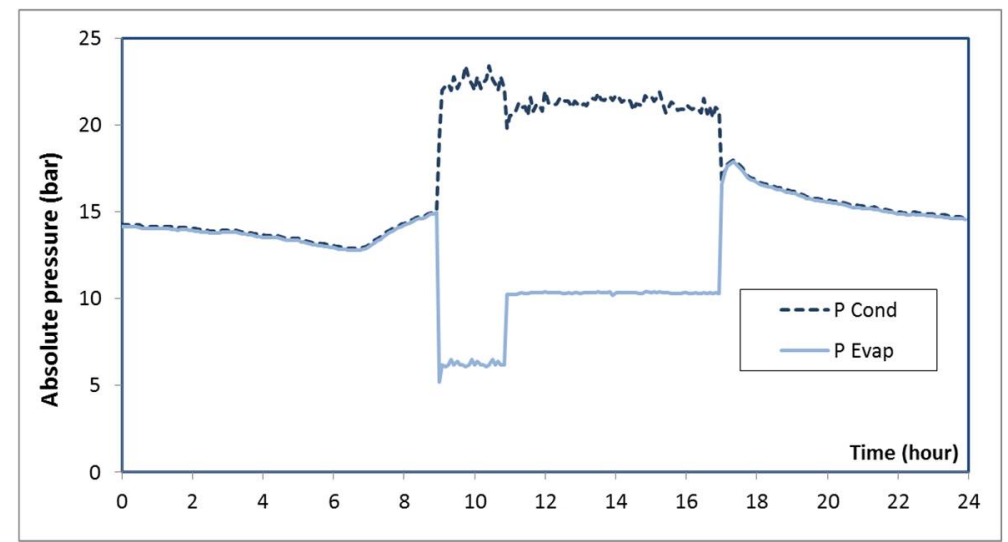

Figure 22 Field measurements of the pressures in the inlet and in the outlet of the compressor

The electrical energy consumed by the unit compressor was measured and related to the total electricity consumed by the unit by:

$$
\mathrm{P}_{\mathrm{EL}, \mathrm{COMP}}=\mathrm{A} \cdot \mathrm{P}_{\mathrm{TOT}}(\mathrm{W})-\mathrm{B}(\mathrm{W})
$$


Where $\mathrm{A}=0.93$ and $\mathrm{B}=50 \mathrm{~W}$.

It is considered a mechanical performance of the compressor of $93 \%$, which means that $93 \%$ of the electrical power goes to the refrigerant (7\% are losses in the compressor).

$$
\mathrm{P}_{\mathrm{EL}, \mathrm{COMP}} \cdot \eta_{\mathrm{M}}=\mathrm{m}_{\mathrm{R}}\left(\mathrm{h}_{2}-\mathrm{h}_{1}\right)
$$

In all cases it was verified that the isentropic efficiency of the compressor was:

$$
\eta_{\text {ISO }} \leq 0.775-0.05\left(\mathrm{p}_{\mathrm{COND}} / \mathrm{p}_{\mathrm{EVAP}}\right)
$$

This equation was applied to give a theoretical value of the refrigerant enthalpy at the inlet $\left(\mathrm{h}_{1 \mathrm{TH}}\right)$. The enthalpy at the compressor outlet $\left(\mathrm{h}_{2}\right)$ was considered to be correctly measured. The enthalpy at the compressor inlet $\left(h_{1}\right)$ was taken the lowest value of the measured and the theoretical values.

The thermal energy flow in $\mathrm{W}$, calculated by the internal method every 5 minutes was calculated by:

$$
\dot{\mathrm{Q}}_{\mathrm{COLD}}=\mathrm{mR}_{\mathrm{R}}\left(\mathrm{h}_{1}-\mathrm{h}_{4}\right)
$$

Figure 23 shows the data calculated during one day.

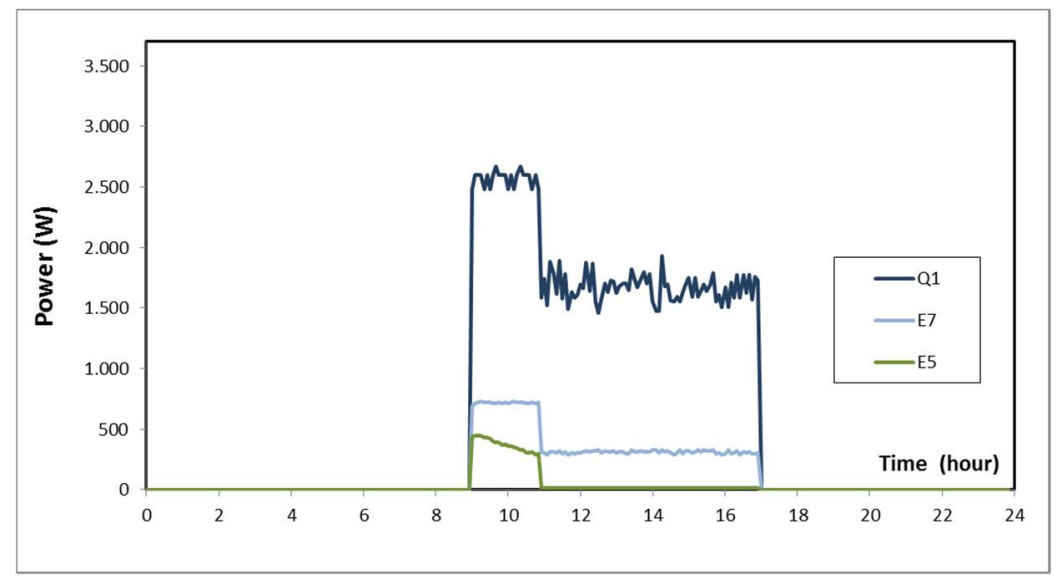

Figure 23 Thermal flow QH1.Hs produced by the HVAC unit

The total thermal energy given by the system in 24 hours in cooling mode is QC1.CS $=11.72 \mathrm{kWh}$.

$$
Q_{C 1 . C S}=\sum_{1}^{288} Q_{C O L D} \cdot\left(\frac{1}{12}\right) \quad E q .41
$$




\section{DETERMINATION OF MEASURING CONDITIONS}

Some of the Key Performance Indicators calculated in the last section depends on measuring conditions. The inlet temperature was fixed by the unit control system to be $23^{\circ} \mathrm{C}$. The climatic conditions were as well measured. The most important daily reference conditions are:

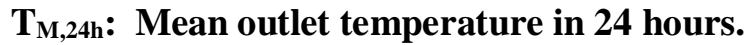

Is the mean value of the 288 measurements taken in 24 hours (one every 5 minutes).

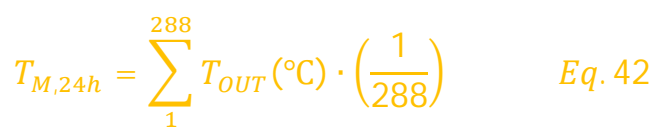

Figure 13 shows the outlet temperatures measured during the analyzed day. The mean temperature in 24 hours was: $\mathrm{T}_{\mathrm{M}, 24 \mathrm{~h}}=26.5^{\circ} \mathrm{C}$.

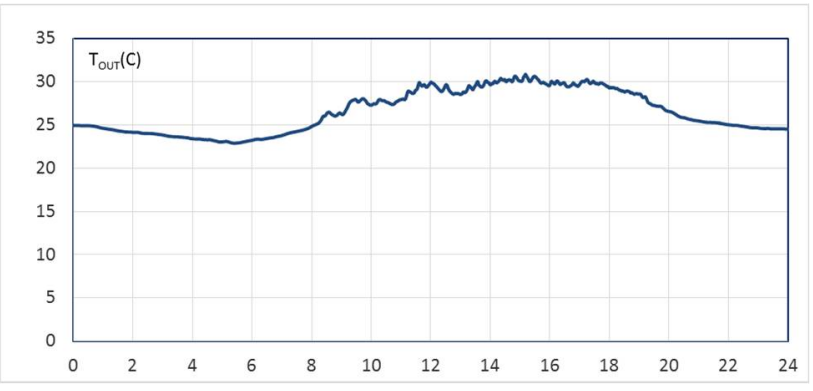

Figure 24. Outlet temperature measured during 24 hours

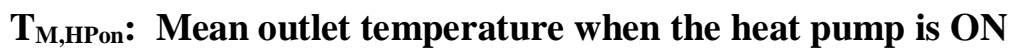

The heat pump was working during 9 hours. To analyze the efficiency of the heat pump, it is worthy to determine the mean outlet temperature when the heat pump is working

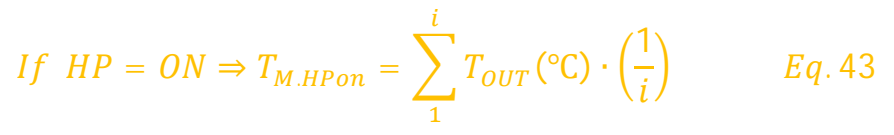

The mean temperature when the heat pump was working, this day was: $\mathrm{T}_{\mathrm{M}, \mathrm{HPon}}=29.1^{\circ} \mathrm{C}$. 


\section{INPUT DATA OF ONE YEAR RESULTS}

Figure 26 shows the results of one year of measurements. Each day was calculated following the procedure explained in the previous section.

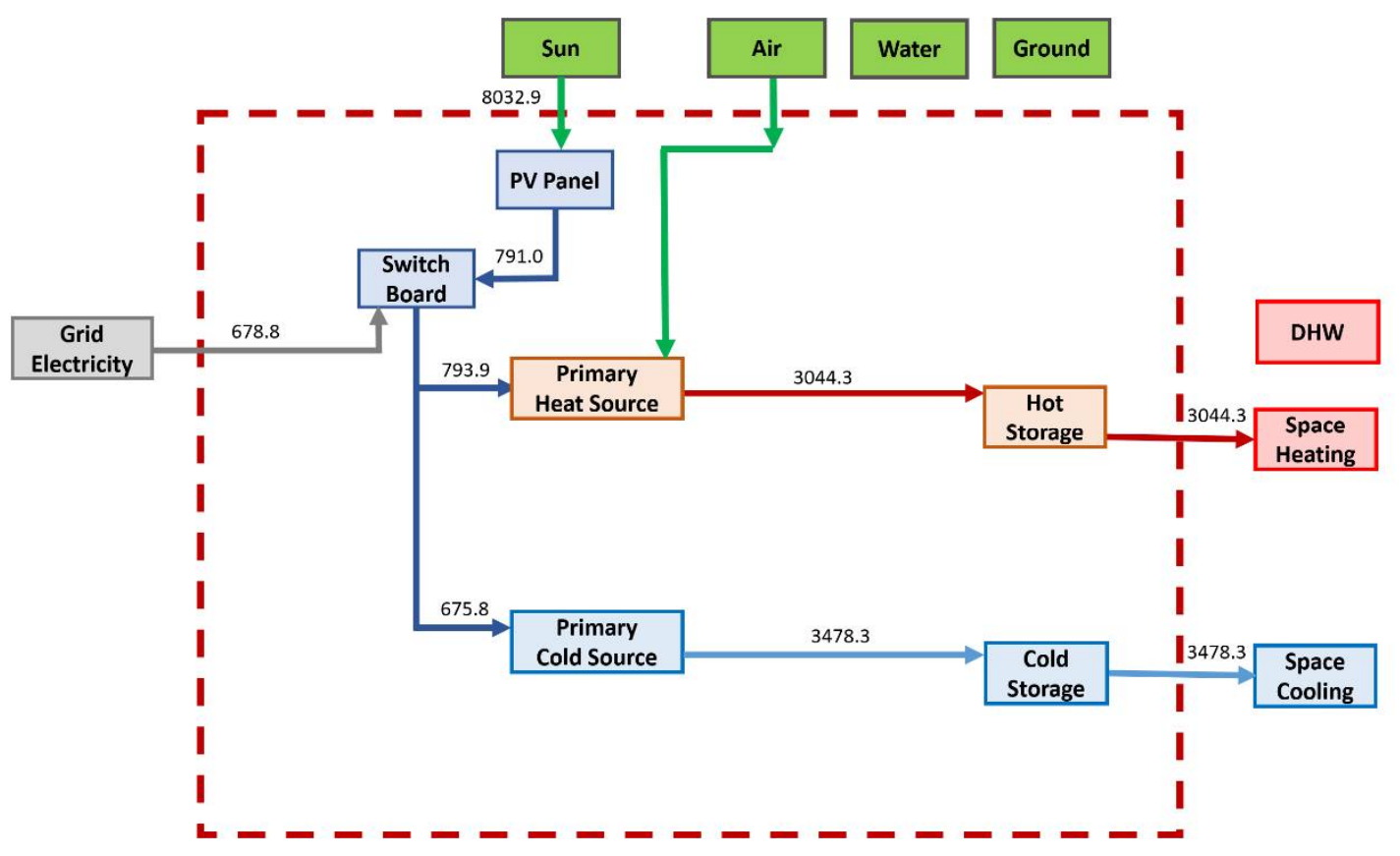

Figure 25 One year results of a PV assisted Air-Conditioner

The input data is shown in Tables 15 and 16. 
Table 15 Annual data of a PV-HP for HVAC: heating and cooling. Monthly imput data

\begin{tabular}{|c|c|c|c|c|c|c|c|c|c|c|c|c|c|c|}
\hline \multicolumn{15}{|l|}{ Heating, Cooling and DHW } \\
\hline Energy Data & Nomenc. & Year & Jan & Feb & Mar & Apr & May & Jun & Jul & Aug & Sep & Oct & Nov & Dec \\
\hline Sun to Photovoltaic Panels & SU.PV & 8032,9 & 502,6 & 541,06 & 664,47 & 726,98 & 834,3 & 893,6 & 925,0 & 819,3 & 722,1 & 597,1 & 403,5 & 403,1 \\
\hline Maximum photovoltaic production & PV.Max & 1124,6 & 70,4 & 75,7 & 93,01 & 101,81 & 116,8 & 125,1 & 129,5 & 114,7 & 101,1 & 83,6 & 56,5 & 56,4 \\
\hline Photovoltaic to Switch Board & PV.EL & 791,0 & 61,9 & 64,0 & 68,9 & 58,5 & 66,0 & 67,1 & 95,1 & 84,8 & 68,2 & 55,4 & 49,4 & 51,7 \\
\hline Grid to Switch Board & GD.EL & 678,8 & 85,0 & 83,0 & 72,0 & 44,8 & 25,8 & 18,7 & 75,6 & 57,0 & 29,9 & 32,2 & 65,3 & 89,5 \\
\hline Battery to Switch board & BS.EL & 0,0 & 0,0 & 0,0 & 0,0 & 0,0 & 0,0 & 0,0 & 0,0 & 0,0 & 0,0 & 0,0 & 0,0 & 0,0 \\
\hline Switch board and bateries looses & EL.LOS & 0,0 & 0,0 & 0,0 & 0,0 & 0,0 & 0,0 & 0,0 & 0,0 & 0,0 & 0,0 & 0,0 & 0,0 & 0,0 \\
\hline Total Switch Board Electricity to System & EL.System & 14697 & 146,9 & 147,01 & 140,91 & 103,3 & 91,8 & 858 & 170,7 & 141,8 & 98,1 & 87,6 & 114,7 & 141,2 \\
\hline Switch Board Electricity to Primary Heat Source & EL.H1 & 793,9 & 146,9 & 147,01 & 140,91 & 103,3 & 0,0 & 0,0 & 0,0 & 0,0 & 0,0 & 0,0 & 114,7 & 141,2 \\
\hline Switch Board Electricity to Secondary Heat Source & EL.H2 & 0,0 & 0,0 & 0,0 & 0,0 & 0,0 & 0,0 & 0,0 & 0,0 & 0,0 & 0,0 & 0,0 & 0,0 & 0,0 \\
\hline Switch Board Electricity to Heat Storage & EL.HS & 0,0 & 0,0 & 0,0 & 0,0 & 0,0 & 0,0 & 0,0 & 0,0 & 0,0 & 0,0 & 0,0 & 0,0 & 0,0 \\
\hline Switch Board Electricity to Primary Cold Source & EL.C1 & 675,8 & 0,0 & 0,0 & 0,0 & 0,0 & 91,8 & 85,8 & 170,7 & 141,8 & 98,1 & 87,6 & 0,0 & 0,0 \\
\hline Switch Board Electricity to Secondary Cold Source & EL.C2 & 0,0 & 0,0 & 0,0 & 0,0 & 0,0 & 0,0 & 0,0 & 0,0 & 0,0 & 0,0 & 0,0 & 0,0 & 0,0 \\
\hline Switch Board Electricity to Domestic Electricity & EL.DE & 0,0 & 0,0 & 0,0 & 0,0 & 0,0 & 0,0 & 0,0 & 0,0 & 0,0 & 0,0 & 0,0 & 0,0 & 0,0 \\
\hline Total Switch Board Electricity to System & $\mathrm{EL}$ System & 1469,7 & 146,9 & 147,01 & 140,91 & 103,3 & 91,8 & 85,8 & 170,7 & $141 ; 8$ & 98,1 & 87,6 & 114,7 & 141,2 \\
\hline Primary Heat Source to Heat Storage and Distribution & H1.HS & 3044,3 & 575,3 & 533,05 & 531,53 & 387,7 & 0,0 & 0,0 & 0,0 & 0,0 & 0,0 & 0,0 & 465,2 & 551,7 \\
\hline Secondary Heat Source to Heat Storage and Distributio & $\mathrm{H} 2 . \mathrm{HS}$ & 0,0 & 0,0 & 0,0 & 0,0 & 0,0 & 0,0 & 0,0 & 0,0 & 0,0 & 0,0 & 0,0 & 0,0 & 0,0 \\
\hline Primary Cold Source to Heat Storage and Distribution & C1.HS & 0,0 & 0,0 & 0,0 & 0,0 & 0,0 & 0,0 & 0,0 & 0,0 & 0,0 & 0,0 & 0,0 & 0,0 & 0,0 \\
\hline Switch board Electricity on Heat Storage & EL.HS & 0,0 & 0,0 & 0,0 & 0,0 & 0,0 & 0,0 & 0,0 & 0,0 & 0,0 & 0,0 & 0,0 & 0,0 & 0,0 \\
\hline Thermal Energy on Heat Storage and Distribution & H:HS & 3044,3 & 575,3 & 533,05 & 531,53 & 387,7 & 0,0 & 0,0 & 0,0 & 0,0 & 0,0 & 0,0 & 465,2 & 551,7 \\
\hline Primary Cold Source to Cold Storage and Distribution & C1.CS & 3478,3 & 0,0 & 0,0 & 0,0 & 0,05 & 519,5 & 514,1 & 720,0 & 655,2 & 545,1 & 524,4 & 0,0 & 0,0 \\
\hline Secondary Cold Source to Cold Storage and Distributior & C2.CS & 0,0 & 0,0 & 0,0 & 0,0 & 0,0 & 0,0 & 0,0 & 0,0 & 0,0 & 0,0 & 0,0 & 0,0 & 0,0 \\
\hline Primary Heat Source to Cold Storage and Distribution & H1.CS & 0,0 & 0,0 & 0,0 & 0,0 & 0,0 & 0,0 & 0,0 & 0,0 & 0,0 & 0,0 & 0,0 & 0,0 & 0,0 \\
\hline Thermal Energy on Cold Storage and Distribution & C.CS & 3478,3 & 0,0 & 0,0 & 0,0 & 0,0 & 5195 & 5141 & 720,0 & 655,2 & 545,1 & 524,4 & 0,0 & 0,0 \\
\hline Total Space Cooling from System & $\mathrm{SC}$ & 3478,3 & 0,0 & 0,0 & 0,0 & 0,05 & 519,5 & 514,1 & 720,0 & 655,2 & 545,1 & 524,4 & 0,0 & 0,0 \\
\hline Total Space Heating from System & $\mathrm{SH}$ & 3044,3 & 575,3 & 533,05 & 531,53 & 387,7 & 0,0 & 0,0 & 0,0 & 0,0 & 0,0 & 0,0 & 465,2 & 551,7 \\
\hline Total DHW from System & DHW & 0,0 & 0,0 & 0,0 & 0,0 & 0,0 & 0,0 & 0,0 & 0,0 & 0,0 & 0,0 & 0,0 & 0,0 & 0,0 \\
\hline Total Thermal Enegy from System & System & 6522,6 & 575,3 & 533,05 & 531,53 & $387,7: 5$ & 519,5 & 514,1 & 720,0 & 655,2 & 545,1 & 524,4 & 465,2 & 551,7 \\
\hline
\end{tabular}

Table 16 Definition of the Reference System input parameters

\begin{tabular}{|c|c|c|c|c|c|c|c|c|c|c|c|c|c|c|}
\hline \multicolumn{15}{|l|}{ REFERENCE SYSTEM. INPUT DATA } \\
\hline Efficiencies and Conversion factors & Nomenc. & Year & Jan & Feb & Mar & Apr & May & Jun & Jul & Aug & Sep & Oct & Nov & Dec \\
\hline Efficiency of Reference System for Heating, boiler & EFFBOILER,Ref & 0,90 & 0,90 & 0,90 & 0,90 & 0,90 & 0,90 & 0,90 & 0,90 & 0,90 & 0,90 & 0,90 & 0,90 & 0,90 \\
\hline Electrical Consumption of the Reference boiler & ECBOILER,Ref & 0,02 & 0,02 & 0,02 & 0,02 & 0,02 & 0,02 & 0,02 & 0,02 & 0,02 & 0,02 & 0,02 & 0,02 & 0,02 \\
\hline Efficiency of Reference System for Cooling, Chiller & EFFCOOLING,Ref & 2,50 & 2,50 & 2,50 & 2,50 & 2,50 & 2,50 & 2,50 & 2,50 & 2,50 & 2,50 & 2,50 & 2,50 & 2,50 \\
\hline Primary energy factor for Electricity & PEFEL & 2,50 & 2,50 & 2,50 & 2,50 & 2,50 & 2,50 & 2,50 & 2,50 & 2,50 & 2,50 & 2,50 & 2,50 & 2,50 \\
\hline Primary energy factor for Gas & PEFGAS & 1,11 & 1,11 & 1,11 & 1,11 & 1,11 & 1,11 & 1,11 & 1,11 & 1,11 & 1,11 & 1,11 & 1,11 & 1,11 \\
\hline
\end{tabular}




\section{CALCULATION OF REFERENCE KEY PERFORMANCE INDICATORS}

One year results are calculated in order to show how the different KPI's are calculated.

The Reference Gas and Electricity consumption calculated from the space heating demand is:

$$
\begin{gathered}
\mathrm{GAS}_{\mathrm{SH} . \text { Ref }}=\frac{\mathrm{Q}_{\mathrm{SH}}}{\eta_{\text {HEAT,Ref }}}=\frac{3044.3}{0.90}=3382.6 \mathrm{kWh} \\
\mathrm{E}_{\mathrm{SH} . \mathrm{DHW} . \text { Ref }}=\mathrm{Q}_{\mathrm{DHW}} \cdot \mathrm{EC}_{\mathrm{BOILER}, \text { Ref }}=3044.3 \cdot 0.02=60.9 \mathrm{kWh}
\end{gathered}
$$

The Reference Electricity consumption calculated from the space cooling demand is:

$$
\mathrm{E}_{\mathrm{SC} . \text { Ref }}=\frac{\mathrm{Q}_{\mathrm{SC}}}{\mathrm{EFF}_{\text {COOLING,Ref }}}=\frac{3478.3}{2.50}=1391.3 \mathrm{kWh}
$$

The Non-Renewable Primary Energy Consumed by the Reference System is given by:

$$
\begin{gathered}
\mathrm{PnRE}_{\mathrm{Ref}}=\mathrm{GAS}_{\mathrm{SH} . \mathrm{DHW} . \mathrm{Ref}} \cdot \mathrm{PEF}_{\mathrm{GAS}}+\mathrm{E}_{\mathrm{SH} . \mathrm{DHW} . \mathrm{Ref}} \cdot \mathrm{PEF}_{\mathrm{EL}}+\mathrm{E}_{\mathrm{SC} . \mathrm{Ref}} \cdot \mathrm{PEF}_{\mathrm{EL}} \\
\text { PnRE }_{\text {Ref }}=3382.6 \times 1.11+60.9 \times 2.50+1452.2 \times 2.50=7388.9 \mathrm{kWh}
\end{gathered}
$$

\begin{tabular}{|c|c|c|c|c|c|c|c|c|c|c|c|c|c|c|}
\hline \multicolumn{15}{|l|}{ REFERENCE SYSTEM } \\
\hline Energy Data of the Reference System & Nomenc. & Year & Jan & Feb & Mar & Apr & May & Jun & Jul & Aug & Sep & Oct & Nov & Dec \\
\hline REF. Natural Gas for Space Heating and DHW & GASSH,DHW,Ref & 3382,6 & 639,2 & 592,2 & 590,5 & 430,7 & 0,0 & 0,0 & 0,0 & 0,0 & 0,0 & 0,0 & 516,9 & 613,0 \\
\hline REF. Electricity for Space Heating and DHW & ELSH,DHW,Ref & 60,9 & 11,5 & 10,7 & 10,6 & 7,8 & 0,0 & 0,0 & 0,0 & 0,0 & 0,0 & 0,0 & 9,3 & 11,0 \\
\hline REF. Electricity for Space Cooling & ELsC,Ref & 1391,3 & 0,0 & 0,0 & 0,0 & 0,0 & 207,8 & 205,6 & 288,0 & 262,1 & 218,0 & 209,8 & 0,0 & 0,0 \\
\hline TOTAL REF ELECTRICITY & ELRef & $1452 ;$ & 11,5 & 10,7 & 10,6 & 7,8 & 207,8 & 205,6 & 288,0 & 262,1 & 218,0 & 209,8 & 9,3 & 11,0 \\
\hline TOTAL REF GAS & GASRef & 3382,6 & 639,2 & 592,2 & 590,5 & 430,7 & 0,0 & 0,0 & 0,0 & 0,0 & 0,0 & 0,0 & 516,9 & 613,0 \\
\hline PRIM NON RENEWABLE ENERG Y OF RE & nRERet & 7388,9 & 739,0 & 684,6 & 682,7 & 498,0 & 519,5 & 5141 & 720,0 & 655 & 545 & 524,4 & 597,6 & 708,7 \\
\hline
\end{tabular}

Monthly results are as well presented in Table 8. Depending on which PEF are used, it is possible to determine Total primary energy or Non-Renewable primary ratio (as it is done in this example).

\section{Table 17 Calculation of the Reference System Indicators. PV HVAC System.}

\begin{tabular}{|c|c|c|c|c|c|c|c|c|c|c|c|c|c|c|}
\hline \multicolumn{15}{|l|}{ PRIMARY ENERGY RATIO } \\
\hline PER Kpi of the Reference System & Nomenc. & Year & Jan & Feb & Mar & Apr & May & Jun & Jul & Aug & Sep & Oct & Nov & Dec \\
\hline PER for space cooling reference system & PERnRE,Ret,SC & 1,000 & 0,000 & 0,000 & 0,000 & 0,000 & 1,000 & 1,000 & 1,000 & 1,000 & 1,000 & 1,000 & 0,000 & 0,000 \\
\hline PER for space heating reference system & PERnRE,Ret,SH & 0,778 & 0,778 & 0,778 & 0,778 & 0,778 & 0,000 & 0,000 & 0,000 & 0,000 & 0,000 & 0,000 & 0,778 & 0,778 \\
\hline PER for DHW reference system & PERNRE,Ref,DHW & 0,000 & 0,000 & 0,000 & 0,000 & 0,000 & 0,000 & 0,000 & 0,000 & 0,000 & 0,000 & 0,000 & 0,000 & 0,000 \\
\hline PER for the reference system & PERNREREA & 0,883 & 0,778 & 0,778 & 0,778 & 0,778 & 1,000 & 1,000 & 1,000 & 1,000 & 1,000 & 1,000 & 0,778 & 0,778 \\
\hline
\end{tabular}

The Primary Energy Ratio of the Reference System (PER) is a KPI which indicates the final heat that can be obtained with one kWh of primary energy. Monthly results are shown in Table 18.

$$
\mathrm{PER}_{\mathrm{NRE}, \mathrm{Ref}}=\frac{\mathrm{Q}_{\mathrm{DHW}}+\mathrm{Q}_{\mathrm{SH}}+\mathrm{Q}_{\mathrm{SC}}}{\mathrm{PnRE}_{\mathrm{Ref}}}=\frac{0+3044.3+3478.3}{7388.9}=0.883
$$

\section{Table 18 Calculation of Primary Energy Ratio of the Reference System}

The Non-Renewable Primary Energy consumed by the PV Air-Conditioner (heating and cooling) is given by:

$$
\mathrm{PnRE}_{\mathrm{Sys}}=\mathrm{E}_{\mathrm{GD} . \mathrm{EL}} \cdot \mathrm{PEF}_{\mathrm{EL}}
$$




$$
\mathrm{PnRE}_{\text {Sys }}=678.8 \times 2.50=1696.9 \mathrm{kWh}
$$

\section{CALCULATION OF SYSTEM KEY PERFORMANCE INDICATORS}

Five KPI's are employed to evaluate the performance of the SHC unit. Every parameter can be calculated from Space Cooling (SC), Space Heating (SH), Domestic Hot Water (DHW) or to the system if the unit produces more than one service. This example can be evaluated as only heating, only cooling or both heating and cooling.

\section{Primary Energy Ratio PERnRE}

The Primary Energy Ratio PERnRE, indicates the relation between the PnRE employed by the analyzed system and the PnRE employed by the Reference for the same energy demand.

$$
\mathrm{PER}_{\mathrm{nRE}}=\frac{\mathrm{PnRE}_{\mathrm{Ref}}}{\mathrm{PnRE}_{\mathrm{Sys}}}=\frac{7388.9}{1696.9}=3.84
$$

Table 19 shows the Primary Energy Ratio of the System, month by month and the final annual result.

\begin{tabular}{|c|c|c|c|c|c|c|c|c|c|c|c|c|c|c|}
\hline \multicolumn{15}{|l|}{ SYSTEM. RESULTS } \\
\hline PER Kpi of the System & Nomenc. & Year & Jan & Feb & Mar & Apr & May & Jun & Jul & Aug & Sep & Oct & Nov & Dec \\
\hline PER for space cooling & PERnRE,SC & 0,00 & 0,00 & 0,00 & 0,00 & 0,00 & 0,00 & 0,00 & 0,00 & 0,00 & 0,00 & 0,00 & 0,00 & 0,00 \\
\hline PER for space heating & PERnRE,SH & 0,00 & 0,00 & 0,00 & 0,00 & 0,00 & 0,00 & 0,00 & 0,00 & 0,00 & 0,00 & 0,00 & 0,00 & 0,00 \\
\hline PER for DHW & PERnRE,DHW & 2,83 & 2,47 & 2,31 & 2,20 & 3,94 & 2,93 & 3,22 & 3,77 & 3,51 & 3,21 & 3,32 & 2,03 & 2,18 \\
\hline PER for the system & PERnRE & 2,83 & 2,47 & 2,31 & 2,20 & 3,94 & 2,93 & 3,22 & 3,77 & 3,51 & 3,21 & 3,32 & 2,03 & 2,18 \\
\hline
\end{tabular}

Table 19 Primary Energy Ratio of the Analyzed System 


\section{Fraction Savings FSAVnRE}

The Fraction Savings of non-Renewable Primary Energy, FSAVnRE indicates the \% of non-Renewable Primary Energy consumption.

$$
\operatorname{FSAV}_{\text {nRE }}(\%)=\frac{\operatorname{PnRE}_{\text {Ref }}-\text { PnRE }_{\text {Sys }}}{\text { PnRE }_{\text {Ref }}}=\frac{7388.9-1696.9}{7388.9}=77.0 \%
$$

\section{Table 20 Fraction Savings of non-Renewable Primary Energy of the Analyzed System}

\begin{tabular}{|c|c|c|c|c|c|c|c|c|c|c|c|c|c|c|}
\hline \multicolumn{15}{|l|}{ SYSTEM. RESULTS } \\
\hline FRACTIONAL SAVINGS & Nomenc. & Year & Jan & Feb & Mar & Apr & May & Jun & Jul & Aug & Sep & Oct & Nov & Dec \\
\hline Fractional savings for space cooling & FSAVnRE,PER,SC & $82,8 \%$ & $0,0 \%$ & $0,0 \%$ & $0,0 \%$ & $0,0 \%$ & $87,6 \%$ & $90,9 \%$ & $73,8 \%$ & $78,3 \%$ & $86,3 \%$ & $644,6 \%$ & $0,0 \%$ & $0,0 \%$ \\
\hline Fractional savings for DHW & FSAVnRE,PER,DW & $0,0 \%$ & $0,0 \%$ & $0,0 \%$ & $0,0 \%$ & $0,0 \%$ & $0,0 \%$ & $0,0 \%$ & $0,0 \%$ & $0,0 \%$ & $0,0 \%$ & $0,0 \%$ & $0,0 \%$ & $0,0 \%$ \\
\hline Fractional savings of the system & FSAV $R E, P E R$ & $77,0 \%$ & $71,3 \%$ & $69 ; 7 \%$ & $73,6 \%$ & $77,5 \%$ & $87,6 \%$ & $90,9 \%$ & $73,8 \%$ & $78,3 \%$ & $86,3 \%$ & $84,6 \%$ & $72,7 \%$ & $68,4 \%$ \\
\hline
\end{tabular}

\section{Equivalent Seasonal Performance Factor SPFEQU}

The Equivalent Seasonal Performance Factor SPFEQU, indicates the grid electricity needed for producing the energy demand. This parameter can be considered like a mean COP or EER, but in working conditions.

$$
\mathrm{SPF}_{\mathrm{EQU}}=\frac{\mathrm{Q}_{\text {Sys }}}{\mathrm{E}_{\mathrm{PV} . \mathrm{EL}}}=\frac{6522.6}{678.8}=9.61
$$

Table 12 shows the SPFEQ month by month.

\begin{tabular}{|c|c|c|c|c|c|c|c|c|c|c|c|c|c|c|}
\hline \multicolumn{15}{|l|}{ SYSTEM. RESULTS } \\
\hline SEASONAL PERFORMANCE FACTOR & Nomenc. & Year & Jan & Feb & Mar & Apr & May & Jun & Jul & Aug & Sep & Oct & Nov & Dec \\
\hline SPF Equivalent for cooling & SPFEQU,SC & 14,54 & 0,00 & 0,00 & 0,00 & 0,00 & 20,14 & 27,49 & 9,52 & 11,49 & 18,23 & 16,29 & 0,00 & 0,00 \\
\hline SPF Equivalent for space heating & SPFEQU,SH & 6,93 & 6,77 & 6,42 & 7,38 & 8,66 & 0,00 & 0,00 & 0,00 & 0,00 & 0,00 & 0,00 & 7,12 & 6,17 \\
\hline SPF Equivalent for DHW & SPFEQU,DHW & 0,00 & 0,00 & 0,00 & 0,00 & 0,00 & 0,00 & 0,00 & 0,00 & 0,00 & 0,00 & 0,00 & 0,00 & 0,00 \\
\hline SPF Equivalent for system & SPEEQU & $9 ; 61$ & 6,77 & 6,42 & 7,38 & 8,66 & 20,14 & 27,49 & 9,52 & 11,49 & 18,23 & 16,29 & 7,12 & 6,17 \\
\hline
\end{tabular}

Table 21 Equivalent Seasonal Performance Factor of the Analyzed System

\section{Solar contribution $\mathrm{SC}(\%)$}

$\%$ of total electricity that has been provided by the PV panels

$$
\mathrm{SC}(\%)=\frac{\mathrm{E}_{\mathrm{PV} . \mathrm{EL}}}{\mathrm{E}_{\mathrm{GD} . \mathrm{EL}}+\mathrm{E}_{\mathrm{PV} . \mathrm{EL}}}=\frac{791.0}{1469.7}=53.8 \%
$$

\section{Production factor $(\%)$}

Thermal heat that has been provided by the facility by the maximum that can be provided by the same electricity (from the grid or from PV). In this unit: EPV,Max $=1124.6$ (measured from PV panels connected to the grid)

$$
\mathrm{PF}=\frac{\mathrm{Q}_{\text {Sys }}}{2.5 \cdot\left(\mathrm{E}_{\mathrm{GD} . \mathrm{EL}}+\mathrm{E}_{\mathrm{PV} . \mathrm{Max}}\right)}=\frac{6522.6}{2.5 \times(678.8+1124.6)}=145 \%
$$

This PF is very high, even when not all the PV electricity was consumed in the Unit. The reason is due to the high efficiency of the Air-conditioner. 


\section{Conclusions}

This document is deliverable D-C1 "Monitoring procedure for field test \& demo systems", which is focused on field installations with compression heat pumps driven by photovoltaic solar energy. The following aspects have been treated:

- A generic scheme of PV driven heat humps.

- Electrical and thermal flows to be measured.

The electrical and thermal flows to be measured have been indicated.

- Definition of Key Performance Indicators (KPI)

A few, but useful Key Performance Indicators have been proposed for heat pumps driven by photovoltaic solar energy.

- $\quad$ Applications. Two examples have been included: Sections 9 and 10.

- Measurement methods for air to air heat pumps

Annex A includes a method for measuring air to air heat pumps by using the "Internal Method". The methodology is based on applying energy conservation on the compressor, and it will be open to other possibilities of measuring refrigerant mass flow in the circuit.

- Instrumentation

Annex B shows the typical instruments employed on measure heat pumps on field applications. Solar radiation measurements and photovoltaic electrical power measurements are also included.

- An uncertainty analysis

Annex $\mathrm{C}$ shows the experimental uncertainty methodology following the Guide to the expression of uncertainty in measurement published by ISO [1995]. Some examples are as well included.

\section{Bibliography}

[1] IEA SHC Task 38, Monitoring Procedure for Solar Cooling Systems

http://www.iea-shc.org/task38/

[2] IEA SHC Task 48, Deliverable M-C4.3 - Final report Measurement and Verification Procedure 


\section{ANNEX A. THE INTERNAL METHOD}

One of the most important data to be measured on electrical compression heat pumps is the useful thermal energy that the unit produces $\left(\mathrm{Q}_{\mathrm{H} 1 . \mathrm{SH}}, \mathrm{Q}_{\mathrm{Cl} . \mathrm{CH}},\right)$. When measurements are carried out on field conditions, generally it is not possible to measure the useful thermal flux produced by the heat pump. In fact, it is only possible to measure it with a good accuracy when the unit heats or cools water (or mixtures of water and glycol).

This document is focused on refrigerant units of power $<12 \mathrm{~kW}$, where the useful thermal flux is difficult to measure:

- In the DHW unit drawn in Figure 3 it is not possible to measure the useful energy in the tank.

- In the HVAC unit drawn in Figure 17, in most of field conditions, it is not possible to measure the useful energy in the air.

In both situations it is impossible (or at least very difficult) to install a flowmeter to measure the refrigerant flow, and therefore and an indirect method must be employed to measure it.

\section{A.1. The theoretical thermodynamic cycle}

The refrigerant is evaporated in a medium and then condenses giving up heat to another medium of higher temperature level; it is therefore a machine that acts between two temperatures.

Its main components are:

- Compressor

- Evaporator

- Expansion valve

- Condenser

The refrigerant must change phase under the conditions of absorption and heat transfer, evaporating or condensing respectively. In compression heat pumps for air conditioning, the most common refrigerants are R134a, R407C and R410A.

Each refrigerant has its own characteristics. The physical properties of the refrigerant in liquid, vapor or liquid + vapor phase can be found in literature as diagrams or tables. Pressure-enthalpy diagrams (p-h) are the most practical to analyze the behavior of compression equipment.

The representation of compression cycles in these diagrams can read directly the energy absorbed or delivered in each phase; Figure 26 shows as an example the p-h diagram of the refrigerant R-134a. 


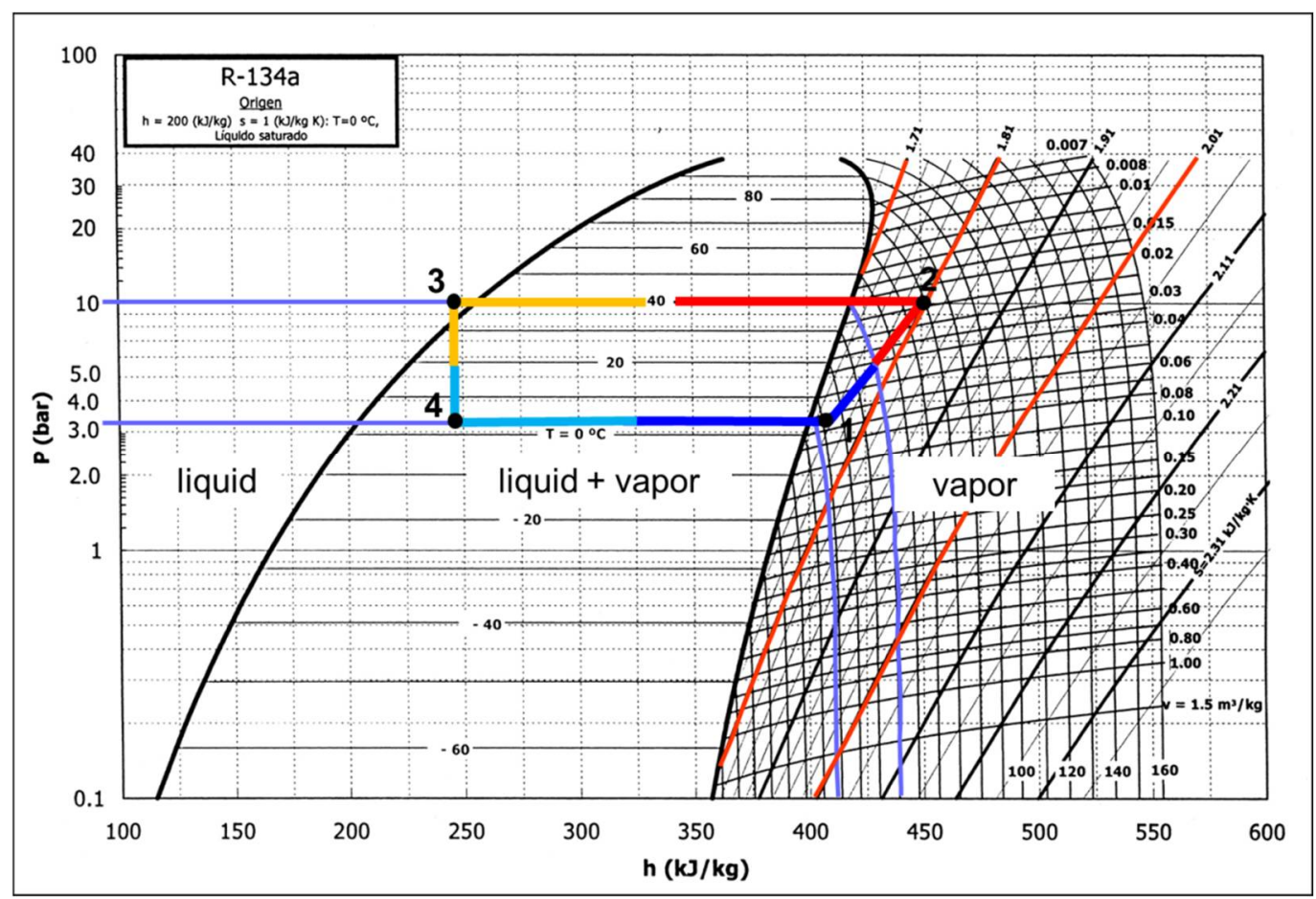

Figure $26 \mathrm{P}$-h diagram of the refrigerant R134a. Representation of a real case of simple thermodynamic cycle of a compression heat pump

The simple direct expansion cycle requires 4 basic elements as shown in Figure 27.

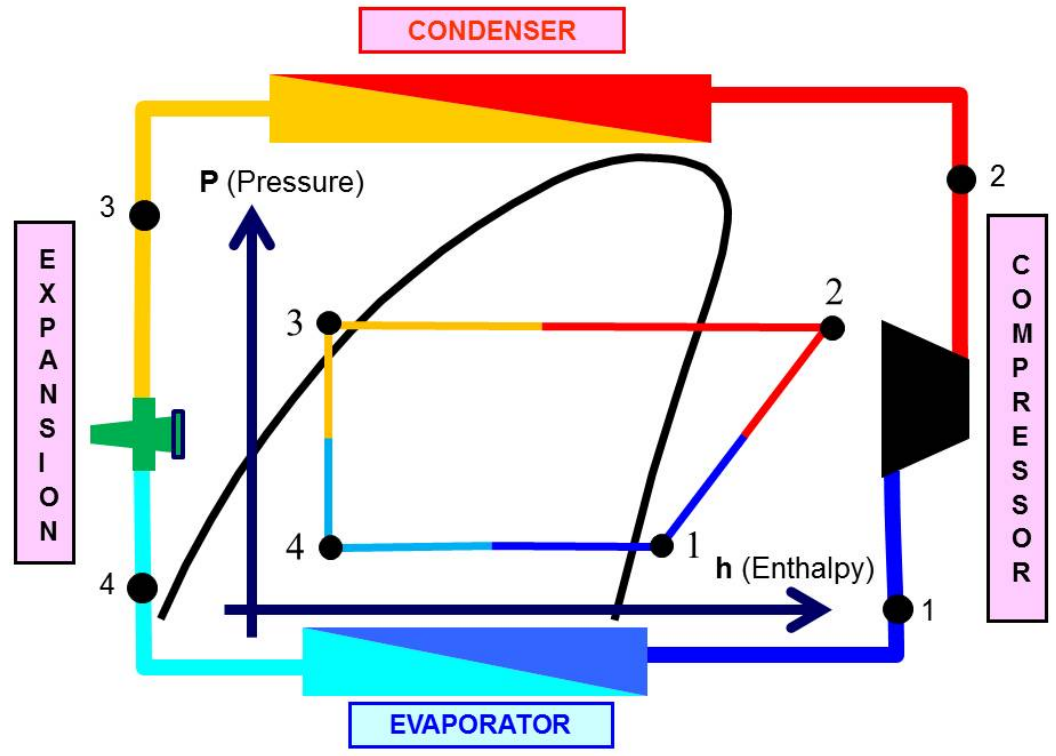

Figure 27 Theoretical compression cycle

The functions of the main components of the cycle are listed below.

\section{Evaporator (4 - 1)}

The evaporator is a heat exchanger which circulates cooling fluid side and on the other the external fluid to be cooled. The refrigerant, at low temperature, evaporates absorbing heat from the fluid (or medium) (4-1). The 
temperature must be, therefore, lower than the temperature of the external environment so that heat transfer is possible. For example, Figure 26 can be the data of a unit that is cooling air from 20 to $12^{\circ} \mathrm{C}$ (the refrigerant temperature is $5^{\circ} \mathrm{C}$ ).

\section{Compressor (1 - 2)}

The compressor takes the low pressure and low temperature vapor from the evaporator. The energy supplied by the compressor can raise the pressure and temperature of the fluid to a value that allows the heat dissipation to the fluid (or medium) to be heated.

\section{Condenser (2 - 3)}

The high pressure and at high temperature vapor from the compressor (point 2) is carried to the condenser. This is a heat exchanger which circulates the refrigerant in one side and on the other the external fluid to be heated

At first, the vapor gives sensible heat until saturation, from this point the refrigerant condenses and still exchanges heat at constant pressure and temperature. Normally the coolant should come out as subcooled liquid (point 3).

Obviously, to exchange heat, the refrigerant condensing temperature must be higher than the external fluid. For example, Figure 26 can be the data of a unit that the condenser is outside and the ambient temperature is $30^{\circ} \mathrm{C}$ (the refrigerant temperature is $40^{\circ} \mathrm{C}$ ).

\section{Expansion valve (3 - 4)}

The high pressure liquid then accesses the expansion valve, in which the pressure is reduced to evaporation and beginning a new cycle. In this transformation, the refrigerant is partly evaporated and lowers its temperature.

It is important that the refrigerant should be sub-cooled liquid at point 3 . The expansion occurs without exchange of heat or work abroad and therefore at constant enthalpy.

\section{A.2. The real Thermodynamic cycle}

In the previous section we have analyzed the theoretical compression cycle where the following simplifications were made:

- No pressure drop or temperature decrease is considered in the pipes that connect the main elements of the cycle.

- Recirculation of the refrigerant is done without pressure drop in condenser or evaporator.

- The compressor is isentropic and adiabatic.

Obviously real heat pumps away from the theoretical cycle for the following imperfections (or irreversibility):

- The compressor is non-isentropic. In addition, the compressor exchanges heat with the environment.

- The flow of refrigerant is performed with pressure losses, where these are greater or less depend on the design of piping and equipment components (especially condenser and evaporator). The smaller the losses are, the most efficient is the unit. 
- In some heat pumps (like air to air splits), the components are located at major distances and pressure drops and heat losses or gains in the connecting pipes could be important.

Figure 28 shows a comparison between the "theoretical cycle" and a "real compression cycle".

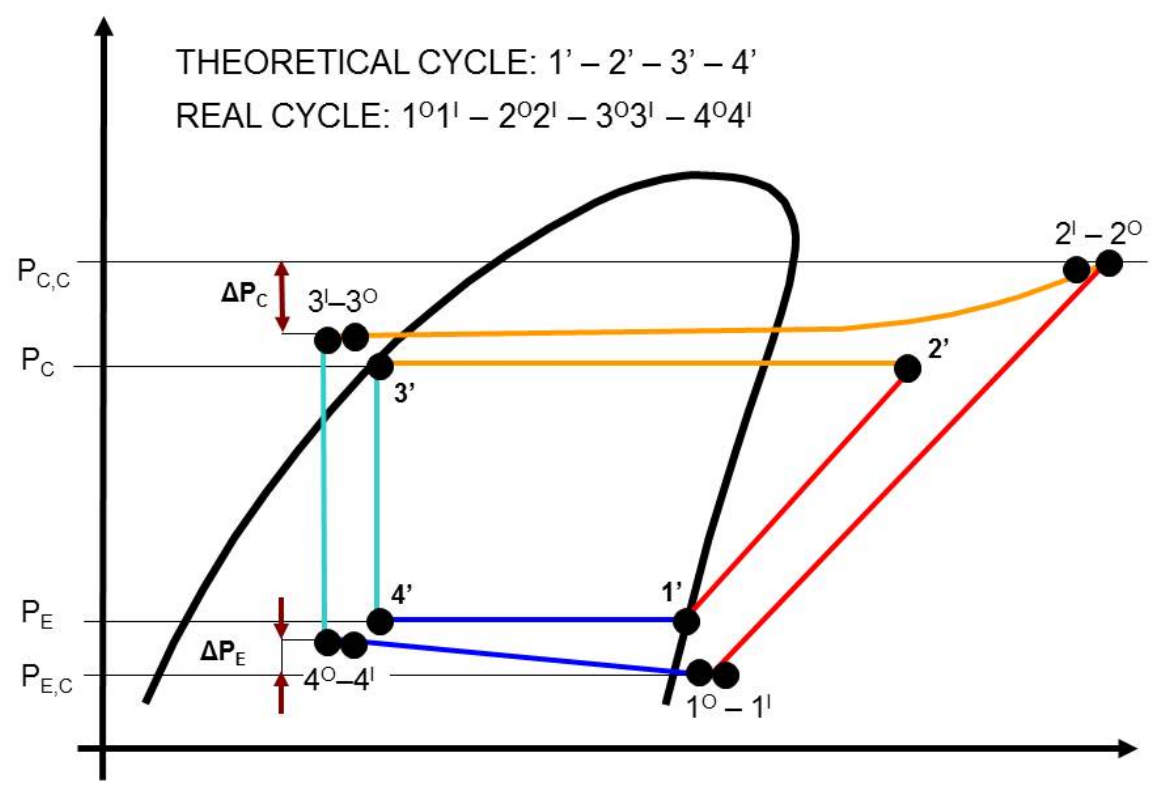

Figure 28 Comparison between theoretical and real thermodynamic cycles

In the real cycle (Figure 28), the following points maybe considered:

Point $1^{\text {I: }}$ Compressor inlet

Point $2^{\mathrm{O}}$ : Compressor outlet

Point 2I: Condenser inlet

Point $3^{\text {s: }}$ Condenser outlet

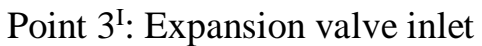

Point $4^{\mathrm{O}}$ : Expansion valve outlet

Point 4: Evaporator inlet

Point $1^{\mathrm{O}}$ : Evaporator outlet

Following this nomenclature, the refrigerant lines would be:

Suction line $1^{\mathrm{O}}-1^{\mathrm{I}}$ : Evaporator to compressor

Discharge line $2^{\mathrm{O}}-2^{\mathrm{I}}$ : Compressor to condenser

Liquid line $3^{\mathrm{O}}-3^{\mathrm{I}}$ : Condenser to expansión valve

Line $4^{\mathrm{S}}-4^{\mathrm{E}}$ : Expansion valve to evaporator (use to be very short) 


\section{A.3. Measurement of the thermodynamic cycle}

\section{Enthalpy calculation in the needed points}

The measurement methodology needs to apply sensors to the unit at strategic points. The data that must be measured are:

1) Temperature at Point $1^{\mathrm{I}}$ (compressor inlet)

2) Temperature at Point $2^{\mathrm{O}}$ (compressor outlet)

3) Temperature at Point $3^{\mathrm{S}}$ (condenser outlet)

4) Pressure at Point $1^{\mathrm{I}}$ (compressor inlet)

5) Pressure at Point $2^{\mathrm{O}}$ (compressor outlet)

This measurements permit to determine the enthalpy of the refrigerant at Points $1^{\mathrm{I}}, 2^{\mathrm{O}}$, and $3^{\mathrm{S}}$.

Problems that must be checked that don't occur during the measurements:

\section{Point 1': Compressor inlet}

The refrigerant should be $100 \%$ vapor: it should be superheated. Sometimes, the refrigerant can be saturated at the inlet, and even with some drops. The compressor can exchange heat from the outlet to the inlet and condense the refrigerant in the inlet. The problem is that if the refrigerant has some liquid, then its enthalpy cannot be measured.

The enthalpy calculation from pressure and temperature at $1^{\mathrm{I}}$ is valid only if the refrigerant is superheated.

\section{Point $2^{\circ}$ : Compressor outlet}

The enthalpy calculation from pressure and temperature at $2^{\mathrm{O}}$ is always valid, since the refrigerant is superheated.

It is important to measure the temperature correctly.

\section{Point $3^{\text {s}}$ : Condenser outlet}

The enthalpy calculation from temperature at $3^{\mathrm{S}}$ is valid if the refrigerant is $100 \%$ liquid at this point. The liquid should be 5 to $10^{\circ} \mathrm{C}$ sub-cooled.

The pressure drop produced between compressor outlet $\left(2^{\mathrm{O}}\right)$ and condenser outlet $\left(3^{\mathrm{S}}\right)$ has a negligible influence on the calculation of its enthalpy.

The enthalpy calculation from pressure and temperature at $3^{\mathrm{s}}$ is valid only if the refrigerant is sub-cooled.

\section{Mass flow calculation from compressor enthalpies}

Applying the first law of thermodynamics to the compressor, you get that energy conservation means the electrical energy consumed by the electric motor should:

- increase the enthalpy of the refrigerant or 
- be transferred to the ambient by heat transfer.
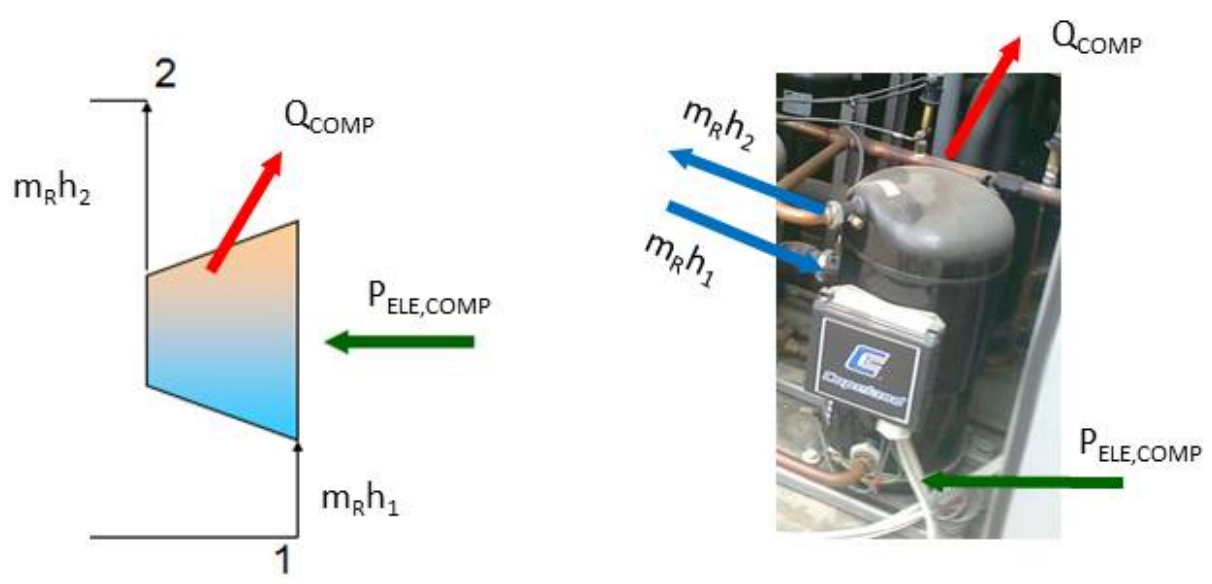

Figure 29 First law of thermodynamics applied to the compressor. Energy conservation

The energy conservation equation is:

$$
P_{\text {ELE, COMP }}=m_{R} \cdot\left(h_{20}-h_{11}\right)+Q_{\text {COM P }}
$$

The active electrical power consumed by the compressor should be therefore measured. This equation is only valid for hermetic compresors.

The energy losses of the compressor are produced by heat transferred to the ambient by conduction, convection and radiation. Depending on the compressor insulation, this losses would be between 5 and 10\% (the typical value considered is $7 \%$ of $\left.\mathrm{P}_{\mathrm{ELE}, \mathrm{COMP}}\right)$.

Is usually defined a mechanical compressor performance that takes into account these losses.

$$
P_{E L E, C O M P} \cdot \eta_{M}=m_{R} \cdot\left(h_{20}-h_{11}\right)
$$

This mechanical performance takes into account the $\%$ of the electrical power that goes to the refrigerant (normally it can be considered to be $93 \%$ ).

The developed equation can be employed to measure de refrigerant mass flow.

\section{Compressor isentropic efficiency}

The methodology presented in the last sections has been tested and use to give higher efficiencies than indirect methods when measuring in chillers.

In some cases, the isentropic efficiency calculated by measurements is $90 \%$ or higher, which cannot be possible. The isentropic efficiency is defines as:

$$
\eta_{150}=\frac{\mathrm{h}_{2 \mid 50}-\mathrm{h}_{1}}{\mathrm{~h}_{2}-\mathrm{h}_{1}}
$$

Where $\mathrm{h}_{2 I S O}$ is calculates from $\mathrm{h}_{1}$, considering that the pressure in 2 in known $\left(\mathrm{P}_{\mathrm{COND}}\right)$ and $\left(\mathrm{S}_{2 I S O}=\mathrm{S}_{1}\right)$. 
In order to obtain realistic results, and for being in the conservative side, the methodology presented propose to verify that the isentropic efficiency of the compressor is lower than the values given by the manufacturer.

Some manufacturers give equations for isoentropic efficiency as a function of the pressure ratio " $\mathrm{t}$ " $\left(\mathrm{t}=\mathrm{P}_{\mathrm{COND}} / \mathrm{P}_{\mathrm{EVAP}}\right)$. Figure 30 shows 2 curves that a manufactures gives for scroll and reciprocicating hermetic compressors.

Technologies specificities : Scrolls Vs. Recip
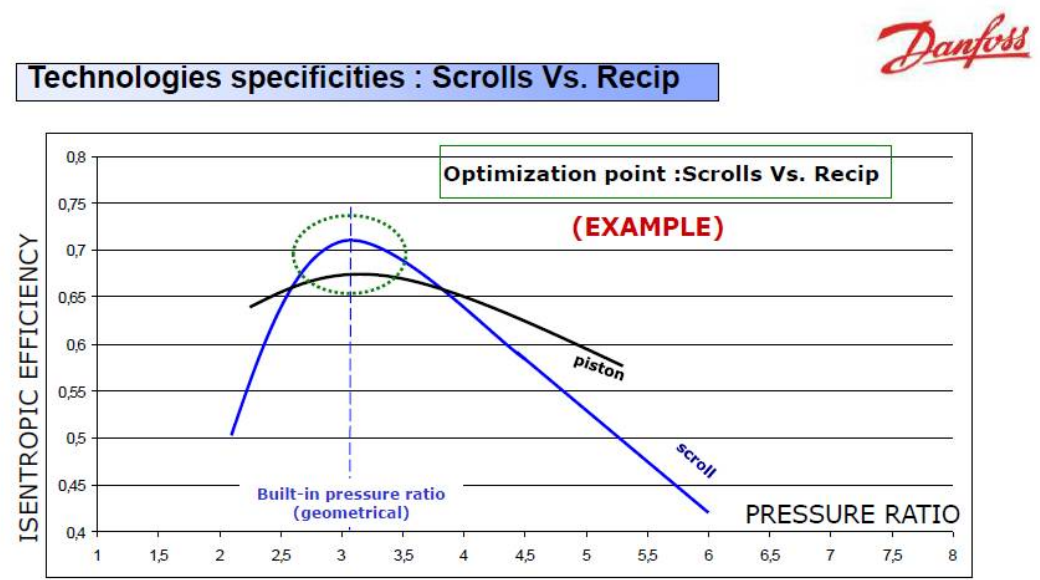

Figure 30 Isentropic efficiency given by Danfoss for their compressors (general curve)

It is recommended to apply the equation given by the manufacturer for an specific compressor. If the equation is not available, it is recommended to apply this simple linear equation:

$$
\eta_{\text {ISO }}=0.775-0.05 \cdot\left(P_{\text {COND }} / P_{\text {EVAP }}\right)
$$

This equation will be applied to give a theoretical value of $h_{1 \text { th }}$. It is going to be considered that the enthalpy at point 2 is correctly calculated and that the problem might be due to the presence of liquid in 1 .

\section{A.4. Other measurement methods for the refrigerant mass flow}

Other methods can be employed to determine the refrigerant mass flow:

- Volumetric efficiency of the compressor

- Use a correlation given by the manufacturer (if available)

- Measure it directly (if possible) 


\section{ANNEX B. MEASURING AND INSTRUMENTATION}

All magnitudes, like electrical and thermal energies should be measured using specially designed equipment. Some measurements cannot be measured directly and a method of estimating the magnitude should be explained in detail (for example, the energy loses of a DHW tank).

The data acquisition system is a key part of the monitoring system. A data logger needs to be installed to obtain and store measurements. A controller use to be used for simulating thermal loads, water consumptions or activate or stop the experimental set-up.

The data acquisition unit may do some calculations to transfer information to the controller or to a remote site. The acquired data can be sent to a computer in order to generate daily or weekly data files. The data processing use to be carried out in a computer using software like MATLAB, EXCEL, EES, etc.

\section{B.1. Solar energy}

The global radiation on the PV panels in $\mathrm{W} / \mathrm{m}^{2}$ should be measured in order to determine the maximum electrical power that can be taken from the PV facility. The pyranometer is the instrument used to measure the global solar radiation (direct + diffuse) on a flat surface and a spectral range comprised between 0.3 and 3.0 microns.

Pyranometers are very expensive. It is therefore more cost effective to use sunlight probes which are accurate enough for in-situ monitoring. Sunlight probes are generally based on a calibrated photovoltaic cell. If there are PV panels are connected to an inverter that keeps them in their optimum voltage, then they can be employed to measure directly the solar radiation.

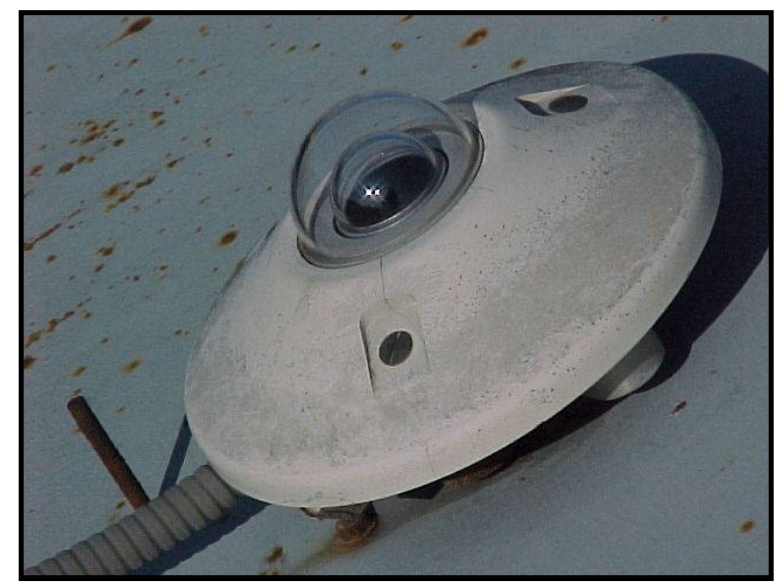

It is recommended to employ first class pyranometers with a resolution of $\pm 5 \mathrm{~W} / \mathrm{m} 2$ and uncertainty of $\pm 3 \%$ in the hourly radiation.

\section{B.2. Electricity}

Electrical energy flows can be measured by:

- Electrical energy meters (measure in $\mathrm{kWh}$ ). Instruments are connected to the data system with pulse emitters. 
- Measure the electrical power (measure in $\mathrm{W}$ ). The data is collected every 1 to 5 minutes and it is considered that the value is constant during this time.

It is advisable to set up Class 0.5 electric energy meters or power meters.

The electrical consumptions of all the electrical parts (circulators, valves, regulators, fans, compressors, etc.) or Joule effect electrical back-ups (resistance) must be measured. The meters chosen need to be equipped either with pulse emitters or a transmission protocol so that they can transmit information to the data acquisition unit.

The electrical power can be measured in direct or alternating current. Direct current produced by the PV panels can be measured with a simple multimeter. The data acquisition unit use to be able to measure a dc voltage of $12-48 \mathrm{~V}$ directly. A current sensor to measure dc current is a calibrated shunt resistor. They are low resistance precision resistors used to measure AC or DC electrical currents by the voltage drop those currents create across the resistance. The voltage drop use to be measured directly by the data acquisition unit.

Alternating current electrical energy meters must be fitted in accordance with electrical security regulations. It is important to check in which direction the intensity transformers should be inserted depending on the chosen model. Class 1 electrical meters must be used. The measured data should be at least $50 \%$ of the instrument range in order to reach high measurement accuracy. Measurement must include the active, reactive and apparent power when capacity or inductive loads are measured (Motors and transformers). When measuring resistive loads it is enough to measure the electrical current and voltage. Instruments and probes can be calibrated by a high accurate power analyzer.

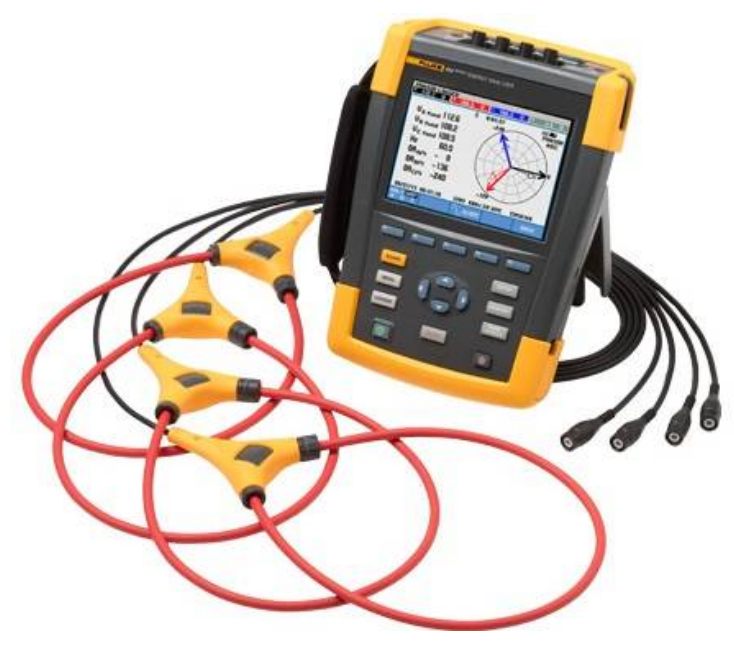

\section{B.3. Thermal power}

Thermal power in a water or water glycol circuit (Q2 and Q3) may be measured by a pair of temperature probes and a volumetric meter (for domestic hot water), or a flow meter for the other circuits.

Temperature should be measured with high accuracy. Recommendations:

- Class A, 2 wires, Pt1000, temperature probes. Each pair should have the same length of cable.

- Class A, 4 wires, PT 100, temperature probes. No problem with the wires length. The data acquisition unit should measure 4 wire RTDs.

- K-Type Thermocouples. They can give good results when measuring temperature differences with the same instrument or directly with the data acquisition unit.

Flow meters use to be expensive, when $2 \%$ or less accuracy is required. Accuracy use to be expressed by a $\%$ of the instrument full scale. Measurement flow rate should be at least $50 \%$ of the instrument full scale. 
Thermal energy meters include flow meter and temperature probes in one instrument. An energy meter which can transmit information regarding temperature/flow/energy to the data logger via bus is a real advantage as it enables measurement details to be accessed. Class 1 thermal energy meters should be chosen and programmed taking into account the type of fluid used (water, insulating antifreeze liquid).

\section{B.4. Temperature probes}

There are two main types of temperature probes:

- Thermocouple probes, which generate a variable voltage depending on the temperature. The voltage depends on the thermocouple materials. In HVAC applications, K-Type thermocouples are widely employed.

- Thermistance probes, based on the use of a metal whose electrical resistance varies according to temperature. Thermistances using platinum (Pt100, PT500, Pt 100) or nickel (Ni500) are generally used for monitoring purposes.

The main characteristics to look for in temperature probes are:

- Their cost;

- Measurement quality (temperature coefficient, response time, accuracy, self-heating, etc.);

- Reliability (durability, stability of responses over time, etc.);

- How easy it is to connect and condition them (sensitivity to electrical implementation,

Connection wires are responsible for a degree of measurement error:

- In thermistance probes the error depends on their length and cross-section: it is necessary to use 4 wire devices (or at least 3 wires) in order to avoid errors when the probes are separated more than 10 meters to the data acquisition unit. Using RTD signal convertors to 4-20 mA or 0-10V produce as well high uncertainties.

- Thermocouples are cheap and can be very accurate when measuring temperature differences. The wires and connections should be selected carefully in order to avoid errors.

In both cases it is recommended to calibrate the full system together: data acquisition unit + probes + wire and connectors. When the important data are temperature differences, the accuracy of the measurements should be high (usually $\pm 3 \mathrm{deg}$ ). In these measurements, it use to be easy to do some kind of calibration or tests on field that improve the quality of the results. 


\section{ANNEX C. MEASUREMENT UNCERTAINTIES}

The experimental uncertainty can be calculated by following the Guide to the expression of uncertainty in measurement published by ISO [1995].

The uncertainty of the result of a measurement reflects the lack of exact knowledge of the given value. The result of a measurement presents two types of uncertainties:

- Systematic uncertainties, produced by instruments errors, or by non-correct use. Examples: a flowmeter connected without following its manufacturer indications, a temperature probe wrong installed or connected with not-adequate wires or uncertainty of the physical properties of the analyzed fluid.

- Random uncertainties, produced by variations in time of the measured value. These uncertainties can be reduced by taken a large amount of data: the random uncertainty of the means if smaller than the random uncertainty of a measure.

Although "ISO Guide" provides a framework for assessing uncertainty, it cannot substitute for critical thinking, intellectual honesty, and professional skill. The evaluation of uncertainty is neither a routine task nor a purely mathematical one; it depends on detailed knowledge of the instrumentation and skills of using it properly. The quality and utility of the uncertainty quoted for the result of a measurement therefore ultimately depend on the understanding, critical analysis, and integrity of those who contribute to the assignment of its value.

\section{C.1. Expression of the uncertainty}

The uncertainty level of the experimental measurements is generally given by a 95 percent confidence, which means that $95 \%$ of the given data are inside the limits given by the uncertainty expression. For example:

The measured electrical power of a PV panel is: $P=221.76 \mathrm{~W}$ with an uncertainty of $5.61 \mathrm{~W}$.

It is considered that the uncertainty follows a normal distribution (see Figure 31). The standard deviation of the sample, $\sigma$ means that $68.2 \%$ of the data are inside this range. The common expression of uncertainty in experimental measurement is given for $95 \%$ of confidence that means $U=1.96 \sigma$ (sometimes is taken $2 \sigma$ ).

The standard deviation of the measured electrical power is $\sigma=2.86 \mathrm{~W}(5.61 / 1.96)$. The uncertainty can be given for a $99 \%$ of confidence ( $\mathrm{U}=3 \sigma$ ), but it is unusual. In any case it is recommended to mention in any document when uncertainties are given, if the data have been provided for 95 or $99 \%$ of confidence.

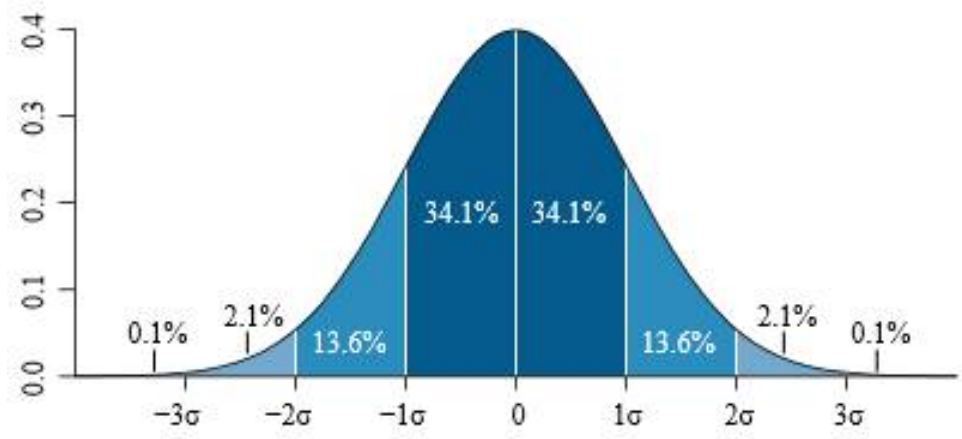




\section{C.2. Uncertainty estimation}

The uncertainty can only be estimated: there use to be a big uncertainty in the estimation of the uncertainty. In the test and field measurements of compression units, the most important data use to be the "solar contribution of the PV panels". Another data like the unit "Coefficient of Performance" can be important in manufacturer tests but not in tests when the objective is to analyze the advantages of using solar energy in heating and cooling applications.

The "ISO Guide" gives a methodology to estimate the standard deviation of the measured data by:

- Method A: Taking a sample of the data with a calibrated instrument.

- Method B: From the technical data of the equipment given by the manufacturer.

\section{Method A.}

An input quantity $\mathrm{X}_{\mathrm{I}}$ can be estimated from $\mathrm{n}$ independent repeated observations $\mathrm{X}_{\mathrm{I}, \mathrm{K}}$. The arithmetic mean $\mathrm{X}$ can be obtained from:

$$
X=\frac{1}{n} \sum_{i=1}^{n} x_{1}
$$

The individual observations $\mathrm{x}_{\mathrm{I}, \mathrm{K}}$. differ in value because of random variations in the influence quantities, or random effects. The experimental variance of the observations (variance of the probability distribution) is given by:

$$
\mathrm{s}\left(\mathrm{x}_{\mathrm{l}}\right)=\sigma^{2}\left(\mathrm{x}_{\mathrm{l}}\right)=\frac{1}{\mathrm{n}-1} \sum_{\mathrm{l}=1}^{\mathrm{n}}\left(\mathrm{x}_{\mathrm{l}}-\mathrm{X}\right)^{2}
$$

In this measurements, the given value is the mean $\mathrm{X}$, and therefore, it is necessary to provide the standard deviation of the mean (not to an individual data). The variance of the mean is given by:

$$
\mathrm{s}(\mathrm{X})=\sigma^{2}(\mathrm{X})=\frac{\sigma^{2}\left(\mathrm{X}_{1}\right)}{\mathrm{n}}
$$

The standard deviation is $\sigma=\mathrm{s}^{0.5}$. It must be taken into account that only random fluctuations are considered.

\section{Method B.}

The standard deviation of the measurements can be calculated from the manufacturer technical information. It is necessary to calculate $\sigma$ of every measured data. The following information is needed:

- If the specify value is $2 \sigma(95 \%$ of confidence level), $3 \sigma(99 \%$ of confidence level) or a square function (100\% inside a domain, but with a constant probability).

- The uncertainty is given for the measured value, instrument full scale or a combination of both.

Case 1. Manufacturer specifications give $3 \sigma$. 
A calibration certificate states that a voltimeter has an uncertainty of $0.1 \%$ of its full scale $(240 \mathrm{~V})$, having a level of confidence of 99 percent".

Therefore, $3 \sigma=0.24 \mathrm{~V}$ and the standard deviation of every measurement is $\sigma=0.08 \mathrm{~V}$.

Case 2. Manufacturer specifications give a rectangle probability.

A manufacturer specifies that an pyrameter is Class 2 that means $2 \%$ of uncertainty based on the instrument full scale and a square probability inside the range $-2 \%$ and $+2 \%$. The pyrameter full scale is $1200 \mathrm{~W} / \mathrm{m}^{2}$.

If the instrument gives $800 \mathrm{~W} / \mathrm{m}^{2}$, the value can be $800 \mathrm{~W} / \mathrm{m}^{2} \pm 0.02 \times 1200 \mathrm{~W} / \mathrm{m}^{2},\left(800 \mathrm{~W} / \mathrm{m}^{2} \pm 24 \mathrm{~W} / \mathrm{m}^{2}\right)$ that means that the real data is $100 \%$ of probability in the range of 776 and $824 \mathrm{~W} / \mathrm{m}^{2}$ and all the values inside this range have the same probability to occur. The standard deviation is given by:

$$
\sigma=\frac{24}{\sqrt{3}}=13.9^{\mathrm{W} / \mathrm{m}^{2}}
$$

\section{C.3. Combined uncertainty}

A variable $\mathrm{Y}$ can be determined by a calculation of different measured data $\mathrm{X}_{1}, \mathrm{X}_{2}, \ldots \mathrm{X}_{\mathrm{N}}$.

$$
Y=f\left(X_{1}, X_{2}, \ldots X_{N}\right)
$$

The uncertainty of $\mathrm{Y}$ is calculated from the uncertainty of the different measurements, given by its standard deviation: $\sigma\left(\mathrm{X}_{1}\right), \sigma\left(\mathrm{X}_{2}\right), . . \sigma\left(\mathrm{X}_{\mathrm{N}}\right)$. The standard deviation $\sigma(\mathrm{Y})$ is given by:

$$
(\sigma(\mathrm{Y}))^{2}=\left(\frac{\partial \mathrm{Y}}{\partial \mathrm{X}_{1}} \cdot \sigma\left(\mathrm{X}_{1}\right)\right)^{2}+\left(\frac{\partial \mathrm{Y}}{\partial \mathrm{X}_{2}} \cdot \sigma\left(\mathrm{X}_{2}\right)\right)^{2}+\ldots+\left(\frac{\partial \mathrm{Y}}{\partial \mathrm{X}_{\mathrm{N}}} \cdot \sigma\left(\mathrm{X}_{\mathrm{N}}\right)\right)^{2}
$$

Example: The thermal power produced by a boiler is given by:

$$
\mathrm{Q}=\mathrm{m} \cdot \mathrm{cp} \cdot \Delta \mathrm{T}
$$

Where, $\mathrm{m}$ is the mass flow, $\mathrm{cp}$ is the specific heat of the fluid and $\Delta \mathrm{T}$ the temperature difference between inlet and outlet. The standard deviation $\sigma(\mathrm{Q})$ is given by:

$$
\begin{aligned}
& (\sigma(\mathrm{Q}))^{2}=\left(\frac{\partial \mathrm{Q}}{\partial \mathrm{m}} \cdot \sigma(\mathrm{m})\right)^{2}+\left(\frac{\partial \mathrm{Q}}{\partial \mathrm{cp}} \cdot \sigma(\mathrm{cp})\right)^{2}+\left(\frac{\partial \mathrm{Q}}{\partial \Delta \mathrm{T}} \cdot \sigma(\mathrm{T})\right)^{2} \\
& (\sigma(\mathrm{Q}))^{2}=((\mathrm{cp} \cdot \Delta \mathrm{T}) \cdot \sigma(\mathrm{m}))^{2}+((\mathrm{m} \cdot \Delta \mathrm{T}) \cdot \sigma(\mathrm{cp}))^{2}+((\mathrm{m} \cdot \mathrm{cp}) \cdot \sigma(\Delta \mathrm{T}))^{2}
\end{aligned}
$$

The uncertainty use to be given for a $95 \%$ of level of confidence, that means $U(Q)=1,96 \sigma(Q)$. 


\section{C.4. Example 1. Uncertainty of the measured thermal power produced by a boiler}

Uncertainty estimation of the thermal power produced by a boiler $\mathrm{Q}(\mathrm{kW})$ when it is measured from these data:

- Mass flow: $\mathrm{m}=1840 \mathrm{~kg} / \mathrm{h}$. Instrument of Class 2 , full scale $=3600 \mathrm{~kg} / \mathrm{h}$

- Specific heat: $\mathrm{cp}=4.18 \mathrm{~kJ} / \mathrm{kg} \mathrm{K}$. Uncertainty $0.1 \mathrm{~kJ} / \mathrm{kg} \mathrm{K}$ for $99 \%$ of confidence level

- Temperature difference: $\Delta \mathrm{T}=12.4^{\circ} \mathrm{C}$. Uncertainty $0.2^{\circ} \mathrm{C}$ for $95 \%$ of confidence level

The thermal power produced by the boiler is given by:

$$
\mathrm{Q}=\mathrm{m} \cdot \mathrm{cp} \cdot \Delta \mathrm{T}=\frac{1840}{3600} \times 4.18 \times 12.4=26.49 \mathrm{~kW}
$$

The mass flow is measured by an instrument of Class 2 , full scale $=1 \mathrm{~kg} / \mathrm{s}(3600 \mathrm{~kg} / \mathrm{h})$. It is considered a constant probability inside the interval of $\pm 2 \%$ f.s.

$$
\sigma(\mathrm{m})=\frac{2 / 100 \times 1 \mathrm{~kg} / \mathrm{s}}{\sqrt{3}}=\frac{0.02}{\sqrt{3}}=0.0115 \mathrm{~kg} / \mathrm{s}
$$

The specific heat is considered to be $4.18 \mathrm{~kJ} / \mathrm{kg} \mathrm{k}$, with an uncertainty $0.1 \mathrm{~kJ} / \mathrm{kg} \mathrm{K}$ for $99 \%$ of confidence level. The standard deviation is given by:

$$
\sigma(\mathrm{cp})=\frac{0.1 \mathrm{~kJ} / \mathrm{kgK}}{3}=0.033 \mathrm{~kJ} / \mathrm{kgK}
$$

The temperature difference is measured by and unique instrument with 2 probes. The uncertainty of the temperature difference is considered to be $0.2^{\circ} \mathrm{C}$ with a $95 \%$ of confidence level.

$$
\sigma(\Delta \mathrm{T})=\frac{0.2 \stackrel{\circ}{ } \mathrm{C}}{1.96}=0.102 \mathrm{~kJ} / \mathrm{kgK}
$$

The thermal energy standard deviation is given by:

$$
\begin{aligned}
& (\sigma(\mathrm{Q}))^{2}=((\mathrm{cp} \cdot \Delta \mathrm{T}) \cdot \sigma(\mathrm{m}))^{2}+((\mathrm{m} \cdot \Delta \mathrm{T}) \cdot \sigma(\mathrm{cp}))^{2}+((\mathrm{m} \cdot \mathrm{cp}) \cdot \sigma(\Delta \mathrm{T}))^{2} \\
& (\sigma(\mathrm{Q}))^{2}=(4.18 \cdot 12.4 \cdot 0,0115)^{2}+(0.511 \cdot 12.4 \cdot 0.033)^{2}+(0.511 \cdot 4.18 \cdot 0.102)^{2} \\
& \sigma(\mathrm{Q})=\sqrt{(0.5985)^{2}+(0.2113)^{2}+(0.2180)^{2}}=\sqrt{0.4504}=0.6711 \mathrm{~kW}
\end{aligned}
$$

The uncertainty use to be given for a $95 \%$ of level of confidence, that means

$$
\mathrm{U}(\mathrm{Q})=1.96 \sigma(\mathrm{Q})=1.96 \times 0,6711=1.315 \mathrm{~kW}
$$

The thermal power can be expressed as: $\mathrm{Q}=26.49 \pm 1.32 \mathrm{~kW}$ for $95 \%$ of confidence level or can be expressed as: $\mathrm{Q}=26.49 \mathrm{~kW}$ with an uncertainty of $4.97 \%$ for $95 \%$ of confidence level. 


\section{C.5. Example 2. Uncertainty of the measured power produced by a PV panel}

Uncertainty estimation of the power produced by a PV panel $\mathrm{P}(\mathrm{W})$ when it is measured from these data:

- Voltage: 26.4 Volt. Instrument of class 0.5, full scale $=100 \mathrm{Vcc}$

- Current: 8.4 Amp. Instrument of class 1, full scale = 10 Amp

Let's consider that the uncertainty given by the manufacturer follows a rectangle. This means that the probability of the measure is the same inside the region $\pm 0.5 \%$ f.s. for the voltage and $\pm 1 \%$ f.s. for the electrical dc current.

The standard deviations of the measured data are given by:

Voltage: Class 0.5, full scale $=100 \mathrm{Vcc}$

$$
\sigma(\mathrm{V})=\frac{0,5 / 100 \times 100}{\sqrt{3}}=\frac{0,5}{\sqrt{3}}=0.288 \mathrm{~V}
$$

The result means that $68,3 \%$ of the data are in the range $\pm 0.288 \mathrm{~V}$ and $95 \%$ of the data in the range \pm $1.96 \times 0.288=0,566 \mathrm{~V}$.

Current: Class 1, full scale $=10 \mathrm{Ac}$

$$
\sigma(I)=\frac{1.0 / 100 \times 10}{\sqrt{3}}=\frac{0.1}{\sqrt{3}}=0.0577 \mathrm{~A}
$$

The result means that $68,3 \%$ of the data are in the range $\pm 0.0577 \mathrm{~A}$ and $95 \%$ of the data in the range \pm $1.96 \times 0.0577=0.113 \mathrm{~A}$.

The electrical power is given by:

$$
P(W)=V(\text { Volt }) \cdot I(\text { Amp })
$$

The standard deviation of the power is given by:

$$
\begin{aligned}
& (\sigma(\mathrm{P}))^{2}=\left(\frac{\partial \mathrm{P}}{\partial \mathrm{V}} \cdot \sigma(\mathrm{V})\right)^{2}+\left(\frac{\partial \mathrm{P}}{\partial \mathrm{l}} \cdot \sigma(\mathrm{I})\right)^{2} \\
& (\sigma(\mathrm{P}))^{2}=(\mathrm{I} \cdot \sigma(\mathrm{V}))^{2}+(\mathrm{V} \cdot \sigma(\mathrm{I}))^{2} \\
& \sigma(\mathrm{P})=\sqrt{8,4^{2} \times 0,288^{2}+26,4^{2} \times 0,0577^{2}}=\sqrt{8,2}=2.86 \mathrm{~W}
\end{aligned}
$$

But we want to express the uncertainty within $95 \%$ of the confidence, that means

$$
u_{D}(P)=1.96 \times 2.86=5.61 \mathrm{~W}
$$

The electrical power is $\mathrm{P}=26.4 \times 8.4=221.76 \mathrm{~W}$ and $5.61 \mathrm{~W}$ is a $2.53 \%$ of the measured power. The uncertainty can be expressed as a $2.53 \%$ of the measured data with $95 \%$ of the confidence interval. 
Note : the IEA SHC Technology Collaboration Programme (IEA SHC TCP) functions within a framework created by the International Energy Agency (IEA). Views, findings and publications of the IEA SHC TCP do not necessarily represent the views or policies of the IEA Secretariat or of its individual member countries. The IEA SHC TCP and the IEA make no representation or warranty, express or implied, in respect of this paper's content (including its completeness or accuracy) and shall not be responsible for any use of, or reliance on, the paper. 